University of Rhode Island

DigitalCommons@URI

Open Access Dissertations

1999

\title{
Maltreating Caregivers: An Application of the Transtheoretical Model of Change
}

Lisa M. Jones

University of Rhode Island

Follow this and additional works at: https://digitalcommons.uri.edu/oa_diss

\section{Recommended Citation}

Jones, Lisa M., "Maltreating Caregivers: An Application of the Transtheoretical Model of Change" (1999). Open Access Dissertations. Paper 953.

https://digitalcommons.uri.edu/oa_diss/953

This Dissertation is brought to you for free and open access by DigitalCommons@URI. It has been accepted for inclusion in Open Access Dissertations by an authorized administrator of DigitalCommons@URI. For more information, please contact digitalcommons-group@uri.edu. 
MALTREATING CAREGIVERS: AN APPLICATION OF THE TRANSTHEORETICAL MODEL OF CHANGE

BY

LISA M. JONES

A DISSERTATION SUBMITTED IN PARTIAL FULFULLMENT OF THE REQUIREMENTS FOR THE DEGREE OF

DOCTOR OF PHILOSOPHY

IN

PSYCHOLOGY

UNIVERSITY OF RHODE ISLAND

1999

740010230 


\begin{abstract}
Many of the decisions that must be made by child protective service (CPS) agencies involve assessing the extent to which maltreating caregivers have made or are ready to make changes in their parenting behaviors. Yet, little is known about the process of change for these caregivers and no method is available to systematically measure their success in making the changes that CPS agencies require of them. The current study applies the Transtheoretical Model of Change to the problem of child abuse and neglect. The Transtheoretical Model has successfully measured change in many health-related behaviors including smoking and excercise. More recently, the model has been applied to more complex social problems such as domestic violence and criminal behaivor. Three preliminary scales based on the model's constructs, "Stages of Change", "Decisional Balance", and "Self-Efficacy", were administered to 157 caregivers involved with Rhode Island's Department of Children Youth and Families (RIDCYF). These measures were refined and analyses indicated the psychometric properties of each scale were solid. Principal Components Analysis performed on the "Stages of Change" scale supported three stages of change, "Precontemplation", "Contemplation", and "Action". Cluster analysis based on staging profiles identified six clusters of maltreating caregivers hypothesized to represent subgroups with different attitudes and intentions regarding change. These groups were labeled, "Resistant", "NonReflective Action", "Discouraged", "Ambivalent", "Participation", and "Action."
\end{abstract}


Differences between the cluster groups on the "Decisional Balance" and "SelfEfficacy" scales supported hypotheses about these groups and offered preliminary support for the applicability of the TTM in this area. Comparison of the groups on two additional scales "Cooperative Attitudes toward Child Protective Services" (CACPS) and "Concerns About Substance Abuse" (CASA) also provided useful information about differences between these sub-groups. Relevance of the findings for child welfare policy and service provision were discussed as well as recommendations for future research. 


\section{ACKNOWLEDGEMENTS}

I would like to thank my dissertation advisor and mentor, Richard Gelles, not only for his support and guidance on this project, but also for his enormous contributions to my overall training as a researcher. Both through his teaching and in his own work, he emphasized that the best research in family violence combines passion for the problems facing children and families, thoughtful challenges to assumptions, and carefully constructed methods of answering one's questions. His enthusiasm for his work is evident and his support for his students encourages them to meet high standards. I look forward to taking what I have learned from him and applying it in my own career in family violence research.

I am equally as indebted to Jody Brown for her mentorship, friendship, and guidance over the past 5 years. The thoughtfulness and empathy with which she conducts her research has helped me to appreciate the importance of understanding the individuals behind the numbers and the larger contexts in which these individuals live their lives. She has consistently reminded me of the importance of balancing all aspects of my life, including work, play, friends, and family. She was an invaluable support during many stressful times and I look forward to her continued guidance and friendship.

I would also like to thank the additional members of my committee, Joe Rossi, Larry Grebstein, and Larry Rothstein. Throughout the entire process they were available, supportive, and offered insights which have made my research stronger and more carefully thought through. In particular, Joe Rossi's advice and 
recommendations on the statistical aspects of this study were essential to its completion and he responded patiently and easily to all of my questions.

The completion of this project, and the completion of my graduate program as a whole, would have been much more difficult without the support of my family and friends. The most substantial source of support came from my husband, Will. He cheered me when I succeeded, he listened compassionately when I complained, he encouraged me to push forward when I felt like stopping, and he gently pointed out when it was time to take a break. His support over the past five years solidifies my feelings that I am lucky to have such a partner with me to share in all aspects of my life.

My close friends and fellow graduate students, Carol and Lori, also offered a great deal of support during my experiences at URI and throughout my work on this project. I was lucky to find two individuals with whom I could so thoroughly share fears, doubts, successes, and laughter. No matter how frustrating a situation, they could always help me find the humor in it. We have continually helped each other place the experience of graduate school in perspective.

Finally I am very grateful to my mother, my father, and my sister, who frequently expressed their pride and encouragement over the years of this project. They kindly respected both the times the dissertation was all I wanted to talk about and the times it was the last thing I wanted to talk about. My mother, who recently completed her dissertation, in particular, offered sage advice on how to survive the 
process and "just get it done." Her thoughts and her experiences during this time, as with other times in my life, have proved invaluable. 


\section{PREFACE}

The research that is presented in this paper has been separated into four manuscript-style chapters. Each chapter was constructed so that it contains an appropriate amount of material for submission as a journal article. Because the chapters were designed to stand alone, some of the information in them is repeated in order to clarify concepts or review research studies that are broadly relevant.

Chapter 1 presents a summary of previous research on the child protective system and argues that part of the problem with decision-making and service provision by that system is a lack of understanding of change. Despite the centrality of assessments of change in many of the protective system's most important decisions, little is known about how maltreating caregivers make changes and how progress in treatment can be clearly distinguished from lack of progress. The Transtheoretical Model of Change is presented as a promising model upon which to structure a study of change with this population.

Chapter 2 outlines the initial development and refinement of an instrument designed to measure one of the Transtheoretical Model's central concepts, Stage of Change, with maltreating caregivers. Initial results from this instrument are presented along with their implications for service provision. Chapter 3 describes the development of two additional instruments based on the model's constructs of Decisional Balance and Self-Efficacy. Results from these scales are compared to results from Chapter 2 in order to help validate those findings. All outcomes were examined in light of previous applications of the Transtheoretical Model. Finally, 
Chapter 4 reviews the research outcomes, suggests directions for future research, and summarizes the implications of the findings for child protective services. 


\section{TABLE OF CONTENTS}

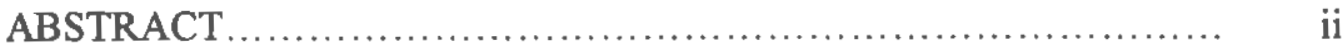

ACKNOWLEDGEMENTS ....................................... iv

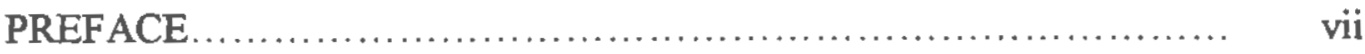

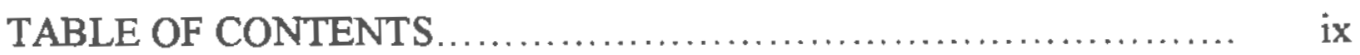

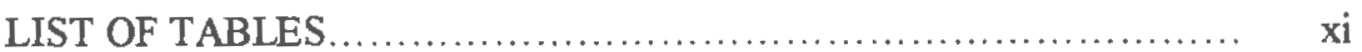

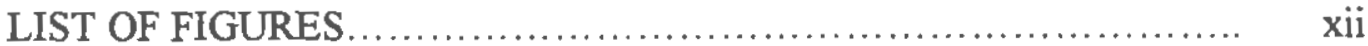

CHAPTER 1 Measuring Change in Maltreating Caregivers: A Case

For the Application of the Transtheoretical Model....................... 1

Introduction.................................................. 2

Efforts to Reduce Child Maltreatment ......................... 6

Risk Assessment............................................ 24

The Transtheoretical Model of Change.......................... 27

Conclusions............................................... 36

References.................................................. 39



CHAPTER 2 Measuring Change in Maltreating Caregivers:

Development of a Preliminary Stage of Change Scale..................... 50

Introduction................................................. 51

Method...................................................... 64

Item Generation....................................... 64

Participants.......................................... 68

Procedure........................................... 69

Results............................................... 72

Instrument Development............................ 72

Profile Analysis...................................... 74

Demographic Data Across Cluster Groups............... 78

Discussion................................................. 79

References..................................................... 86

Tables.................................................... 94

Figures......................................................... 97 
CHAPTER 3 Measuring Change in Maltreating Caregivers:

Additional Tests of the Applicability of the Transtheoretical Model........ 109

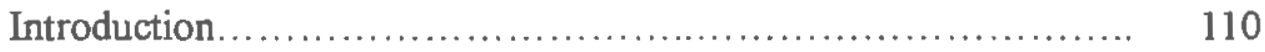

Method...................................................... 124

Item Generation...................................... 124

Participants.......................................... 126

Procedure ............................................... 128

Results...................................................... 129

Instrument Development.............................. 129

Scale Comparisons...................................... 132

Discussion................................................ 135

References.................................................... 143

Tables..................................................... 150

Figures................................................... 157

CHAPTER 4 Measuring Change in Maltreating Caregivers:

Conclusions and Recommendations .................................. 162

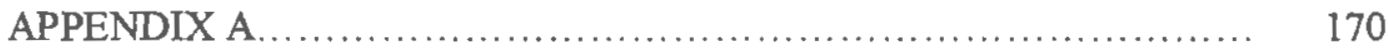

BIBLIOGRAPHY .................................................. 183 


\section{LIST OF TABLES}

Table 2.1 Final Items and Component Loadings for the Stage of

Change Scale (Varimax Rotation) ..................... 94

Table 2.2 Inter-scale Correlations, Coefficient Alpha, Means, and Standard Deviation for Three Stage of Change

Scales.

Table 2.3 Count, Expected Count, and Percentage Differences

for Referral Source Across Six Stage Clusters

Table 3.1 Final Items and Component Loadings for the

Decisional Balance Measure.

Table 3.2 Final Items and Component Loadings for the

Confidence and Temptation Scales of the

Self-Efficacy Measure

Table 3.3 Final Items and Component Loadings for the Cooperative Attitudes Toward Child Protective Services Scale....

Table 3.4 Final Items and Component Loadings for the Concerns About Substance Abuse Scale.

Table 3.5 Inter-Scale Correlations and Coefficient Alphas, Means, and Standard Deviations for the Pros, Cons, Temptations, Confidence, Cooperative Attitudes Toward Child Protective Services and Concerns About Substance Abuse Scales

Table 3.6 Pros, Cons, Temptations, Confidence, Cooperative Attitudes Toward Child Protective Services (CACPS) and Concerns About Substance Abuse (CASA) Mean T-Scores and Standard Deviations Across Six Staging Clusters

Table 3.7 Pros, Cons, Temptations, Confidence, Cooperative Attitudes Toward Child Protective Services (CACPS) and Concerns About Substance Abuse (CASA) Raw Means and Standard Deviations Across Six Staging Clusters 


\section{LIST OF FIGURES}

Figure 1.1 Two Dimensions of Risk Assessment For Child Abuse And Neglect.

Figure 2.1 Mean Scale Scores for the Resistant Cluster................ 97

Figure 2.2 Mean Scale Scores for the Non-Reflective Action Cluster... 98

Figure 2.3 Mean Scale Scores for the Discouraged Cluster............. 99

Figure 2.4 Mean Scale Scores for the Ambivalent Cluster.............. 100

Figure 2.5 Mean Scale Scores for the Participation Cluster............. 101

Figure 2.6 Mean Scale Scores for the Action Cluster.................. 102

Figure 2.7 Individual Scores for the Resistant Cluster .................. 103

Figure 2.8 Individual Scores for the Non-Reflective Action Cluster..... 104

Figure 2.9 Individual Scores for the Discouraged Cluster............... 105

Figure 2.10 Individual Scores for the Ambivalent Cluster................ 106

Figure 2.11 Individual Scores for the Participation Cluster.............. 107

Figure 2.12 Individual Scores for the Action Cluster................... 108

Figure 3.1 Mean Profiles of Six Staging Cluster Groups............... 157

Figure 3.2 Mean Standardized Decisional Balance Scores Across Six Staging Clusters................................. 158

Figure 3.3 Mean Standardized Self-Efficacy Scores Across Six Staging Clusters ......................................... 159

Figure 3.4 Mean Standardized Cooperative Attitudes Towards Child Protective Services (CACPS) Across Six Staging Clusters.

Figure 3.5 Mean Standardized Concerns About Substance Abuse (CASA) Scores Across Six Staging Clusters 


\section{CHAPTER 1}

Measuring Change in Maltreating Caregivers: A Case

For the Application of the Transtheoretical Model 


\section{Introduction}

In 1997 over 2 million reports were made on approximately 3 million $(3,195,000)$ children to child protective service (CPS) agencies across the U.S. for allegations of child maltreatment (Wang \& Daro, 1998). This is a slight increase $(1.7 \%)$ in the number of children reported in 1996 and a substantial increase (41\%) in children reported for maltreatment since 1988 (USDHHS, 1998). Over one million children, or 15 out of every 1,000 children, were victims of maltreatment in which the allegations were supported by substantial evidence and the case was opened to a child protective service agency. Fifty-four percent of these cases were classified as neglect, $22 \%$ as physical abuse, $8 \%$ as sexual abuse, and $4 \%$ as emotional abuse (Wang \& Daro, 1998).

Unfortunately, it is likely that these numbers are an underestimate of the true extent of the problem of child maltreatment in the U.S (see Finkelhor, 1993, for an extensive argument of this point). Many of the unfounded or unsubstantiated reports are most likely valid cases of child maltreatment for which there happens to be little conclusive evidence. Furthermore, many instances of child maltreatment are never even investigated by the Child Protective Service system. In the Third National Incidence Study of Child Abuse and Neglect (NIS-3) (Sedlak \& Broadhurst, 1996) a nationally representative sample of over 5,600 professionals, including those from child protective agencies, mental health agencies, hospitals, schools, and daycare agencies in 42 U.S. counties, were surveyed. An estimated 
forty-two out of every 1,000 children were recognized as having been maltreated by these professionals and only $33 \%$ of these cases had been investigated by child protective agencies.

Studies that sample child maltreatment in the general population find higher rates of child victimization. Straus and Gelles (1986) found in their 1985 national survey of conflict tactic strategies used in families that 19 out of 1,000 children had experienced "very severe violence". More recently, Straus, Hamby, Finkelhor, Moore, and Runyan (1998), reported that in a national survey using the revised Parent-Child Conflict Tactics Scale, 49 out of 1,000 parents disclosed that they had used a form of "severe physical assault" toward their children in the last year. These numbers are 11 times greater than the rates of reported physical abuse tabulated by the Children's Bureau (4 per 1,000) (USDHHS, 1998) and 5 times greater than the physical abuse rates reported by the NIS-3 $(9$ per 1,000$)$ (Sedlak \& Broadhurst, 1996).

The large number of children victimized by child maltreatment becomes particularly concerning when the effects of the abuse on these children are documented. The most grievous and permanent result of child abuse and neglect is death. In 1997 , an estimated 1,185 children (or 1 out of every 100,000 children) were killed due to child maltreatment (Wang \& Daro, 1998). This is a rate almost twice as high as the rate of children who die each year from motor vehicle accidents (USDHHS, 1995) and a 34\% increase in child abuse fatalities since 1985. Furthermore, the National Research Council (NRC) (1993) reviewed fatality- 
related research and concluded that up to $85 \%$ of child maltreatment fatalities are misidentified as accidents, general "homicides", natural deaths, or Sudden Infant Death Syndrome (SIDS). The Centers for Disease Control (CDC) estimated in 1993 that 5 out of every 100,000 children under age 4 are killed from physical abuse or neglect (McClain, Sacks, \& Frohlke, 1993).

Many more victims of child maltreatment suffer lasting and debilitating injuries. Abuse and neglect can result in lacerations, burns, broken bones, head injuries, intra-abdominal injuries, and nonorganic failure to thrive (Kolko, 1996; NRC, 1993). The NIS-3 measured "serious harm" to children (including loss of consciousness, broken bones, and serious burns) in their survey of professionals. They estimated 8.4 children per 1,000 suffered from "serious harm" in 1993 (Sedlak \& Broadhurst, 1996). The number of children suffering from this level of harm has quadrupled since the NIS-2 survey in 1986, effectively increasing the rate by $282 \%$.

In addition to physical injury, child maltreatment has also been shown to be related to a range of serious cognitive and emotional problems. Child abuse and neglect has been connected with problems such as delayed cognitive development, academic problems, heightened aggressivity, increased depression, Post-Traumatic Stress Disorder (PTSD), and increased substance use in adolescence (Kolko, 1996; NRC, 1993; Wekerle \& Wolfe, 1996). Some of the greatest emotional harm to children may occur early on in a disruption in attachment to their caregivers (Cicchetti \& Howes, 1991; Cicchetti \& Rogosch, 1994; Cicchetti \& Toth, 1995; 
Crittenden, 1998; George, 1996). Healthy patterns of attachment establish a foundation upon which normal development can occur for most children. Disruptions in this attachment can affect a child's ability to regulate emotions, accurately interpret social cues, and form healthy relationships with others.

Abuse and neglect experienced by a child also increases the likelihood that the cycle of abuse will continue into the next generation. Although most children who have been maltreated do not grow up to be abusive parents themselves, the rates of re-abuse are higher in parents who were maltreated as children. Kaufman and Zigler (1987) reviewed the research on the intergenerational transmission of violence and estimated that around $30 \%$ of maltreated children grow up to become abusive parents compared to base rates of $5 \%$ in the general population.

Child maltreatment is pervasive in our society, its consequences for children dire, and efforts to address the problem seem to be making little headway. Treatment of abusive and neglectful caregivers has shown limited documented success (NRC, 1993, 1998; Schellenbach, 1998; Wolfe \& Wekerle, 1993) and there are indications that families recycle through the few programs that are implemented by child protective agencies. Of the 577,000 cases around the country that were being served by child protective agencies on March 1,1994, $40 \%$ had been previously open to the agencies and $61 \%$ of those cases were open due to concerns about the same child (USDHHS, 1994). In $41 \%$ of the 1,215 child maltreatment fatalities in 1995 reported by Lung and Daro (1996) caregivers had had on-going or previous involvement with a child protective service agency. 
DePanfilis and Zuravin (1998) reviewed studies of re-abuse rates and found that rates reached as high as $85 \%$ when families were followed for $8-10$ years. These authors concluded that it seemed clear child protective service agencies are serving many of the same families over and over again. In a 1990 report, the U.S. Advisory Board on Child Abuse and Neglect warned, "the scope of the problem of child maltreatment is so enormous and serious, and the failure of the system designed to deal with the problem so catastrophic, that the crisis has reached the level of a national emergency" (USDHHS, 1990, p. 95).

This chapter examines some of the problems inherent in the child protective system and argues that part of what is hindering efforts to work with maltreating caregivers and effectively treat this population is a lack of understanding and ability to measure change. The Transtheoretical Model of Change (Prochaska \& DiClemente, 1982, 1983b, 1984, 1986a, 1992; Prochaska, Norcross, \& DiClemente, 1994) will be outlined and introduced as a promising theory around which to explore and measure the process of change in abusive and neglectful caregivers. Implications of this model for the decision-making process of child protective agencies and for aiding treatment efforts will be discussed.

\section{Efforts to Reduce Child Maltreatment}

The problem of child abuse came to national attention in 1962 when a pediatrician, C. Henry Kempe, alerted colleagues to his conclusion that many of the injuries he was treating had been forcefully inflicted (Kempe, Silverman, Steele, Droegenmueller, \& Silver, 1962). Prior to this consequential article, efforts to 
address the problem of child maltreatment had been relatively unorganized. In 1874, the well-publicized case of Mary Ellen Wilson, a child who was physically abused and neglected by her step-mother, was one of the first dramatic cases of child maltreatment to fuel a public response. The advocacy of a charity worker for court intervention on Mary Ellen's behalf eventually led to the establishment of the Society for the Prevention of Cruelty to Children (SPCC). By the turn of the century there was a SPCC branch in every state (Hubner \& Wolfson, 1996). Another organization for children, the Children's Aid Society (CAS) was founded in 1853 by Charles Loring Brace. Both the SPCC and the CAS were important in advocating the proposition that children had the right to freedom from exploitation, extreme neglect, and serious physical harm and that the state should intervene if these rights were being violated. However, the interventions of these organizations were directed haphazardly and criticisms arose that little distinction was made between maltreating caregivers and those who were merely impoverished.

Child protective services have increased exponentially since the establishment of these organizations and now include an enormous web of state child protective workers, court officials, and service providers. However, today's child protective system continues to struggle with the very same criticisms leveled against the earlier private organizations and seems no closer to increasing children's safety and well-being. 
Although particular details vary from state law to state law, the current structure of child protective agencies across the country is fairly similar. These agencies are set up to screen and investigate reports of child maltreatment, make a decision about whether or not to open the case to the agency, provide services to help caregivers end their abusive or neglectful behavior, and assist courts in making decisions about whether children should be removed from the home or reunited with the maltreating caregiver. This work requires assessing the level of abuse or neglect the child has experienced, the likelihood of re-abuse, the likelihood of reabuse given a particular intervention, and the child's developmental needs. The decisions are difficult because they involve evaluations of private family interactions, assessments of complex problems in a frequently hostile environment, predictions of future behavior, and the knowledge that an error in judgment could result in serious damage to a child's health and safety. Given the difficulty of these tasks, it is not surprising that criticisms of the child protective system abound at each level of the decision making process.

\section{Reporting}

In most cases, the first crucial screening decisions are not made by an official agency but by those who are in a position to monitor children on a day-today basis. Gelles (1996) described these individuals as the "sentinels" of child protection and they include neighbors, family members, day care workers, police officers, doctors, psychologists, and social workers. The National Center on Child Abuse and Neglect (NCCAN) (USDHHS, 1998) notes that in 1996, over half of the 
reports of child maltreatment received by child protective agencies were from professional sources such as the education, legal, medical, and social service fields. About $20 \%$ of the reports came from relatives and family members and another $20 \%$ of the reports were from neighbors or were anonymous calls.

That a large proportion of the reports are made by professional groups is not surprising, given that nearly all professionals who work with children are required by state laws to immediately report child maltreatment when it is suspected. In 1963, Kempe organized a group of physicians who convinced the Children's Bureau to draft model legislation mandating physicians to report child abuse (Hubner \& Wolfson, 1996). By 1967, every state and Washington D.C. had passed reporting laws. The Child Abuse Prevention and Treatment Act (CAPTA) (P. L. 93-247) drafted in 1974 expanded the scope of reporting laws and increased the number of professionals who were mandated to report. Incorporating the expanded reporting laws into state legislation was a prerequisite for obtaining national funding through CAPTA (Kaufman \& Zigler, 1996). And states readily complied. Gelles (1996) explains that reporting laws were extremely popular because they were easy to set up, relatively inexpensive and, were demonstrable evidence that states were "doing" something about the problem. However, officials grossly underestimated the numbers of reports these laws and early public awareness campaigns were going to bring in. While there were 669,000 reports of child maltreatment in 1976, the numbers of reports quickly doubled and quadrupled to 
over 1 million reports in 1980, and over 3 million reports in 1997 (Kaufman \& Zigler, 1996; Wang \& Daro, 1998).

Despite extensive laws requiring professionals to report any suspected abuse or neglect, those working with children still wrestle with such decisions. Zellman (1990) surveyed mandated reporters and found that $40 \%$ indicated they had on some prior occasion failed to report suspected child abuse. The respondents cited a lack of evidence, fears of making a false accusation, concerns that a report was not in the child's best interest, and, most disturbingly, a lack of confidence in child protective service agencies, as reasons for failing to make a report.

\section{Screening}

Once an individual does decide to report child maltreatment, the assessment and decision-making process of state child protective systems begins. Not all calls that come in are referred for investigation. In most states, allegations of abuse are screened at intake based on state definitions of maltreatment, state laws about appropriate cases for investigation, risk, and believability (Wells, Downing, \& Fluke, 1991). In 1996, around 2 million reports were made to child protective service agencies and 1,625,000 investigations were conducted (USDHHS, 1998). Almost 400, 000 reports were therefore screened out at intake.

It is not entirely clear why many calls are screened out. Screening guidelines are established by federal, state, and agency policy. Giovannoni (1991) conducted a survey with child protective workers and found that the majority described the screening process as problematic. Only 5 out of 117 workers felt that 
the screening criteria were clear. And, unfortunately, there are indications that the lack of clarity can result in decisions that are not based on the facts of the report.

Wells (1997) found that many caseworkers' decisions to screen in or screen out allegations of child maltreatment are based on current caseloads. As caseloads fill up, more cases are screened out. In a study on child protective screening practices at 12 sites, Wells and his colleagues found that the sites with higher numbers of reports were also the sites that screened out reports to a higher degree (Wells, Downing, \& Fluke, 1991). National data also support the influence of caseload on child protective screening decisions. The number of children investigated for maltreatment between 1986 and 1993 remained the same, however, the percentage of reported cases of maltreatment that were investigated decreased (Wells, 1997). A saturation point is reached in which limited child protective service staff and resources can no longer keep up with maltreatment allegations. Thresholds must necessarily then be raised limiting what is accepted for investigation. The limitation in available investigatory resources requires that screening policies need to be explicit and procedures for identifying high-risk cases need to be clear.

Investigation

After a case has been screened in, investigation is the next level of intervention for child protective agencies. If a case is accepted for investigation, a child protective worker must make several important decisions immediately upon meeting with the family by answering the following questions: Has abuse or 
neglect occurred? Who is the likely perpetrator? Is the child in imminent danger? Should the child be removed from the home temporarily?

In the majority of cases, responses to these questions end child protective involvement. Out of the $1,625,000$ reports investigated by child protective services in 1996 , about $66 \%$ failed to result in a substantiation or indication of maltreatment (USDHHS, 1997). Substantiation and indication, although defined differently by individual states, generally refer to cases in which a determination was made that maltreatment occurred and the case was opened to a child protective agency. A lack of substantiation does not necessarily mean that no maltreatment occurred. In a survey of child protective workers from three states, Giovannoni (1991) found that, in over half of the "unsubstantiated" reports, some form of maltreatment was noted as likely. Case workers reported that most cases (39\%) were not validated because of "lack of proof," $28 \%$ were not substantiated because the report was determined to be "malicious," or the basis of a custody dispute, and $10 \%$ of the reports did not meet the state requirements for severity. English (1997) found that the demographics of the child, the family, the referral source, and the case worker have also been shown to impact substantiation rates, as well as definitions of maltreatment and screening policies used by the child protective agency.

\section{Post-Substantiation Services}

Once a case has been substantiated, child protective agencies have the authority to intervene more intensively. Interventions can include individual treatment for either the child or the parent, family therapy, self-heip services, 
substance abuse treatment, assistance with basic living needs such as housing or financial assistance, or placement of the child in foster care. However, even in cases that have been substantiated, investigation is often the only "service" that is provided. Wang and Daro (1998) found that in $30 \%$ of substantiated cases, child protective involvement included no provision of services. This is a slight decrease from the $40 \%$ of cases receiving no services in 1993 (McCurdy \& Daro, 1994) but still identifies 316,200 victims of substantiated abuse or neglect in 1997 who received no services or assistance. It is unclear exactly why these families received no services; there is little information available on what happens to children and families after a substantiation of maltreatment (McCurdy \& Daro, 1994; USDHHS, 1998). Although research on this area of the child protective system is increasing, the information coming in generates more questions than answers.

Research has documented a dramatic decrease in the number of families who receive child protective services since 1977 . This decrease only applies to those families receiving services while the children were living in the home (as opposed to foster care services). "In-home services" decreased from 1,250,000 in 1977 to 500,000 in 1994 (USDHHS, 1994; Wang \& Daro, 1998). Foster care numbers on the other hand have not decreased and appear, in fact, to be increasing. Five-hundred thousand children were in out-of-home placements (including foster care, respite care, and kinship care) in 1977 and, after declining in the early 1980s, those numbers rose again to a little under 500,000 in 1994 (NRC, 1993; Pelton, 1997; USDHHS, 1994; Wang \& Daro, 1998). In 1977 the number of children in 
foster care represented $30 \%$ of all children receiving child protective services, while the 1994 numbers represent about $50 \%$.

According to Wang and Daro (1998), for those maltreating caregivers who do receive "in-home" services, most receive family focused interventions such as parent aid, parent education, or homemaker and childcare services. Case management and caseworker services were the second most common services provided and individual and family counseling was the third most common. Another study (USDHHS, 1994) found that outpatient treatment, parent in-home training, and parent-training classes were provided most frequently. However, these treatment-oriented interventions were provided in less than $25 \%$ of the cases. The most common services provided by the child protective agencies themselves were "monitoring child safety," coordination, and advocacy activities. These were provided in $50-70 \%$ of the cases. Furthermore, the study found that for caregivers with identified problems such as substance abuse, parenting difficulties, and mental health problems, treatment for those problems were only provided to $50 \%$ of the caregivers. Approximately a quarter were offered services that were not provided, either because of lack of availability, or refusal of the services. For another quarter of the caregivers, the services were not even offered.

It is unclear why so few families are receiving direct services through the child protective system. One possibility may be that available treatment options for these families have decreased. The National Research Council (1993) concluded that resources vary from county to county and state to state, so that options are 
often limited. And the U.S. Advisory Board on Child Abuse and Neglect (USDHHS, 1990, p. 40) noted, "There are not enough staff, funds, training programs, services to special populations, or prevention and treatment services to make a serious reduction of child abuse and neglect a reality."

Another possible reason for decreasing in-home services could be that the funding for such services has become less available. During the 1960s and 1970s, changes were made in how funding was supported by the federal government for services for maltreated children (USDHHS, 1994). Due to early concerns about children having to remain in unsafe families, money to support foster care was set up separately from money to support services for maltreating families. Foster care money was established as an open-ended entitlement program, with no ceiling on how much money states could receive to support these services. Even with the establishment of Title XX of the Social Security Act in 1974, which made more funds available for a variety of direct social services, funding for service provision to families was capped, effectively putting a ceiling on the amount of services that could be offered.

The decreasing in-home services and increasing numbers of children in foster care is particularly confusing given the strong commitment that the federal government made in the early 1980 's to keeping children out of foster care. The Adoption Assistance and Child Welfare Act (AACWA) of 1980 (P. L. 96-272) specified that by October 1983, federal funding was to be contingent upon a state plan to make "reasonable efforts" to help keep maltreating families together. The 
basis of this piece of legislation was a fear that too many children were being placed for too long in foster care without any concrete plan for finding the children a permanent placement. "Reasonable efforts" were to be made to keep the biological family together and only after those efforts had been tried and had failed could child protective agencies move to terminate parental rights and place the child up for adoption.

Also, an important change was occurring in ideas about the etiology of maltreatment that encouraged the emphasis on providing services in order to preserve families in the 1980s. A psychopathological model of child maltreatment that prevailed in the 1960s and early 1970s was replaced in the late 1970s and the 1980s by the ecological model (Belsky, 1980). Instead of explaining child abuse and neglect as the result of mental illness and individual psychopathology, the ecological model suggested that factors at many levels were creating an environment that increased the occurrence of child maltreatment. These levels included child factors (vulnerability, difficult temperament), parent factors (history of abuse, lack of parenting skills), family factors (stress, isolation, domestic violence), neighborhood factors (lack of resources), and social factors (unemployment, economic disadvantage). Implications for treatment were that if child abuse occurred because of a variety of social factors, many of which were imposed on caregivers by their history and environment, what was needed was not policing of these families but offers of extensive services that could help ameliorate some of these outside factors. 
This philosophy was the basis of widespread intensive family preservation programs that were established in the mid-1970s such as the Homebuilders Program (Kinney, Madsen, Fleming, \& Haapala, 1977). Similar family preservation programs have become an increasingly popular approach to intervening with maltreating families. The National Governor's Association noted in 1992 that family preservation services were available in 30 states (USDHHS, 1994). These programs offer short-term, 24-hour services in whatever area is deemed vulnerable for the family. This might include help with child-care, job seeking, housing, economic difficulties, marital difficulties, and isolation. The programs also include elements of parent education and training, as well as family therapy, but the emphasis is on crisis-intervention. Caseloads tend to be small (2-4) and duration of services is short (4-8 weeks). The guiding philosophy of these programs is that if a broad range of intensive in-home services is offered to maltreating families during periods of crisis the safety of the child can be ensured and the family preserved.

The family preservation programs have produced some results suggesting that they do reduce out-of -home placement to a greater degree than control groups. However, evaluations of these widespread family preservation programs report that they have been unable to offer any solid evidence that they help children remain safe (Barth, 1998; Gelles, 1996; NRC, 1993; Schellenbach, 1998; Wolfe \& Wekerle, 1993). And there is some evidence that the Family Preservation Programs might actually be most effective with families who are not at risk for placement and 
are experiencing transitory stress rather than chronic crises (Smokowski \& Wodenski, 1996). Furthermore, the intensive nature of these programs necessarily mean that few families can be offered such services. The Homebuilders Program served 50 families per month in 1994, in the state of Washington in comparison to 500 children placed in foster care each month in that state (USDHHS, 1994). Although the Intensive Family Preservation Programs have proliferated, the decreasing numbers of families receiving in-home services nation-wide suggest that their efforts are not having an impact on keeping families together.

\section{Criticisms and Recommendations for Reform}

The confusion over what happens to children and families that enter the child protective system and fears that the system is not having any effect on reducing child maltreatment is causing disagreements between advocates and researchers over where the problem lies. One of the current tensions is between those who feel that child protective services works too hard to preserve unsafe families and those who feel it does not offer enough support to families in the system whose real problem is poverty.

Some feel that the emphasis on family preservation and the requirement that states make "reasonable efforts" to keep biological families together has placed too many children in harm's way. Gelles (1996) maintains that family preservation has been oversold and over-esteemed in the child protective service field. He points out that those who argue that family preservation and child safety can be achieved simultaneously are using flawed logic. Decisions emphasizing one necessarily 
weaken the other. He concludes that child-centered federal policies are needed, supported by strong risk-assessment measures, and service provision for families that are most likely to take advantage of it. Berry (1998) points out that while the Adoption Assistance and Child Welfare Act of 1980 had some positive results in that it temporarily decreased foster care and supported programs that strengthened families, ultimately foster care began to increase again and there was no notable increase in children freed for adoption. She recommends a clearer specification of "reasonable efforts". Barth (1998) also argues that too much emphasis has been placed on the needs of the adults and not enough on the needs of the children for a safe, legally permanent home. He claims that a movement is in place to put child safety first and family preservation second. A report on child maltreatment related fatalities by the Advisory Board on Child Abuse and Neglect (USDHHS, 1995) offered as one of its recommendations that child protective agencies should "first conduct a review of risk to all family members and ... decide to pursue preservation efforts only if it presents a reasonably safe strategy for the child and others. (p. 116)"

Congress heard some of these concerns and passed legislation to try and help clarify some limitations to the "reasonable efforts clause" of the Adoption Assistance and Child Welfare Act. The Adoption and Safe Families Act (P. L. 105-89) was signed into law in 1997. It amended the terms of the 1980 Act in order to emphasize that child safety should be the "paramount concern" when determining how best to make decisions about cases of child maltreatment. 
"Reasonable efforts" may now be suspended if a maltreating caregiver has been convicted of murder or other felonious assault against a child, or if the child's health and safety is deemed seriously at risk by the agency.

Others argue that child protective services do not suffer at all from an overemphasis on family preservation. Instead, they feel that too many children are unnecessarily taken from their families. These advocates point out that the majority of substantiated maltreatment is neglect and argue that many of these cases are families that suffer mainly from poverty. Pelton (1997) points to the increasing rates of children in foster care placement in his argument that the country has never really shown any commitment to preserving the family. He recommends a revamped system in which allegations of child abuse and neglect are limited to cases of serious harm or endangerment and are investigated by the police. Child protective agencies would then be transformed into family preservation agencies and offer services to families on a voluntary basis. Kaufman and Zigler (1996) also offer their recommendations for an overhaul of the system in which coercive state intervention is replaced by a coordinated system of voluntary family support services. The authors believe that state intervention should not involve any determinations of guilt or risk and should instead determine need in families that are reported for child maltreatment. They write:

By providing supportive interventions instead of just making categorical decisions about families (e.g., atrisk vs. not at-risk), sources of stress and identified problems can be alleviated, risk of reabuse lowered, and a system of checks and balances established with the capacity to promote early identification and 
intensification of service delivery at times of heightened risk. (p. 237)

However, these authors, and others who advocate for a voluntary system of service delivery to all but the highest-risk cases (e.g., Emery \& Laumann-Billings, 1998) are failing to acknowledge that such a system does not address the primary difficulties of the current system: How to decide which families are at high-risk for seriously harming their child and which are not. Despite Kaufman and Zigler's (1996) suggestion that state protective services should not make such a determination, the reality is that someone, somewhere is going to have to decide the degree to which a particular parent is likely to further endanger his or her child's physical and emotional health. However difficult such assessments are, denying that they need to occur is dangerous. Without carefully studying who is making those decisions and how, the bases for assessments of risk will be hidden and arbitrary.

An additional problem with the above recommendations is that a voluntary system for all families not at high risk for harming their child (including those, theoretically, who are at moderate risk) belies an assumption that all families would be eager to participate in and would benefit from purely voluntary services.

Research does not support this assumption and instead supports a view that many families are either unable or unwilling to make use of services offered to them. Jones (1987) reviewed five studies on treatment outcome for abusive and neglectful caregivers and found that $20-87 \%$ of the families made no changes or were worse 
upon termination. Cohn and Daro (1987) reviewed four major, multi-year evaluations of relative treatment efficacy with maltreating caregivers and found that one-third of the sample re-abused their children during the course of treatment. One-half of the sample was judged by child protective caseworkers as likely to reabuse their children on termination of treatment. Finally, Willet, Ayoub, and Robinson (1991) used a growth modeling procedure to evaluate family functioning changes in maltreating families who were involved in treatment. They concluded that a large proportion of the families were at the same level of functioning or worse, even after intensive long-term treatment.

Reviews of different types of direct interventions for maltreating caregivers also show few positive results (NRC, 1993, 1998; Schellenbach, 1998; Wolfe \& Wekerle, 1993). Cognitive/behavioral treatments show some improved outcomes in specific behavioral criteria but few studies have been able to demonstrate a change in parent-child relationships or a reduction in recidivism rates. There is even less documented support for self-help services such as Parents Anonymous. One comprehensive intervention program, Project-12 Ways, has shown some support for reducing recidivism (Lutzker \& Rice, 1987) but critics argue that the results are weak (Schellenbach, 1998).

There is an additional, critical, difficulty in intervening with maltreating caregivers --time constraints due to the developmental needs of the children for a consistent, permanent caregiver. Even an incurable optimist, who believes that anyone given the right services, in the right amount, in the right areas, over time, 
can make important lasting behavior changes, must admit that testing such a hypothesis is ill-advised for many maltreating caregivers. Cicchetti and his colleagues (Cicchetti, 1996; Cicchetti \& Rogosch, 1994; Cicchetti \& Toth, 1995) have examined the impact of child maltreatment from a developmental perspective, looking particularly at the impact of maltreatment on attachment difficulties in children. Cicchetti \& Toth (1995) place estimates of attachment difficulties in children who have been maltreated as high as $70-100 \%$. These authors also suggest that attachment problems early in the maltreated child's development might be an explanatory factor in the later emotional and behavioral sequelae of maltreatment such as acting out behavior, distrust, and problematic peer relations.

In reality, there are maltreating caregivers who will not be able to make changes in their behavior in time to meet the developmental needs of their children for safety and for consistent, competent caregiving. Several of the most prominent researchers in the field have come to this conclusion (Gelles, 1996; Kolko, 1996; Oates \& Bross, 1995). And whether or not structural reforms are implemented in the child protective system over the next several years there will be no way to avoid including risk assessment as a necessary part of the process. The goal should be to make such assessments standardized, comprehensive, and clear rather than ignore that they are an inherent part of the process. The following section outlines what is currently known about risk assessment in child protective services and argues that an inclusion of readiness to change would increase their current utility. 


\section{Risk Assessment}

The major decisions that must be made by those involved in child protection require the ability to identify: 1) caregivers at risk for re-abuse; 2) caregivers at risk for severe re-abuse; 3 ) caregivers who are able or willing to make the necessary changes in their behavior; and 4) caregivers who have successfully made meaningful changes in their behavior. While much of current risk assessment is based on personal intuition and experience, several formal risk assessment measures have been developed in the past 10 years to assist in these decisions. A survey conducted in 1991 found that 42 of the 50 states have experimented with or implemented some form of systematic, formal risk assessment (Berkowitz, 1991).

There are several different types of risk assessment measures that have been used (Pecora, 1991). The matrix approach uses a grid in which caseworkers rate 16-35 factors that are believed to be associated with child, parent, or family functioning (e.g., child vulnerabilities, parenting skills, living conditions, family relationships). All of the items are equally weighted and risk is determined through a summary score. A second approach, the empirical predictors method, is similar to the matrix approach except a small number of actual predictors of abuse are used, not just a list of associated variables. Family assessment scales have also been used in the risk assessment process by some agencies. These assess child and family functioning more than actual risk but provide a good strengths/weakness analysis for the family. And finally, an assessment tool known as the Child at Risk 
Field Instrument is available. This instrument has 14 open-ended questions and is based on an ecological model of risk.

Pecora (1991) notes that there are several benefits to the use of structured risk assessment measures. Most importantly, they can 1) document caseworker decision-making; 2) reduce decision-making bias; 3) focus caseworker attention on critical, empirically-based risk factors; and 4) help caseworkers assess risk throughout the life of the case. Unfortunately, as they are currently used, the risk assessment measures also have many limitations. Several reviewers (DePanfilis \& Scannapieco, 1994; English \& Pecora, 1994; Pecora, 1991; Wald \& Woolverton; 1990) note the methodological problems of current instruments including low interrater reliability, low validity, use of correlates instead of predictors, few prospective evaluation designs, and low classification and prediction rates $(50 \%$ false positive rate, $30 \%$ false negative rate). Gelles (1996) also notes that child protective workers receive very little training in the use of these instruments resulting in unsystematic application and misuse.

Currently, work is being done to address the methodological limitations of these instruments. As research on predictors of recidivism continues, the validity of actuarial methods of assessing risk of re-abuse and risk of severe abuse will become stronger. Developers are working on designing better systems that can effectively classify high-risk groups of caregivers beyond current methods. However, even if they succeed, risk assessment measures will not be effective at examining who is more likely to make changes in their behavior and who has made 
changes. There is no serious consideration of potential for change or measurement of change included in current risk assessment instruments.

The only acknowledgment of change in most risk assessment measures is a brief measure of compliance with child protective case plans. For example, in the risk assessment procedures used by the city of Philadelphia, the County of Los Angeles, and the states of Illinois and Rhode Island, change is assessed with a single item that rates the caregiver's "level of cooperation" on a five point scale (Gelles, 1996). There are two major problems with this method of measuring change: 1) a single item is not sufficient to assess changes in behavior, and, most importantly, 2) an assessment of compliance is not an assessment of change. Caregivers who have an open case with child protective service agencies have an incentive to "play the game": either comply with case plans or lose custody of their children. A measure of compliance does not address the real cognitive and motivational adjustments necessary for true change.

Morton and Holder (1997) describe frustration with considerations of change as they are assessed currently in the child protection decision-making system. They note, "Change issues such as readiness, emotional overload, motivation, vision, capacity, resistance, support and the like receive little or no attention. People are referred to services with minimal differentiation about the likely success of the service or implications of barriers" (p. 147). They also point out how change as it is currently assessed is confused with an assessment of compliance: 
First, absence of a repeated incident of maltreatment is considered evidence of change. Second, adherence to the task plan outlined in the service plan is used as evidence of family motivation. Unfortunately, the approach often leads to a problem when the caseworker believes that the family has not changed, yet the family has complied with the case plan. The experience of the authors in reviewing cases exhibiting this approach suggests that there is often no assessment accompanying the service plan and that the problems identified are frequently not the core dynamics influencing the maltreatment (p. 148).

Instead of relying on compliance or lack of evidence of further abuse as a measure of change, what is needed is a valid and reliable method of assessing the cognitive, emotional, motivational, and behavioral indicators of real change.

The Transtheoretical Model of Change

The Transtheoretical Model of Behavior Change (Prochaska \& DiClemente, 1982, 1983b, 1984, 1986a, 1992; Prochaska, Norcross, \& DiClemente, 1994) offers a much more dynamic assessment of change than a simple recording of compliance. Change is conceptualized as a complex process in which one progresses through a number of stages in trying to modify behavior. Each stage has measurable cognitive, behavioral, and emotional characteristics. The Transtheoretical Model was originally developed by Prochaska and DiClemente for assessing change in smoking behavior (DiClemente \& Prochaska, 1982; Prochaska \& DiClemente, 1983a) and for individuals seeking psychotherapy (McConnaughy, Prochaska, \& Velicer, 1983; Prochaska \& DiClemente, 1982, 1983b, 1984, 1986b) and came out of an effort to bridge the commonalties of 18 popular theories of psychotherapy by matching the strategies or processes of these therapies with a 
temporal or stage-based conceptualization of change. The model also integrated other theoretical constructs central to change such as Janis and Mann's theory of decisional balance (1977) and Bandura's theory of self-efficacy (1977).

Since its development, the reliability and validity of the model's core constructs have been well established in the area of smoking cessation (DiClemente et al., 1991; Prochaska, DiClemente, Velicer, Ginpil, \& Norcross, 1985; Prochaska, Velicer, Guadagnoli, Rossi, \& DiClemente, 1991; Velicer, DiClemente, Prochaska, \& Brandenburg, 1985) and other areas of health behavior (Prochaska \& Velicer, 1997; Prochaska, Velicer, et al., 1994) including weight control (O’Connell \& Velicer, 1988), exercise (Marcus, Rossi, Selby, Niaura, \& Abrams, 1992), alcohol use (DiClemente \& Hughes, 1990), drug use (Tsoh, 1995), condom use (Grimley, Prochaska, Velicer, \& Prochaska, 1995), and sun and radon exposure (Rossi, Blais, Redding, \& Weinstock, 1995). In the area of interpersonal violence, the model has been used to study juvenile delinquency (Fiore-Lerner, 1990) and both victims and perpetrators of domestic violence (Brown, 1997; Daniels \& Murphy, 1997; Levesque, 1998; Murphy \& Baxter, 1997).

\section{Core Constructs of Change}

There are four core constructs of the Transtheoretical Model of Change that could be applied to risk assessment for child maltreatment: the stages of change, the processes of change, decisional balance, and self-efficacy. 


\section{The Stages of Change}

Early in the development of the model, Prochaska and DiClemente's stagebased conceptualization of behavior change was empirically tested using the University of Rhode Island Change Assessment scale (URICA)(McConnaughy, DiClemente, Prochaska, \& Velicer, 1989; McConnaughy, Prochaska, \& Velicer, 1983). The URICA asks respondents to rate, on a 5-point Likert-type scale, the extent to which they agree with items that have been operationally defined to measure the theoretical stages of change originally outlined by Prochaska and DiClemente (1983b). Items were included such as: "I'm starting to think I have some problems I need to work on." or "I guess I have faults, but there's nothing I really need to change."

Research with the URICA measure (McConnaughy, DiClemente, Prochaska, \& Velicer, 1989; McConnaughy, Prochaska, \& Velicer, 1983) supported four stages: Precontemplation, Contemplation, Action, and Maintenance. In Precontemplation, individuals deny they have a problem and express no intention of changing their behavior in the foreseeable future. They are unaware of the negative consequences of their behavior, believe the consequences are insignificant, or have given up the thought of changing because they are demoralized. Applications of the Transtheoretical Model with smokers found that $40 \%$ of smokers are in Precontemplation (Velicer et. al., 1995). Precontemplators are likely to make up an even larger proportion of caregivers involved with child protective agencies given that most involvement is usually court-ordered. Denial 
of the substantiated abuse or neglect, a lack of any personal responsibility for the problems, and an antagonistic relationship with the child protective agency could mark this stage for maltreating caregivers.

Contemplation is the stage in which individuals begin to consider the benefits of changing. They are more likely to recognize or acknowledge some of the negative consequences of their problem behaviors. They may be seeking information on their problem but are not ready to take immediate action. Abusive and neglectful caregivers at this stage might accept that there is a problem with their parenting and begin to consider the possibilities and consequences of changing their behavior. They might also begin to show a willingness to work with child protective agencies to make changes.

In Action, individuals are actively modifying their behaviors and acquiring new, health-promoting behaviors. Although the Action stage is traditionally marked by behavioral efforts to change, for maltreating caregivers, the Action stage cannot be solely defined by behavior. As described above, compliance with courtordered treatment is not necessarily the same as making active changes.

Maltreating caregivers who are truly in Action might, in addition to complying with treatment plans, show energized efforts to make difficult changes, have an awareness of the impact of their behaviors on their children, be working cooperatively with their child protective worker, and be engaging other supports.

Finally, in Maintenance, individuals strive to maintain the changes they have made and to prevent relapse. At this stage, the changes have been maintained 
for an extensive period of time, often defined as at least six months. Maltreating caregivers at this stage might theoretically be able to acknowledge their accomplishments and are, at the same time, still acutely aware of the difficulty of changing. They may have received feedback from treatment providers that they are doing well and they would continue to be vigilant for "triggers" in themselves or their environment that might lead to relapse.

A fifth stage, Preparation, emerged over the next few years of the Transtheoretical Models' development as Prochaska and DiClemente continued their work with the process of change and smoking cessation (DiClemente et al., 1991; Prochaska \& DiClemente, 1992; Prochaska, DiClemente, \& Norcross, 1992). The Preparation stage came after Contemplation but prior to Action. Individuals in this stage had made a firm commitment to changing and were making plans to follow through with their goals in the near future, usually defined as within the next month. The Preparation stage also involved some small behavioral changes made in preparation for more extensive changes. (Prochaska, DiClemente, \& Norcross, 1992; Prochaska \& Velicer, 1997). A Preparation stage has not been found in past applications of the model using a URICA-style stage of change measure (Brown, 1997, Levesque, 1998). However, maltreating caregivers in such a stage could theoretically show an increased trust in their child protective worker and be making important planning steps toward change (e.g., working out child care or transportation issues so that a parenting group can be attended regularly). 
In the Transtheoretical Model, movement through these stages is not conceptualized as a strictly linear progression but as a cyclical process in which relapse is assumed to be part of the process. Relapse is defined as a movement from the Action or Maintenance stage to an earlier stage of change (Prochaska \& Velicer, 1997). In any area of behavior change, few individuals who set out to cease unhealthy behaviors or acquire healthy ones succeed perfectly the first time they try. Instead individuals usually "recycle" through the stages as they attempt to change their behavior, relapse, and strengthen their resolve to attempt the changes again. Research has documented the problem of relapse among maltreating caregivers (DePanfilis \& Zuravin, 1998; Lung \& Daro ,1996; USDHHS, 1994). However, relapse in child abuse and neglect can be life threatening. Assuming that relapse is a part of the process of change points to the importance of including a careful assessment of how severe the consequences of such a relapse might be.

There are other unique aspects of applying the Transtheoretical Model to maltreating caregivers that are important to consider. While the participants in the development study for the original URICA were, for the most part, self-motivated into treatment, a caregiver's involvement with child protective services is likely to be court-ordered. A lack of cooperation could result in the removal of their child or loss of parental rights. Therefore, any measure of readiness to change with maltreating caregivers has to take into account a strong social desirability component and, as stated previously, would have to be able to discriminate true change from mere compliance. Clients who were complying with their case plan 
but who had no intention to change represent a subset of precontemplators. Yet both they and caregivers in Action might endorse behaviorally-oriented items. Variables would need to be identified that would distinguish the "compliers" from the caregivers in Action. For example, "compliers" might 1) have a different relationship with child protective agencies and 2) exhibit a differential willingness to take responsibility for the abuse or neglect. Such variables would have to be measured and incorporated into a stage of change instrument with this population.

\section{Processes of Change}

The proponents of the Transtheoretical Model do not assume that there is a single optimal intervention when helping people to change, but instead propose that individuals at different stages require different intervention strategies or make use of different processes. The processes were developed by examining the techniques of some of the more common theories of psychotherapy. Research found that "experiential processes" (thinking about, evaluating, and emotionally reacting to one's problem) tended to be used in earlier stages while "behavioral processes" (committing to change, removing temptations, planning rewards for success) were employed during later stages (DiClemente \& Prochaska, 1982; Prochaska \& DiClemente, 1992; Prochaska \& Velicer, 1997).

These results suggest that a behaviorally oriented parenting program might work well with maltreating caregivers who were in Action but would be less effective for "precontemplators" who were denying parenting problems. Precontemplative caregivers would theoretically either drop out of such a program 
or reluctantly "comply" with the case plan directive that they attend the program without making active changes in their behavior. Given the large number of maltreating caregivers who are probably in a Precontemplation stage and the limited treatment resources available, offering action-oriented interventions to the entire population is ineffective. Applying the Transtheoretical Model to the area of child abuse and neglect offers the possibility of better matching caregivers with interventions that are more likely to be effective and move the caregiver to a more advanced stage of change.

\section{Decisional Balance}

According to Janis and Mann (1977), sound decision-making requires the consideration of the potential gains (pros) and the potential losses (cons) associated with a decision's consequences. In a recent integrative report of 12 studies, Prochaska, Velicer, et al. (1994) found that the balance of pros and cons was systematically related to stage of change in all 12 behaviors examined: the cons of changing outweighed the pros in the Precontemplation stage and the pros outweighed the cons during the Action and Maintenance stages. The pros and cons tended to switch places of importance during a period immediately prior to the Action stage. From these 12 studies, Prochaska and his colleagues discovered that to progress from Precontemplation to Action involved approximately a one standard deviation increase in the pros of making the healthy behavior change, and a .5 standard deviation decrease in the cons of making the change. 
Change in maltreating caregivers might also be related to a differential assessment of the pros and cons of changing. For example, maltreating caregivers in the Precontemplation stage might feel that the difficulties of learning new things and the dislike of having to cooperate with child protective workers who have forcefully intruded into their family life outweigh the pros of changing. Caregivers in Action, on the other hand, might feel that the pros of changing their parenting behavior outweighed the cons.

\section{Self-Efficacy}

Self-efficacy, or the degree to which an individual believes he or she has the capacity to attain a desired goal, can influence motivation and persistence and therefore also influence change (Bandura, 1977). In previous research applying the Transtheoretical Model to smoking cessation (DiClemente, Prochaska, \& Gibertini, 1985), measures of self-efficacy were obtained by asking subjects to indicate how confident they were that they could abstain from smoking in a variety of situations, and how tempted they would be to smoke in these situations. In applications of the Transtheoretical Model with other problem areas, self-efficacy has been measured similarly. Like decisional balance, levels of self-efficacy differ systematically across the stages of change, with subjects further along in the stages of change experiencing greater self-efficacy and less temptation regarding the behavior in question. Issues of self-efficacy tend to be more crucial during later stages (Action and Maintenance) when an individual is trying to maintain a healthy pattern of behaviors and prevent relapse. Decisional balance, on the other hand, is a greater 
concern during earlier stages (Precontemplation, Contemplation, and Preparation) when an individual is trying to acquire healthy behaviors (Prochaska \& DiClemente, 1992). For maltreating caregivers, temptations to relapse could involve emotionally negative situations, such as feeling anger or loneliness, socially negative situations such as fighting with a partner or acting-out children, or socially positive situations such as celebrations or parties. Levels of temptation and confidence could be assessed with this population and compared to movement through the stages.

\section{Conclusions}

This chapter has outlined some of the criticisms of current child protective services that led the U.S. Advisory Board on Child Abuse and Neglect to label it a "failed system". Some of the difficulties of the system stem from the complexity and the size of the problem of child maltreatment, but also, as this chapter has emphasized, a lack of understanding of how maltreating caregivers make changes. Without understanding change, the system has been unable to implement a consistent policy in deciding when to provide services, which services to provide to whom, when a reunification plan is working, and when the caregiver is not making acceptable changes and parental rights need to be terminated. Measuring change is a crucial piece to some of the most important decisions that child protective agencies must make.

Barth (1998) pointed out, "predicting which families will succeed, which will fail..., and which will fail tragically.... is very difficult for child welfare 
service providers. (p. 222)" Although prediction will always be difficult, assessing the process of change in these families is one way to move toward better decision making and risk assessment. The Transtheoretical Model offers a reliable and valid model of change around which to begin studying change in maltreating caregivers. An application of the model could potentially offer two important tools for those who work with this population: 1) the ability to measure a caregiver's readiness to make the changes that would help keep their child safe from harm and 2) the ability to track a caregiver's movement through the stages of change as a case plan is implemented. The ability to measure readiness to change means that child welfare agencies will be able to move to protect children by identifying risk in terms of the severity of the abuse and a reluctance, unwillingness, or inability to change.

Gelles (1996) outlined the usefulness that the addition of a measure of readiness to change could have for decision-making in child protective service agencies (See Figure 1). By looking at risk assessment with change as an added dimension there are clearer implications for how to combine the need for permanency planning and child safety with the goals of family preservation. Family preservation programs would be reserved for those caregivers who were in Action and Maintenance stages, with careful observation for caregivers whose maltreating behaviors had been more serious. This would be particularly useful given the limited availability and funding for such services. Instead of offering the services arbitrarily, services would be offered to those individuals who would be more likely to take advantage of them. Caregivers in Precontemplation whose 
maltreatment had been less severe could receive educational programs designed to move them forward to more advanced stages. And finally, caregivers who had been severely abusive or neglectful and showed no intention or willingness to change their behavior would not be considered strong candidates for reunification. Agencies would not have to wait for a child to be seriously or permanently injured to suspend "reasonable efforts," because they would have the ability to identify families in which "reasonable efforts" are unlikely to work.

The following chapter will discuss the development and initial validation of a preliminary scale designed to measure readiness to change in maltreating caregivers and further examine how such a scale could be used by child protective agencies to assist in decision-making and treatment planning. Chapter 3 will describe the development of additional scales designed to measure constructs that are theoretically related to the Stages of Change. Both of these chapters will also address some of the unique qualities of caregivers involved with child protective services that challenge the application of the Model with this population. Chapter 4 will summarize the results of the initial instrument development research, discuss the implications of the findings for child protective service systems, and outline suggestions for further research in this area. 


\section{References}

Bandura, A. (1977). Self-efficacy: Toward a unifying theory of behavior change. Psychological Review, 84, 191-215.

Barth, R. P. (1998). Abusive and neglecting parents and the care of their children. In M. A. S Mason, A. Skolnick, \& S. D. Sugarman (Eds.), All our families: New policies for a new century (pp. 217-235). New York: Oxford University Press.

Berkowitz, S. (1991). Findings from the state survey component of the study of high risk child abuse and neglect groups. Rockville, MA: Westat.

Berry, M. (1998). Adoption in an era of family preservation. Children and Youth Services Review, 20(1), 1-12.

Belsky, J. (1980). Child maltreatment: An ecological integration. American Psychologist, $\underline{35}, 320-335$.

Brown, J. (1997). Working toward freedom from violence: The process of change in battered women. Violence Against Women, 3(1), 5-26.

Cicchetti, D. (1996). Child maltreatment: Implications for developmental theory and research. Human Development, 39, 18-39.

Cicchetti, D., \& Howes, P. W. (1991). Developmental psychopathology in the context of the family: Illustrations from the study of child maltreatment. Canadian Journal of Behavioural Science, 23(3), 257-281.

Cicchetti, D., \& Rogosch, F. A. (1994). The toll of child maltreatment on the developing child: Insights from developmental psychopathology. Child and Adolescent Psychiatric Clinics of North America, 3(4), 759-776.

Cicchetti, D., \& Toth, S. L. (1995). A developmental psychopathology perspective on child abuse and neglect. American Academy of Child and Adolescent Psychiatry, 34(5), 541-565. 
Cohn, A. H., \& Daro, D. (1987). Is treatment too late? What ten years of evaluative research tell us. Child Abuse \& Neglect, 11, 433-442.

Crittenden, P. M. (1998). Dangerous behavior and dangerous contexts: A 35-year perspective on research on the developmental effects of child physical abuse. In P. K. Trickett \& C. J. Schellenbach (Eds.), Violence Against Children in the Family and the Community (pp. 11-38). Washington D.C: American Psychological Association.

Daniels, J. W., \& Murphy, C. M. (1997). Stages and processes of change in batterers' treatment. Cognitive and Behavioral Practice, 4, 123-145.

DePanfilis, D., \& Scannapieco, M. (1994). Assessing the safety of children at risk of maltreatment: Decision-making models. Child Welfare, 73(3), 229-245.

DePanfilis, D., \& Zuravin, S. J. (1998). Rates, patterns, and frequency of child maltreatment recurrences among families known to CPS. Child Maltreatment, $\underline{3(1)}, 27-42$.

DiClemente, C. C., \& Hughes, S. O. (1990). Stages of change profiles in outpatient alcoholism treatment. Journal of Substance Abuse, 2, 217-235.

DiClemente, C. C., \& Prochaska, J. O. (1982). Self-change and therapy change of smoking behavior: A comparison of processes of change in cessation and maintenance. Addictive Behaviors, 7, 133-142.

DiClemente, C. C., Prochaska, J. O., Fairhurst, S., Velicer, W. F., Velasquez, M. M., \& Rossi, J. S. (1991). The process of smoking cessation: An analysis of Precontemplation, contemplation and preparation stages of change. Journal of Consulting and Clinical Psychology, 59, 295-304.

DiClemente, C. C., Prochaska, J. O., \& Gibertini, M. (1985). Self-efficacy and the stages of self-change of smoking. Cognitive Therapy Research, 9 , 181-200. 
Emery, R. E., \& Laumann-Billings, L. (1998). An overview of the nature, causes, and consequences of abusive family relationships: Toward differentiating maltreatment and violence. American Psychologist, 53(2), 121-135.

English, D. J. (1997). Current knowledge about CPS decision making. In T. D. Morton \& W. Holder (Eds.), Decision making in children's protective services: Advancing the state of the art (pp. 56-74). Atlanta, GA: Child Welfare Institute.

English, D. J., \& Pecora, P. J. (1994). Risk assessment as a practice method in child protective services. Child Welfare, 73 (5), 451-473.

Finkelhor, D. (1993). The main problem is still underreporting, not overreporting. In R. J. Gelles \& D. R. Loseke (Eds.), Current Controversies on Family Violence (pp. 273-287). Newbury Park, CA: Sage Publications.

Fiore-Lerner, C. (1990). The Transtheoretical Model of change: Self-change in adolescent delinquent behaviors. Unpublished doctoral dissertation, University of Rhode Island, Kingston.

Gelles, R. J. (1996). The book of David: How preserving families can cost children's lives. New York: BasicBooks.

George, C. (1996). A representational perspective of child abuse and prevention: Internal working models of attachment and caregiving. Child Abuse and Neglect, 20(5), 411-424.

Giovannoni, J. M. (1991). Unsubstantiated reports: Perspectives of child protection workers. Child and Youth Services Review, 15 (2), 51-62.

Grimley, D. M., Prochaska, J. O., Velicer, W. F., \& Prochaska, G. E. (1995). Contraceptive and condom use adoption and maintenance: A stage paradigm approach. Health Education Quarterly, 22(1), 20-35. 
Hubner, J., \& Wolfson, J. (1996). Somebody else's children: The courts, the kids, and the struggle to save America's troubled families. NYC, New York: Crown Publishers.

Janis, I. L., \& Mann, L. (1977). Decision making: A psychological analysis of conflict, choice and commitment. New York: Free Press.

Jones, D. P. H. (1987). The untreatable family. Child Abuse and Neglect, 11 , 409-420.

Kaufman, J., \& Zigler, E. F. (1987). Do abused children become abusive parents? American Journal of Orthopsychiatry, 57(2), 186-192.

Kaufman, J., \& Zigler, E. F. (1996). Child abuse and social policy. In Zigler, E. F., Kagan, S. L., \& Hall, N. W. (Eds.), Children, families, and government: Preparing for the 21st century (pp. 233-255). New York: Cambridge University Press.

Kempe, C. H., Silverman, F. N., Steele, B. F., Droegemueller, W., \& Silver, H. K. (1962). The battered-child syndrome. Journal of the American Medical Association, 181(1), 105-112.

Kinney, J., Madsen, B., Fleming, T., \& Haapala, D. (1977). Homebuilders: Keeping families together. Journal of Consulting and Clinical Psychology, 45(4), 671-672.

Kolko, D. J. (1996). Child physical abuse. In J. Briere, L. Berliner, J. A. Bulkley, C. Jenny, \& T. Reid (Eds.), The APSAC handbook on child maltreatment (pp. 21-50). Thousand Oaks, CA: Sage Publications.

Levesque, D. (1998). Violence desistance among battering men: Existing interventions and the application of the Transtheoretical Model of Change. Unpublished doctoral dissertation, University of Rhode Island, Kingston, Rhode Island. 
Lung, C. T. \& Daro, D. (1996). Current trends in child abuse reporting and fatalities: The results of the 1995 annual fifty state survey. Chicago, IL: NCPCA.

Lutzker, J. R., \& Rice, J. M. (1987). Using recidivism data to evaluate Project $12-$ Ways: An ecobehavioral approach to the treatment and prevention of child abuse and neglect. Journal of Family Violence, 2(4), 283-290.

Marcus, B. H., Rossi, J. S., Selby, V. C., Niaura, R. S., \& Abrams, D. B. (1992). The stages and processes of exercise adoption and maintenance in a worksite sample. Health Psychology, 11, 257-261.

McClain, P., Sacks, J., \& Frohlke, T. (1993). Estimates of fatal child abuse and neglect, United States, 1979 through 1988. Pediatrics, 91, 338-343.

McConnaughy, E. A., DiClemente, C. C., Prochaska, J. O. \& Velicer, W. F. (1989). Stages of change in psychotherapy: A follow-up report. Psychotherapy, 4 , 494-503.

McConnaughy, E. A., Prochaska, J. O., and Velicer, W. F. (1983). Stages of change in psychotherapy: Measurement and sample profiles. Psychotherapy, $\underline{3}$, 368-375.

McCurdy, K., \& Daro, D. (1994). Child maltreatment: A national survey of reports and fatalities. Journal of Interpersonal Violence, 9(1), 75-94.

Morton, T. D., \& Holder, W. (1997). What must change? What actions are necessary for Change? In T. D. Morton and W. Holder (Eds.), Decision making in children's protective services: Advancing the state of the art (pp. 143-158). Atlanta, GA: Child Welfare Institute.

Murphy, C. M., \& Baxter, V. A. (1997). Motivating batterers to change in the treatment context. Journal of Interpersonal Violence, 12(4), 607-619. 
National Research Council. (1993). Understanding child abuse and neglect. Washington, D. C.: National Academy Press.

National Research Council. (1998). Violence in families: Assessing prevention and treatment programs. Washington, D. C.: National Academy Press.

Oates, R. K. \& Bross, D. C. (1995). What have we learned about treating child physical abuse? A literature review of the last decade. Child Abuse \& Neglect, 19(4), 463-473.

O'Connell, D., \& Velicer, W. F. (1988). A decisional balance measure and the stages of change model for weight loss. The International Journal of the Addictions, 23, 729-750.

Pecora, P. J. (1991). Investigating allegations of child maltreatment: The strength and limitations of current risk assessment systems. In M. Robin (Ed.), Assessing reports of child maltreatment (pp. 73-92). Binghamton, NY: Haworth Press.

Pelton, L. H. (1997). Child welfare policy and practice: The myth of family preservation. American Joumal of Orthopsychiatry, 67(4), 545-553.

Prochaska, J. O., \& DiClemente, C. C. (1982). Toward a more integrative model of change. Psychotherapy: Theory, Research, and Practice, 19, 276-288.

Prochaska, J. O., \& DiClemente, C. C. (1983a). Stages and processes of selfchange of smoking: Toward an integrative model of change. Journal of Consulting and Clinical Psychology, 51(3), 390-395.

Prochaska, J. O., \& DiClemente, C. C. (1983b). Transtheoretical therapy: Toward a more integrative model of change. Psychotherapy: Theory, Research, and Practice, 20, 161-173.

Prochaska, J. O., \& DiClemente, C. C. (1984). The Transtheoretical approach: Crossing traditional boundaries of therapy. Howewood, $\mathrm{I}$ : Dow JonesIrwin. 
Prochaska, J. O., \& DiClemente, C. C. (1986a). Toward a comprehensive model of change. In W. Miller and N. Heather (Eds.), Addictive behaviors: Processes of change. New York: Plenum Press, pp.3-28.

Prochaska, J. O., \& DiClemente, C. C. (1986b). The Transtheoretical approach. In J. Norcross (Ed.), Handbook of eclectic psychotherapy. New York: Brunner/Mazel.

Prochaska, J. O., \& DiClemente, C. C. (1992). Stages of change in the modification of problem behaviors. In M.Hersen, R.M. Eisler \& P.M. Miller (Eds.), Progress on Behavior Modification. Sycamore, IL: Sycamore Press.

Prochaska, J. O., DiClemente, C. C., \& Norcross, J. C. (1992). In search of how people change: Applications to addictive behaviors. American Psychologist, 47(9), 1102-1114.

Prochaska, J. O., DiClemente, C. C, Velicer, W. F., Ginpil, S. E., \& Norcross, J. C. (1985). Predicting change in smoking status for self-changers. Addictive Behaviors, 10, 395-406.

Prochaska, J. O., Norcross, J. C., \& DiClemente, C. C. (1994). Changing for good. New York: Morrow.

Prochaska, J. O., \& Velicer, W. F. (1997). The Transtheoretical Model of health behavior. American Journal of Health Promotion, 12, 38-48.

Prochaska, J. O., Velicer, W. F., Guadagnoli, E., Rossi, J. S., \& DiClemente, C. C. (1991). Patterns of change: Dynamic typology applied to smoking cessation. Multivariate Behavioral Research, 26, 83-107.

Prochaska, J.O., Velicer, W.F., Rossi, J.S., Goldstein, M., Marcus, B.H., Rakowski, W., Fiore, C., Harlow, L., Redding, C., Rosenbloom, D., \& Rossi, S.R. (1994). Stages of change and decisional balance for twelve problem behaviors. Health Psychology, $\underline{13}, 39-46$. 
Rossi, J. S., Blais, L. M., Redding, C. A., \& Weinstock, M. A. (1995). Preventing skin cancer through behavior change: Implications for interventions. Dermatoepidemiology, 13(3), 613-622.

Schellenbach, C. J. (1998). Child maltreatment: A critical review of research on treatment for physically abusive parents. In P. K. Trickett and C. J. Schellenbach (Eds.), Violence Against Children in the Family and the Community (pp. 251-268). Washington D.C: American Psychological Association.

Sedlak, A. J. \& Broadhurst, M. L. A. (1996). Third National Incidence study of Child Abuse and Neglect (NIS-3). National Center on Child Abuse and Neglect, U.S. Department of Health and Human Services. United States Governments Printing Office: Washington DC.

Smokowski, P. R., \& Wodarski, J. S. (1996). The effectiveness of child welfare services for poor, neglected children: A review of the empirical evidence. Child Welfare Services, $\underline{6(4)}$, 504-523.

Straus, M. A., \& Gelles, R. J. (1986). Societal change and change in family violence from 1975 to 1985 as revealed by two national surveys. Journal of Marriage and the Family, $\underline{48}$, 465-479.

Straus, M. A., Hamby, S. L., Finkelhor, D., Moore, D. W., Runyan, D. (1998). Identification of child maltreatment with the parent-child Conflict Tactics Scales: Development and psychometric data for a national sample of American parents. Child Abuse and Neglect, 22(4), 249-270.

Tsoh, J. Y. (1995). Stages of change, dropouts, and outcome in substance abuse treatment. Unpublished doctoral dissertation, University of Rhode Island.

U.S. Department of Health and Human Services, Children's Bureau. (1990). Child abuse and neglect: Critical first steps in response to a national emergency. Washington DC: Government Printing Office. 
U.S. Department of Health and Human Services, Children's Bureau. (1994). National study of protective, preventive, and reunification services delivered to children and their families. Washington DC: U.S. Government Printing Office.

U.S. Department of Health and Human Services, Children's Bureau. (1995). A nation's shame: Fatal child abuse and neglect in the United States. Washington DC: Government Printing Office.

U.S. Department of Health and Human Services, Children's Bureau. (1998). Child maltreatment 1996: Reports from the states to the national child abuse and neglect data system. Washington DC: Government Printing Office.

Velicer, W. F., DiClemente, C. C., Prochaska, J. O., \& Brandenburg, N. (1985). A decisional balance measure for predicting smoking cessation. Journal of Personality and Social Psychology, 48, 1279-1289.

Velicer, W. F., Fava, J. L., Prochaska, J. O., Abrams, D. B., Emmons, K. M., \& Pierce, J. P. (1995). Distribution of smokers by stage in three representative samples. Preventive Medicine, 24, 401-411.

Wald, M. S., \& Woolverton, M. (1990). Risk assessment: The emperor's new clothes? Child Welfare, 64 (6), 483-511.

Wang, C. T., \& Daro, D. (1998). Current trends in child abuse reporting and fatalities: The result of the 1997 annual fifty state survey. Chicago, IL: National Committee to Prevent Child Abuse.

Wekerle, C., \& Wolfe, D. A. (1996). Child maltreatment. In E. J. Mask \& R. Barkley (Eds.), Child psychopathology. New York City, NY: The Guilford Press.

Wells, S. J. (1997). Screening in child protective services: Do we accept a report? How do we respond. In T. D. Morton \& W. Holder (Eds.), Decision making in children's protective services: Advancing the state of the art. (pp. 94-106). Atlanta, GA: Child Welfare Institute. 
Wells, S. J., Downing, J., Fluke, J. (1991). Responding to reports of child abuse and neglect. Child and Youth Services Review, 15 (2), 63-72.

Willet, J. B., Ayoub, C. C., \& Robinson, D. (1991). Using growth modeling to examine systematic differences in growth: An example of change in the functioning of families at risk of maladaptive parenting, child abuse, or neglect. Journal of Consulting and Clinical Psychology, $\underline{59}$, 38-47.

Wolfe, D. A., \& Wekerle, C. (1993). Treatment strategies for child physical abuse and neglect: A critical progress report. Clinical Psychology Review, 13, 473-500.

Zellman, G. L. (1990). Child abuse reporting and failure to report among mandated reporters. Journal of Interpersonal Violence, $5,3-22$. 
Figure 1.1

Two Dimensions Of Risk Assessment For Child Abuse And Neglect

\begin{tabular}{|c|c|c|}
\hline \multirow[b]{2}{*}{ Stage of Change } & \multicolumn{2}{|c|}{ Severity of Risk } \\
\hline & Mediu & Low \\
\hline $\begin{array}{l}\text { Precontemplator } \\
\text { Contemplator }\end{array}$ & $\begin{array}{l}\text { No reunification; } \\
\text { high likelihood } \\
\text { of terminating } \\
\text { parental rights }\end{array}$ & $\begin{array}{l}\text { Parent education } \\
\text { classes }\end{array}$ \\
\hline Preparation & & \\
\hline $\begin{array}{l}\text { Action } \\
\text { Maintenance }\end{array}$ & $\begin{array}{c}\text { Family } \\
\text { preservation } \\
\text { only with close } \\
\text { monitoring }\end{array}$ & $\begin{array}{l}\text { Family } \\
\text { preservation } \\
\text { reunification } \\
\text { recommended }\end{array}$ \\
\hline
\end{tabular}

Note: From The Book of David (p. 129), by R. J. Gelles, 1996, New York, NY: BasicBooks. Copyright 1998 by Richard J. Gelles. Reprinted with permission. 


\section{CHAPTER 2}

Measuring Change in Maltreating Caregivers: Development

of a Preliminary Stage of Change Scale 


\section{Introduction}

Despite recent estimates placing the number of known maltreated children entering the child protection system at over 1 million each year (USDHHS, 1998; Wang \& Daro, 1998), there is substantial evidence to indicate that many of families of these children are not offered services, that the available services are distributed haphazardly, and that most of the caregivers who receive services are not being successfully treated. The National Research Council (NRC) (1993) noted that the availability of resources varies across counties and states limiting options for intervention in cases of child maltreatment. The U.S. Advisory Board on Child Abuse and Neglect (USDHHS, 1990) concluded, "There are not enough staff, funds, training programs, services to special populations, or prevention and treatment services to make a serious reduction of child abuse and neglect a reality. (p. 40)." In 1997, 316,200 children who were victims of substantiated abuse or neglect received no services or assistance (Wang \& Daro, 1998) and only about $50 \%$ of caregivers with identified problems such as substance abuse, parenting difficulties, and mental health problems were provided with treatment for those issues (USDHHS, 1994). Of those families who do receive services, most are provided with interventions such as parent aid, parent education, homemaker and childcare services, case management services, or outpatient treatment for the caregiver or the family (Wang \& Daro, 1998, USDHHS, 1994). Unfortunately, 
research examining the efficacy of such services is inconclusive at best and discouraging at worst.

\section{Treatment Efficacy Research}

In reviewing research on treatment efficacy for child maltreatment, the NRC $(1993,1998)$ deplored the lack of treatment outcome for child abuse and neglect and was discouraged by the extent of the methodological limitations in the studies they found. In general studies were limited by: 1) lack of appropriate control groups, 2) small sample sizes, 3) the use of multiple outcome measures with limited reliability and validity, 4) an absence of, or very short, follow-up periods, and 5) confounding inclusion of subject targets (children vs. adults) and behavioral targets (physical abuse vs. neglect or problem parenting). In a ten-year review of treatment outcome literature on child physical abuse, Oates and Bross (1995) found similar methodological shortcomings. Their modest inclusion criteria were research articles between 1983 and 1992, that had: 1) at least 5 or more subjects, 2) randomization between a treatment group and a control group, comparison of a treatment group and a matched comparison group, or a pre-test/post-test design, and 3) at least $15 \%$ of the subjects (victims or perpetrators) identified as physically abused or abusive. Twenty-five published studies met these criteria. Thirteen of these studies targeted caregivers, but given the different treatment objectives, outcome measures, and follow-up information, the authors felt no general conclusions could be made about treatment efficacy. 
The limited treatment outcome studies for abusive and neglectful caregivers tend to either focus on cognitive/behavioral parenting programs or on coordinated family intervention programs. The cognitive/behavioral programs generally target behaviors and cognitive styles that are demonstrated in the etiological literature to be associated with maltreating behaviors. Wolfe and Wekerle (1993) describe these programs as usually addressing either parenting behaviors or general stress and anger management. A focus on parenting behaviors might teach behavior management techniques such as reinforcement, appropriate punishment, and the importance of consistency. A program focusing on stress and anger management is designed to help caregivers recognize cues that their anger is building, teach them to replace anger-producing thoughts, and often includes relaxation training.

Those who have reviewed outcome research (Cohn \& Daro, 1987; Kolko, 1996; NRC, 1993, 1998; Wolfe \& Wekerle, 1993) indicate that there is some evidence that caregivers who participate in cognitive/behavioral treatment programs are able to learn the targeted behaviors and apply them in a clinical setting. These individuals show better parent/child interactions, better behavior control, and less negative, coercive child management strategies than controls. Cognitive programs show some success at teaching caregivers relaxation skills, cognitive restructuring skills, and problem-solving. There is also some evidence that parents who go through these programs exhibit less distress and there are fewer out-of-home placements. However, little follow-up research is conducted so it is unclear how long these gains are maintained. Furthermore, there is little research 
on whether these programs reduce recidivism rates or improve child mental health, two criteria that are important to the goal of treating child abuse and neglect. One comprehensive intervention program, Project-12 Ways, has shown some support for reducing recidivism (Lutzker \& Rice, 1987) but critics argue that the results are weak (Schellenbach, 1998).

There is even less documented support for popular multi-focused interventions, sometimes described as intensive family preservation programs. One of the earliest of these was the Homebuilders Program (Kinney, Madsen, Fleming, \& Haapala, 1977). Similar family preservation programs have been developed and have proliferated since that time. These programs offer short-term, 24-hour services in whatever area is deemed vulnerable for the family, including help with child-care, job seeking, housing, economic difficulties, marital difficulties, and isolation. The programs also can include elements of parent education and training, as well as family therapy, but the emphasis is on crisis-intervention. There is some evidence that parent-child relationships improve as a result of these programs and negative child behaviors are reduced, but it is unclear how long these results are maintained (NRC, 1993, 1998; Schellenbach, 1998; Smokowski \& Wodenski, 1996; Wolfe \& Wekerle, 1993). Out-of-home placements may be delayed for families that participate in the programs although the use of such an outcome measure is questionable. And, again there have been few indications that recidivism for the families who take part in these services decreases. In general, reviews of the outcome data on these programs have questioned their over-all 
effectiveness (Barth, 1998; Gelles, 1996; NRC, 1993, 1998; Schellenbach, 1998; Wolfe \& Wekerle, 1993).

In almost every case, treatment evaluation reviews have concluded that a substantial percentage of maltreating caregivers are not changing. Jones (1987) reviewed five studies on treatment outcome for abusive and neglectful caregivers and found that $20-87 \%$ of families made no changes or were worse upon termination. Cohn and Daro (1987) reviewed four major, multi-year evaluations of treatment efficacy with maltreating caregivers and found that one-third of the sample re-abused their children during the course of treatment. One-half of the sample was judged by child protective caseworkers as likely to re-abuse their children on termination of treatment. Finally, Willet, Ayoub, and Robinson (1991) used a growth modeling procedure to evaluate family functioning changes in maltreating families who were involved in treatment. They concluded that a large proportion of the families were at the same level of functioning or worse, even after intensive long-term treatment.

Furthermore, families who receive child protective services often end up relapsing and re-entering the system. Of the 577,000 cases around the country that were being served by child protective agencies on March 1, 1994, $40 \%$ had been previously open to the agencies and $61 \%$ of those cases were open due to concerns about the same child (USDHHS, 1994). DePanfilis and Zuravin (1998) reviewed studies of re-abuse rates and found that rates reached as high as $85 \%$ when families were followed for 8-10 years. 
And of the 1,215 child maltreatment fatalities in 1995 reported by Lung and Daro (1996) $41 \%$ of caregivers had had on-going or previous involvement with a child protective service agency.

\section{Treatment matching}

Treatment with this population is difficult for many reasons. Part of the problem is that caregivers who enter the child protective system often present with multiple problems in addition to child maltreatment. Crittenden (1996) outlined the problems that are associated with a maltreating population, including less parenting experience, economic difficulties, less education, more children, less stable relationships, personal trauma histories and a greater likelihood of substance use problems and marital violence. Maltreating caregivers are also often court-ordered into treatment so that service providers may be dealing with large amounts of resistance, anger, denial, and the potential for a high rate of drop-outs. A third problem is that current child protective treatment and intervention services for the caregivers are offered haphazardly, based on availability and with little consideration of who might benefit most from what type of treatment. Treatment matching or, matching caregivers to the intervention that is most likely to be effective, is a potentially important way to increase treatment efficacy for this population.

Given that the population of maltreating caregivers is a large, heterogeneous group with complex treatment needs, and given that resources are limited, it is likely that different interventions work better for different subgroups of caregivers 
(Oates \& Bross, 1995; Wolfe, 1987). The first step in examining this hypothesis is to work towards creating empirically based typologies. There are many possible variables on which maltreating caregivers can be grouped such as type and severity of maltreatment or coexisting difficulties such as substance abuse problems or domestic violence.

Bowdry (1990) suggests typologies based on intent and severity of maltreatment. She divides maltreatment into the following categories: 1) excessive discipline, 2) misguided attempts at education, 3) excessive corporal punishment of the oldest child, 4) the battered child, 5) serial battery, and 6) sadistic or tortuous abuse. According to Bowdry, in categories 1 and 2, the parents are often surprised that their behavior is considered abusive, and parent training programs/ behavioral interventions have a good chance at success. Category 3 often involves the scape-goating of an older, usually male child who is at risk for behavior problems and frequent out-of-home placement. The abuse in category 4 usually involves a younger child and explanations for the injuries are either nonexistent or inconsistent. Categories 5 and 6 indicate very high levels of risk for the child and termination of parental rights is strongly indicated.

Crittenden (1996) suggests a typology of maltreating families based on the level of intervention they will require from the child protective system. She describes families as either, 1) independent and adequate, 2) vulnerable to crisis, 3) restorable, 4) supportable, or 5) inadequate. Families who are independent and adequate need no intervention. Families vulnerable to crisis may need periodic 
crisis-management services but will generally be okay. Families who are restorable or supportable will need on-going treatment, restorable families for several years and supportable families, potentially for as long as a child remains in the home (e.g., in cases of parental mental illness). Inadequate families are likely not to change and parental rights should be terminated.

Typological considerations at this point in the child maltreatment literature are hypothetical and there is no clear way to assess which caregivers belong in which category. The Transtheoretical Model of Change (Prochaska \& DiClemente, $1982,1983 b, 1984,1986,1992)$, on the other hand, offers the ability to empirically identify subgroups of caregivers based on a measure of their readiness to make changes in their abusive or neglectful behavior. Grouping caregivers by readiness to change is useful because it has direct implications for an individual's likeliness to take advantage of different types of treatment. Applications of the Transtheoretical Model in other areas of behavioral and mental health have shown a relationship between stage of readiness to change and the efficacy of an intervention (DiClemente \& Prochaska, 1982; Prochaska \& DiClemente, 1992; Prochaska \& Velicer, 1997). Typology based on the model's stages of change also offers the ability to study differences among caregivers who do not seem able or willing to make changes. This group is most likely to put a child at risk and are most frustrating to child protective workers who are trying to work towards maintaining or reunifying the family. And, finally, typology based on the Transtheoretical Model offers an ability to measure growth and change within and among groups of 
maltreating caregivers. This contrasts with other possible grouping variables, such as type of abuse, which are static, based on past behavior, and do not allow individuals to move out of a typological category once placed.

\section{The Transtheoretical Model of Change}

The Transtheoretical Model of Change was originally developed by Prochaska and DiClemente for assessing self-change in smoking behavior (DiClemente \& Prochaska, 1982; Prochaska \& DiClemente, 1983b) and the process of change for individuals seeking psychotherapy (McConnaughy, Prochaska, \& Velicer, 1983; Prochaska \& DiClemente, 1982, 1983a, 1984, 1986). These authors conceptualized change as a process in which individuals move through a series of stages in thinking about and implementing changes in their behavior. The Transtheoretical Model also integrated other theoretical constructs believed to be central to change such as Janis and Mann's theory of decisional balance (1977) and Bandura's theory of self-efficacy (1977).

The model hypothesizes that different strategies or "processes" of change are more or less likely to be effective at different stages of the change process. Processes are different interventions that individuals employ in making changes in their behavior and were developed by examining the techniques of some of the more common psychotherapeutic approaches. Research found that "experiential processes" (e.g., thinking about, evaluating, and emotionally reacting to one's problem) tended to be used in earlier stages while "behavioral processes" (e.g., committing to change, removing temptations, planning rewards for success) were 
employed during later stages (DiClemente \& Prochaska, 1982; Prochaska \& DiClemente, 1992; Prochaska \& Velicer, 1997).

Since its development, the reliability and validity of the model's core constructs have been well established in the area of smoking cessation (DiClemente et al., 1991; Prochaska, DiClemente, Velicer, Ginpil, \& Norcross, 1985; Prochaska, Velicer, Guadagnoli, Rossi, \& DiClemente, 1991; Velicer, DiClemente, Prochaska, \& Brandenburg, 1985) and other areas of health behavior (Prochaska \& Velicer, 1997; Prochaska et al., 1994) including weight control (O'Connell \& Velicer, 1988), exercise (Marcus, Rossi, Selby, Niaura, \& Abrams, 1992), alcohol use (DiClemente \& Hughes, 1990), drug use (Tsoh, 1995), condom use (Grimley, Prochaska, Velicer, \& Prochaska, 1995), and sun and radon exposure (Rossi, Blais, Redding, \& Weinstock, 1995). In the area of interpersonal violence, the model has been used to study juvenile delinquency (Fiore-Lerner, 1990) and both victims and perpetrators of domestic violence (Brown, 1997; Daniels \& Murphy, 1997; Levesque, 1998; Murphy \& Baxter, 1997).

The organizing construct for the Transtheoretical Model is the Stages of Change (SOC) instrument, which measures an individual's stage of readiness to make changes in their behavior. Stage of change has been assessed two different ways in the various applications of the model. The first method is the use of an algorithm that, based on the responses, places the respondent in a mutually exclusive stage of change. To define an individual's stage, the algorithms usually specify periods of time during which the individual plans to change or in which the 
individual has maintained changes. For example, with smokers: Precontemplation is defined as having no intention to quit smoking in the next six months; Contemplation as having plans to quit within six months; Preparation as having plans to quit in the next month and having made one quit attempt in the past year; Action as having quit for a period of less than six months; and Maintenance as having maintained the changes for over six months (DiClemente et al., 1991; Prochaska \& DiClemente, 1992; Prochaska, DiClemente, \& Norcross 1992).

A second method of assessing an individual's stage of change is with a continuous measure in which respondents rate, on a 5-point Likert-type scale, the extent to which they agree with items that have been operationally defined to measure cognitive and behavioral markers of the Stages of Change. This was the design used in the original University of Rhode Island Change Assessment (URICA) instrument created by McConnaughy and her colleagues (McConnaughy, DiClemente, Prochaska, \& Velicer, 1989; McConnaughy et al., 1983) to examine change with psychotherapy patients. Research with the URICA measure supported four of the five stages originally hypothesized by Prochaska and DiClemente (1982, 1983a, 1984): 1) Precontemplation, in which individuals deny they have a problem and have no intention to change their behavior in the foreseeable future; 2) Contemplation, in which individuals consider the benefits of changing; 3) Action, in which individuals have begun to actively modify their behaviors and acquire new, health-promoting behaviors, and 4) Maintenance, in which individuals strive to maintain the changes they have made and prevent relapse. The continuous nature 
of the respondent's scoring results in a profile in which he or she shows varying degrees of identification with each stage of change.

A URICA-style Stage of Change measure allows an examination of subgroups based on their scores on this measure. Because the Stage of Change measure creates a score profile that can be compared with the profiles of other individuals, hypotheses can be drawn about what groups with similar profiles have in common. This process has been used successfully with applications of the Transtheoretical Model in different problem areas such as mental health problems, alcohol and drug use, and contraceptive compliance and in the area of domestic violence. (Brown, 1997; DiClemente \& Hughes, 1990; Johnson, 1995; Levesque, 1998; McConnaughy et al., 1983; McConnaughy et al., 1989; Prochaska \& DiClemente, 1992; Tsoh, 1995).

These studies found groups considering change in different ways. One group, labeled "Decision-Making" had begun to take some action yet were still considering the utility of making changes. Another group, labeled "Participation" was actively engaged in making changes and maintaining changes they had already made by working to avoid relapse. A "Maintenance" group was also found who were almost exclusively engaged in maintaining previous improvements.

Several of the resulting profile groups in each of these studies were also subgroups of individuals who were not changing or not planning to change. Some of the groups that seem to occur across studies include: 1) the "Immotive" group who deny that there are any problems and plan on maintaining the status quo; 2) the 
"Uninvolved" group who, while not ignoring the problem, is not really thinking about it either; 3) the "Reluctant/Ambivalent" group who, while seeing a problem, is reluctant to take action; and 4) the "Discouraged" group who, while recognizing a problem, feels overwhelmed and unable to make any changes.

Also of interest to the current study is another group found in an early study with psychotherapy patients (McConnaughy et al., 1983). They found what they called a "Non-Reflective Action" group. This group was taking action while at the same time under the impression that there was no problem at all. This would seem to correspond to those individuals who comply with child protective case plans, yet at the same time have no real intention of making any changes in their behavior. With a better understanding of the different subgroups of maltreating caregivers, child protective workers could more accurately discriminate those who are ready to make changes from those who are more resistant. Furthermore, an ability to look at readiness to change profiles in this population could potentially aid child protective agencies in delivering services with a more precise method of distribution.

A URICA-style stage of change measure can be used to examine whether such sub-groups exist among maltreating caregivers. The initial step is to develop and validate an instrument that can measure readiness to change in this population. The current chapter will describe how an initial instrument was designed based on the Transtheoretical Model and administered to a group maltreating caregivers (Gelles, Brown, Jones, \& Youngblood, 1997). The information presented in the current study is an analysis of the data collected using that measure in an effort to 
1) reduce the items into a cohesive, refined SOC instrument that can be used with maltreating caregivers and 2) to compare the results of the instrument to past applications of the Transtheoretical Model in order to assess the applicability of the model's stages of change construct with this population.

\section{Method}

\section{Item Generation}

A preliminary instrument was designed (Gelles et al., 1997) using the Transtheoretical Model to measure readiness to change in parents and caregivers who abuse and neglect their children (see Appendix A for the instructions and items included in the questionnaire). The process of designing and administering this instrument will be summarized here because it has not been described previously and has important implications for the subsequent instrument development process that is outlined below.

Initially, nineteen interviews were conducted with abusive and neglectful caregivers involved with the Rhode Island Department of Children, Youth, and Families (RIDCYF) in order to gather information in their own words about their experiences with change. Twenty-four interviews were also completed with RIDCYF supervisors and direct care workers in order to include their perspective on the issues of change with this population. The interviews were transcribed and examined for the experiences of maltreating caregivers that corresponded with the constructs of the Transtheoretical Model. Item generation for the preliminary instrument was based on this qualitative data. 
Decisions were made at this point in the scale development process concerning the maltreating behaviors that would be targeted with the preliminary instrument. Initially, the instrument was going to focus only on caregivers trying to change physically abusive behaviors. However, conversations with the RIDCYF staff indicated that these caregivers made up a small proportion of their caseload. In 1996, less than $30 \%$ of substantiated cases of child maltreatment in Rhode Island involved physical abuse, while over $60 \%$ were cases of neglect (USDHHS, 1998). Nationally, neglect accounts for $50 \%$ of all substantiated cases. It was therefore decided that a measure of readiness to change would be most useful to child protective services if it targeted both physically abusive and neglectful behaviors. Sexual abuse, however, was excluded from the focus of the instrument. These behaviors are substantiated at a relatively lower frequency ( $8 \%$ of all cases in Rhode Island and $12 \%$ nationally, USDHHS, 1998). There is also evidence in the literature that perpetrators of sexual abuse are different in many ways from perpetrators of physical abuse or neglect and that change for these groups is likely to be qualitatively different (Milner, 1998; Swenson \& Hanson, 1998).

Many of the abusive and neglectful caregivers that were interviewed described the importance of dealing with substance abuse problems as crucial to the changes they were making regarding their children. The RIDCYF staff echoed this impression; substance abuse was described by the direct care workers as present in $80 \%$ of the cases that they dealt with. Research also indicates that substance abuse problems occur at a high frequency among abusive and neglectful caregivers. 
Kelleher, Chaffin, Hollenberg, \& Fischer (1994) found that $40 \%$ of adults reporting physically abusive behaviors and $56 \%$ of adults reporting neglectful behaviors met criteria for drug or alcohol problems. These rates were significantly higher than in a control group of non-maltreating caregivers. Magura and Laudet (1996) found in a review of research on child maltreatment and substance abuse that rates of parental substance abuse for children involved with child protective services ranged from $13-70 \%$. Items measuring attitudes toward substance use were therefore included as part of the preliminary stages of change scale.

Items measuring attitudes toward child protective services were also included. One of the primary goals in designing the Stage of Change instrument was to be able to distinguish between those caregivers who were just complying with child protective orders and those who were truly interested in changing. The interviews with the caregivers and the RIDCYF staff suggested that "compliers" and "changers" differed from each other in their relationship with child protective services. "Compliers" were interested in "playing the system" and did not see any real problem with their behavior. They were suspicious and angry at the RIDCYF and saw the relationship as antagonistic. On the other hand, those who seemed to be making real changes described a sincere desire to find a better way of living their life and caring for their children. These "changers" were less defensive, more willing to take responsibility for their behaviors, and seemed to appreciate help from those who offered it, including the RIDCYF. 
The design of the preliminary instrument was based on the original URICA (McConnaughy et al., 1983; McConnaughy et al., 1989). The continuous nature of the URICA-style instrument permits subgroup analysis based on a stage of change profile. A decision was also made to use a continuous measure of staging rather than algorithms because of the difficulty of defining a specific target behavior for maltreating caregivers and the difficulty specifying time constraints for change on high-risk/low frequency behaviors. A greater understanding of change with this population will be important before an algorithmic measure of change can be considered. An eighteen item version of the original URICA instrument was included in the current scale in order to assess the ability of the original items to identify readiness to change with a population of abusive and neglectful caregivers. An initial pool of 165 Stage of Change items was developed based on the qualitative data and, in an effort to account for a comprehensive range of dynamics, hypothesized to be relevant for maltreating caregivers at each of five possible stages of change. These items were reduced in the interest of parsimony based on feedback from "experts" of both child maltreatment (RIDCYF staff, supervisors, and service providers) and the Transtheoretical Model. For example, some items were eliminated due to disagreement among child maltreatment "experts" about which stage was represented by a particular item. The completed preliminary Stage of Change scale included 70 items, with 11 to 17 items hypothesized to represent each of the five stages of the Transtheoretical Model. 


\section{$\underline{\text { Participants }}$}

The preliminary instrument was administered to a group of 163 participants who either currently had a case open to the RIDCYF or who had a case open within the last year. Caregivers involved with the RIDCYF were informed of the study and invited to participate through their direct care worker, through a treatment group leader, by mail, or through pamphlets that were distributed around child protective offices and other community treatment centers. The participants were informed by group leaders or through the flyer that they would be filling out an anonymous pencil-and-paper questionnaire, that the study was confidential and that they would receive $\$ 25$ for their participation. Over the course of a year, onehundred and sixty-three individuals contacted or were contacted by the researchers and agreed to participate. The survey (see Appendix A), which included the preliminary Stage of Change scale along with demographic questions and Decisional Balance and Self-Efficacy scales, was administered either in the participant's home (46 participants) or in a private office at a community agency (RIDCYF office or substance abuse treatment facility) (117 participants). The majority of participants (114 participants or $70 \%$ of the sample) were identified and contacted through their participation in a substance abuse treatment program.

Prior to administration of the questionnaire, the participants were informed of the purpose of the study and their rights to confidentiality. They were informed that the questionnaire was anonymous and were specifically told that their participation or decision not to participate would have no impact on their current 
case with the RIDCYF. Administration of the instrument took approximately 30 minutes. Seven questionnaires were discarded; four were discarded due to the participants' difficulty reading English, two were discarded because their cases were not open due to child abuse and neglect, and one was discarded due to extensive missing data.

The remaining 156 participants were primarily women ( 146 women and 10 men, mean age $=31.6$ years). Fifty-two percent of the sample identified themselves as "White", $25 \%$ as "Black or African-American", $15.4 \%$ as "Mixed Race", $8 \%$ as "Hispanic", and $4 \%$ as "American Indian or Alaskan Native" or "Asian or Pacific Islander". The participants had an average of 2.3 children and 87 (56\%) had at least one of those children in foster care placement. While $66 \%$ of the sample described incomes of less than $\$ 10,000$ per year, the majority, or $59 \%$, had graduated from high school or had received their GED. At the time of the administration of the questionnaire, 127 participants' cases were open to the RIDCYF (81\%) and 28 were closed (18\%).

\section{Procedure}

\section{Instrument Development}

Initially, a $70 \times 70$ matrix of inter-item correlations was calculated for the preliminary Stages of Change (SOC) Scale. Since no case was missing more than $10 \%$ of the data, pairwise deletion was used to deal with all missing values. Exploratory principal component analysis (PCA) using SPSS 8.0 for Windows was then performed on the correlation matrix in order to examine the component 
structure of the SOC instrument. Analyses were conducted both with no restrictions on the number of components and by forcing a five-, a four-, and a three-component model. Examination of the scree plot and theoretical considerations were used in extracting components. Varimax rotation was performed on the data to aid interpretation of the results. Decisions about the best items to retain for each of the SOC scales were made based on component loadings, item variability, Coefficient Alphas for each scale with and without particular items included, and theoretical considerations.

\section{Profile Analysis}

The summed and standardized profile scores (T-scores) from the SOC scales were then used as the basis of a cluster analysis (see Lorr, 1983) using SPSS 8.0 for Windows. Cluster analysis is an exploratory procedure and is appropriate for the beginning stages of a research area. Squared Euclidean distance was used to compare the profiles. Euclidean distance is one of the more commonly used distance measures (Everitt, 1980) and provides information on relative profile elevation, shape, and scatter. This information is more robust than that from Pearson product-moment correlations, which are only sensitive to cluster shapes (Blashfield, 1980).

Ward's method (Ward, 1963), a hierarchical agglomerative clustering technique was used to perform the cluster analysis. In Ward's method, analysis begins with $\mathrm{N}$ clusters. At each step (for a total of N-1 steps), two clusters are combined so that the smallest possible increase in the error sum of squares occurs. 
This process is continued until the data are reduced to a single cluster (Everitt, 1980). Milligan's (1981) review of Monte Carlo tests of cluster analysis cites Ward's method as giving the "best recovery of cluster structure".

Since there is no completely satisfactory way to determine the appropriate number of clusters to retain (Everitt, 1980), visual inspection of the hierarchical dendrogram (Aldenderfer \& Blashfield, 1984), and interpretability of the profiles was used including consideration of previous cluster analysis outcomes using the Transtheoretical Model's Stage of Change scale (DiClemente \& Hughes, 1990; Johnson, 1995; Levesque, 1998; Mcconnaughy et al., 1983; McConnaughy et al., 1989; Prochaska \& DiClemente, 1992; Tsoh, 1995). Based on these findings, three to fifteen cluster solutions were specified and examined.

The sample size of the study was not large enough to run a split-half analysis to confirm the resulting profiles. However, the stability of the profiles was checked informally by simultaneously plotting the individual profiles of each member of the cluster groups. Profiles that are very similar with little deviation suggest some relative stability in the cluster solution. Further information on the cluster groups was examined by comparing the groups on demographic variables using Analysis of Variance (ANOVA) and Chi-square tests. Stage of Change cluster membership should theoretically be independent of demographic variables. 
Results

\section{Instrument Development}

Principal Components extraction with Varimax rotation was conducted to examine the component structure of the preliminary 70 -item SOC instrument. In initial solutions, five components were extracted. However, upon examining these components, two did not appear to be stage-related. Instead, these were composed of items that were related to 1) attitudes towards substance abuse and 2) trust in and a desire to work with the RIDCYF. These items were removed from the SOC scale and later organized to form separate scales (see Chapter 3).

The structure of the remaining 51 items was again examined using Principal Component Analysis and three components were extracted. A three-component structure was unexpected and post-hoc analyses were run forcing the expected four or five component model. These were conducted with all 51 variables and also using selected variables that were theoretically expected to load on a four or five component model. However, none of these analyses produced an acceptable component structure; the four and five component solutions were poorly defined and were difficult to interpret. An effort to examine the 18 original URICA items that were included also did not produce a coherent component structure. A threecomponent model, with Precontemplation, Contemplation, and Action as the identified constructs, was therefore accepted as best describing the data.

The items in the three components were further reduced based on eliminating items that were complex and items that did not load well on any of the 
components and by keeping items that were theoretically consistent, had greater variability, and contributed to the over-all reliability of the scale. An effort was made to balance the goals of parsimony, comprehensiveness, brevity, and adequate internal reliability. Table 2.1 presents the items that were retained for the three scales with corresponding component loadings. All items had a component loading of .5 or greater after rotation. Loadings for each item on other components were all under .4 , with 14 of the 18 items loading under .25 .

In general, items loading on each of the three scales were theoretically created to do so. However, three items that were designed to load on a Maintenance scale, instead loaded on either the Action scale or the Contemplation scale. Two items indicating active efforts to avoid relapse loaded on "Action" ("I'm working to prevent myself from having a relapse." and "I know what my triggers are and I actively avoid them.") and one item expressing worries about relapse loaded on "Contemplation" ("I sometimes worry that I will fall back on old behaviors when DCYF is out of my life.").

Scale scores were calculated for each stage by summing the unweighted scores of the six items representing the scale and converting the summed scores to T-scores (mean $=50, \mathrm{SD}=10)$. Inter-scale correlations, Cronbach's Coefficient Alphas, means, and standard deviations are presented for each scale in Table 2.2. The Contemplation and the Action scales have a minimal, positive correlation with each other $(r=.32)$ and both of those scales have a small negative correlation with 
the Precontemplation scale $(r=-.34$ and -.39 respectively). Coefficient Alphas for the scales ranged from .84 to .75 , indicating good to moderate internal reliability.

\section{Profile Analysis}

The cluster analysis yielded a 6-cluster solution. This solution was based on an $\mathrm{N}$ of 151 participants. Five participants had been removed from these analyses due to more than $50 \%$ missing data on one of the three scales. Although these clusters are based on cross-sectional data, it is hypothesized that they represent a roughly linear progression from least to most advanced on a continuum of readiness to change. The cluster groups will be described below in that order and will be compared to the clusters identified in other applications of a URICAstyle Stage of Change instrument (Brown, 1998; Brown et al., 1999; DiClemente \& Hughes, 1990; Levesque, 1998; McConnaughy et al., 1983; McConnaughy et al., 1989). The profiles of standardized mean scores on Precontemplation, Contemplation, and Action for each of the clusters are presented in Figures 2.12.6 .

1) Resistant Cluster. The 13 subjects who were included in this cluster scored well above average on Precontemplation (1 1/2 standard deviations above the mean) and well below average on Contemplation and Action (1 1/2-2 standard deviations below the mean). The shape of the profile is linear and decreasing with a large amount of scatter. This cluster is most similar to the Precontemplation cluster found by McConnaughy et al. (1989) and the Resistant cluster found by Levesque (1998) which both had a similar shape. Subjects in this cluster do not 
feel they have a problem, are not interested in working with child protective services and show no indication that they are involved in making or planning to make changes.

2) Non-Reflective Action Cluster. The 8 subjects in this cluster were well above average on Precontemplation ( 2 standard deviations above the mean), below average on Contemplation ( 1 standard deviation below the mean), and a little above average on Action (1/2 standard deviation above the mean). The shape of this profile is most like a V-shaped pattern with a large amount of scatter. A NonReflective Action Cluster was described in both McConnaughy et al. (1983) and Levesque (1998). Subjects in this group are denying that they have a problem, have no interest in working with the RIDCYF, and at the same time are claiming to be making active changes in their behavior.

3) Discouraged Cluster. The 11 subjects in this cluster are characterized by a profile of approximately average scores on Precontemplation and Contemplation (within 1/2 standard deviation of the mean) but well-below average scores on Action ( $21 / 2$ standard deviations below the mean). The shape is flat with a large drop at the end and has moderate scatter. This profile is slightly unique among profiles that have been observed in other applications of a URICA-style Stage of Change scale. Brown et al. (1999) found a similar cluster group they labeled "Reluctance" but whose scores on Contemplation were a standard deviation lower. DiClemente \& Hughes (1990) found a cluster group in their study of alcohol treatment patients they called "Univolved" who were also slightly lower on 
Contemplation. This group was labeled "Discouraged" because they show ambivalence about whether they need help or have a problem but feel strongly that they are doing nothing to actively make changes.

4) Ambivalent Cluster. This cluster represents the largest number of subjects. Fifty-four subjects were included in the Ambivalent Cluster and their profiles indicated that they scored around average on Precontemplation and Action and slightly above average on Contemplation. The shape of the profile is relatively flat with a slight rise in the middle and minimal scatter. Several other studies have also found a cluster with a similarly flat shape (Brown et al., 1999; DiClemente \& Hughes, 1990; Levesque, 1998; McCounnaghy et al., 1989). Some have labeled this group "Uninvolved" and others, "Ambivalent". The latter term seems more appropriate for the current group who appear to be struggling with at least a moderate endorsement of both the difficulty working with DCYF and also of the belief that they need to make some changes.

5) Participation Cluster. This cluster of 26 participants scored below average on Precontemplation (one standard deviation below the mean) and above average (over $1 / 2$ standard deviation above the mean) on Contemplation and Action. This profile shape rises sharply at first and then levels off and shows moderate amount of scatter. Similar clusters were found in many other studies (Brown, 1998; DiClemente \& Hughes, 1990; Levesque, 1998; McConnaughy et al., 1983; McConnaughy et al., 1989). Some of these groups were labeled "Participation" and others "Decision-Making". "Participation" was chosen to 
describe the current group of maltreating caregivers whose profile suggests active efforts to change while also a large amount of worry and concern about trying to make the changes.

6) Action Cluster. Thirty-one subjects were grouped into this cluster which was defined by slightly low scores on Precontemplation (almost $1 / 2$ standard deviation below the mean), lower scores on Contemplation (almost 1 standard deviation below the mean) and above average scores on Action (almost 1/2 standard deviation above the mean). This profile is similar to that of the NonReflective Action Cluster but the Precontemplation scores are much lower. This profile's shape is also V-shaped, but the $\mathrm{V}$ is flatter and higher towards the end. Scatter is moderate. This cluster profile was also relatively unique when compared to other cluster profiles found in similar studies. The only study that found a similar cluster profile was Brown (1998). Her "Action" group had similar scores on the equivalent scales. The subjects in this profile seem to be strongly endorsing their active efforts to change while not feeling concerned about making the changes and not indicating a difficulty in working with child protective services. A label of "Action" seems appropriate and these individuals were placed at the end of the continuum of change.

Due to the sample size, checking the stability of the profiles on half of the sample was not possible. However, since the number of participants in several of the cluster groups was relatively small, it was important to examine, at least informally, how well the mean cluster profiles accounted for individual score 
profiles. Where individual profiles hang together fairly well, greater confidence can be placed on the reliability of the mean cluster profile. Figures 2.7 through 2.12 show the individual scores plotted against each other for each of the six clusters. The first three clusters, the "Resistant, "Non-Reflective Action", and "Discouraged" clusters, all of which had less than 15 subjects per cluster, were the most similar and showed little deviation from the pattern described by the mean scores. The subjects in the "Ambivalent" cluster were also well represented by the mean cluster profile for that group. The "Participation" cluster showed relatively more spread on the Contemplation scores and the "Action" cluster showed a relatively greater degree of individual differences on Precontemplation scores.

\section{Demographic Data Across Cluster Groups}

In order to gather more information on the different SOC cluster groups, comparisons between these groups were made based on demographic data. Analysis of Variance (ANOVA) and Chi square tests were performed on the data in order to determine if demographic differences existed among the cluster groups. No significant differences were found among groups with regard to age, sex, race, education, employment status, income, status of their case with the RIDCYF (closed or open), or relationship status. Additionally, significant differences among groups were not found in regard to child-related variables including number of children, age of children, or having a child in foster care.

The only area in which significant differences were found among SOC cluster groups was with the variable noting the source of the subject referral. 
Twenty referral sources were broken down into those that were substance abuse treatment related (i.e., residential or outpatient substance abuse treatment) and those that were not (e.g., response to flyer or RIDCYF referral). In the total sample, $70 \%$ of subjects were referred by a substance abuse agency and $30 \%$ were not. Chi square tests revealed differences across the clusters in referral source $\left(\chi^{2}(5\right.$, $\mathrm{N}=151)=40.14, \mathrm{p}<.001)$. Table 2.3 presents the counts, expected counts, and percentages for each of the cluster groups on referral source. Caregivers in the Participation cluster group were more likely than expected to have been referred to the study from a substance abuse treatment source while those in the Resistant and the Non-Reflective Action groups were less likely to have been referred from such a source.

\section{Discussion}

The results of the current study show preliminary support for the use of the Transtheoretical Model's Stages of Change (SOC) construct with abusive and neglectful caregivers. An SOC instrument for use with this population was refined and analysis of the instrument's structure supported three of four stages that have been found in previous applications of the model using the URICA format: Precontemplation, Contemplation, and Action. Six cluster groups resulted from analysis of the subjects' scores on the three stages. These groups were generally comparable to staging clusters that have been found in previous research using a continuous measure of stage of change. The cluster groupings presented interesting hypotheses about subgroups of caregivers involved with child protective services. 
The first step in applying the concept of readiness to change to maltreating caregivers was the refinement of an SOC instrument. The results of the current study show that an SOC instrument administered to a sample of 156 caregivers involved with the RIDCYF supported three 6-item scales. The scales measure the constructs of Precontemplation, Contemplation, and Action. Endorsement of the Precontemplation items appear to indicate caregivers' reluctance to work with child protective services and a feeling that they have no serious problems with their parenting skills. The Contemplation items indicate that caregivers are interested in making changes in their parenting behaviors and have fears about making these changes. The Action items, when endorsed, indicate that caregivers feel that they are currently engaged in active efforts to make changes. The three identified scales were psychometrically sound, although at this stage, psychometric data is preliminary and will need to be replicated with additional samples.

It is important to comment on the finding of a three-factor SOC model. In the majority of previous applications of the Transtheoretical Model using a continuous stage of change measure, the research has resulted in a model with four stages, Precontemplation, Contemplation, Action, and Maintenance (DiClemente \& Hughes, 1990; Levesque, 1998; McConnaughy et al., 1983; McConnaughy et al., 1989). A Maintenance component was not elicited with the current group of maltreating caregivers.

During the instrument development stage, Maintenance items had been designed to identify caregivers' concerns about falling back into previous abusive 
and neglectful behaviors and their efforts to reduce the chance of a relapse occurring. Relapse concern was distinguished as the primary consideration for those in Maintenance by the initial developers of the URICA instrument (McConnaughy et al, 1983; McConnaughy et al., 1989). However, with the maltreating caregivers, items indicating relapse concerns loaded with the Contemplation items that described an interest in making changes. Brown et al. (1999) also found relapse concerns loading with traditional Contemplation items in their application of the Transtheoretical Model with incarcerated women whose recidivism rate is roughly $50 \%$. They decided upon a three-factor model as best accounting for the data with that population.

Relapse, when the targeted behavior is child abuse or neglect, is high-risk and results in serious consequences. Furthermore, as research has documented, relapse is common for those trying to change their maltreating behaviors. Many of those in Contemplation are most likely individuals who have relapsed from Action and are anxious to both 1) make further changes and 2) avoid future relapse. Maintenance, while theoretically occurring with maltreating caregivers, appears not to be uniquely defined by concerns about relapse. Future research will have to identify differences between those in Action or Contemplation and those in Maintenance, including perhaps a time component (e.g., time passed since last abusive or neglectful incident) and/or emotional/cognitive components. Future studies will also be needed to support the stability and the validity of the three staging components that were found in the current study. 
In examining the differences among participant scores on the SOC scales, six cluster groups emerged hypothetically representing subgroups of maltreating caregivers with different attitudes toward change. These were labeled 1) Resistant, 2) Non-Reflective Action, 3) Discouraged, 4) Ambivalent, 5) Participation, and 6) Action. Almost all were clusters that had been identified in previous applications of the Transtheoretical Model. Only the Discouraged and Action clusters showed profiles that were relatively unique compared with previous research. The Resistant, Non-Reflective Action, and Discouraged clusters appear to be possible subgroups of Precontemplators due to their high scores on this scale or notably low scores on the Action scale. The Ambivalent group could be seen as comparable to a Contemplation stage and the Participation and Action groups could be considered earlier and later forms of Action given their relatively moderate to low scores on Precontemplation and high scores on Action.

First, it is important to note that due to the smaller numbers of individuals in several of the cluster groups, notably the Resistant, Non-Reflective Action, and Discouraged groups, hypotheses and descriptions of these groups must be extremely preliminary. Support for the stability of these profiles was seen in the wide spread of mean scores on the different stages and the similarity of the individual scores within each profile group. It is also encouraging that the clusters are 1) interpretable and 2) similar to cluster findings in previous research using the Transtheoretical Model. However, replications of the profiles on additional samples will be necessary to verify their reliability. 
Second, the hypothesis that the cluster groups are analogous to the Transtheoretical Model's stages of change will need to be further tested. The model describes the stages of change as a progression of least to most likely to change and research using a URICA-style stage of change measure has suggested that staging cluster groups may be hypothesized to represent a similar progression. For example, a caregiver working with a child protective service agency may move from one of the earlier three cluster groups through Ambivalence, and on to Participation and Action. However, longitudinal data will be needed to test the hypothesis that staging clusters are related to readiness to change and roughly represent earlier and later stages of the change continuum.

Some preliminary support for cluster groups representing stages on a change continuum can be seen in the uneven distribution of subjects in different cluster groups who were drawn from a substance abuse treatment program. A large number of maltreating caregivers participating in these programs were included partly because they were easy to reach and because these individuals showed an interest in participating in research on the process of change. A greater percentage of these individuals showed up in the cluster groups hypothesized to be "later" stages of change. This makes sense given their eagerness to participate in the study and their involvement in intensive treatment programs and suggest that the profiles capture their active interest in making changes.

It may also be that one or more of the subgroups identified in the current study represent personality characteristics in addition to readiness to change. 
Levesque (1998) found that some of the staging groups of battering men differed on measures of substance use, social desirability, and strategies used to change their violent behavior. A greater understanding of differences between maltreating caregiver change profiles will have to be explored in subsequent studies. For example, staging groups could be compared on a number of different variables that would be theoretically related to readiness to change. Some of those variables will be examined in the following chapter including comparisons on a Decisional Balance scale, a Self-Efficacy scale, and attitudes toward substance abuse and the RIDCYF. But additionally, comparisons on actual substance use, social desirability, processes of change, and case related variables, such as details of the charges against the caregiver and details of the treatment history, would be useful to better understand replicated cluster groups.

If the hypotheses resulting from the current analyses are supported by subsequent reliability and validity studies, the data from the refined SOC instrument support interesting implications for service provision to maltreating caregivers. Stage of change cluster membership may offer a useful way to define typologies of this large, heterogeneous population. Different score profiles may be related to different levels of amenability to treatment and a differential ability to learn from particular interventions. Furthermore, unlike previous efforts to define typologies of maltreating caregivers, individuals can theoretically move in and out of staging subgroups. In many categorization methods, inclusion is based on previous behavior and therefore subgroup membership is static. A grouping 
method based on readiness to change, however, assumes the presence of, and would provide a method to identify, movement to more "advanced" staging subgroups. Once the reliability and validity of the SOC measure has been established, implications of the measure for longitudinal change and treatment response can be further studied. 


\section{References}

Aldenderfer, M. S., \& Blashfield, R. K. (1984). Cluster analysis. Beverly Hills, CA: Sage.

Bandura, A. (1977). Self-efficacy: Toward a unifying theory of behavior change. Psychological Review, 84, 191-215.

Barth, R. P. (1998). Abusive and neglecting parents and the care of their children. In M. A. S Mason, A. Skolnick, \& S. D. Sugarman (Eds.), All our families: New policies for a new century (pp. 217-235). New York: Oxford University Press.

Blashfield, R. K. (1980). Propositions regarding the use of cluster analysis in clinical research. Journal of Consulting and Clinical Psychology, 48(4), 456-459.

Bowdry, C. (1990). Toward a treatment-relevant typology of child abuse families. Child Welfare, 69(4), 333-340.

Brown, J. (1997). Working toward freedom from violence: The process of change in battered women. Violence Against Women, 3(1), 5-26.

Brown, J. (1998, July). The process of change in abused women scale (PROCAWS): Stage of change, pros and cons, and self-efficacy as measurable outcomes. Paper presented at the Program Evaluation and Family Violence Research: An International conference, Durham, NH.

Brown, J., Varna Garis, A., \& Mitchell, K. (1999, March). Beyond recidivism: Assessing change in incarcerated women--challenges and rewards. Paper presented at the meeting of the Academy of Criminal Justice Sciences, Orlando, FL.

Cohn, A. H., \& Daro, D. (1987). Is treatment too late? What ten years of evaluative research tell us. Child Abuse \& Neglect, 11 , 433-442. 
Crittenden, P. M. (1996). Research on maltreating families: Implications for intervention. In J. Briere, L. Berliner, J. A. Bulkley, C. Jenny, \& T. Reid (Eds.), The APSAC handbook on child maltreatment (pp. 158-174). Thousand Oaks, CA: Sage.

Daniels, J. W., \& Murphy, C. M. (1997). Stages and processes of change in batterers' treatment. Cognitive and Behavioral Practice, 4, 123-145.

DePanfilis, D., \& Zuravin, S. J. (1998). Rates, patterns, and frequency of child maltreatment recurrences among families known to CPS. Child Maltreatment, 3(1), 27-42.

DiClemente, C. C., \& Hughes, S. O. (1990). Stages of change profiles in outpatient alcoholism treatment. Journal of Substance Abuse, 2 , 217-235.

DiClemente, C. C., \& Prochaska, J. O. (1982). Self-change and therapy change of smoking behavior: A comparison of processes of change in cessation and maintenance. Addictive Behaviors, $\underline{7}, 133-142$.

DiClemente, C. C., Prochaska, J. O., Fairhurst, S., Velicer, W. F., Velasquez, M. M., \& Rossi, J. S. (1991). The process of smoking cessation: An analysis of precontemplation, contemplation and preparation stages of change. Journal of Consulting and Clinical Psychology, 59, 295-304.

Everitt, B. S. (1980). Cluster analysis (2nd ed.). London: Heineman Educational Books Ltd.

Fiore-Lerner, C. (1990). The Transtheoretical Model of change: Self-change in adolescent delinquent behaviors. Unpublished doctoral dissertation, University of Rhode Island, Kingston.

Gelles, R. J. (1996). The book of David: How preserving families can cost children's lives. New York: BasicBooks. 
Gelles, R. J., Brown, J., Jones, L. M., \& Youngblood, J. (1997, June).

Compliance or change: Issues in risk assessment for abusive and neglectful parents using the Transtheoretical Model of Change. Paper presented at the meeting of the $5^{\text {th }}$ International Family Violence Research Conference, Durham, NH.

Grimley, D. M., Prochaska, J. O., Velicer, W. F., \& Prochaska, G. E. (1995). Contraceptive and condom use adoption and maintenance: A stage paradigm approach. Health Education Quarterly, 22(1), 20-35.

Janis, I. L., \& Mann, L. (1977). Decision making: A psychological analysis of conflict, choice and commitment. New York: Free Press.

Johnson, S. S. (1995). Profiles and predictors of compliance in oral contraceptive users. Unpublished master's thesis, University of Rhode Island.

Jones, D. P. H. (1987). The untreatable family. Child Abuse and Neglect, 11 , 409-420.

Kelleher, K., Chaffin, M., Hollenberg, J, \& Fischer, E. (1994). Alcohol and drug disorders among physically abusive and neglectful parents in a communitybased sample. American Journal of Public Health, 84(10), 1586-1590.

Kinney, J., Madsen, B., Fleming, T., \& Haapala, D. (1977). Homebuilders:

Keeping families together. Journal of Consulting and Clinical Psychology, 45(4), 671-672.

Kolko, D. J. (1996). Child physical abuse. In J. Briere, L. Berliner, J. A. Bulkley, C. Jenny, \& T. Reid (Eds.), The APSAC handbook on child maltreatment (pp. 21-50). Thousand Oaks, CA: Sage.

Levesque, D. (1998). Violence desistance among battering men: Existing interventions and the application of the Transtheoretical Model of Change. Unpublished doctoral dissertation, University of Rhode Island, Kingston, Rhode Island. 
Lorr, M. (1983). Cluster analysis for social scientists. San Francisco, CA: Jossey-Bass Publishers.

Lung, C. T. \& Daro, D. (1996). Current trends in child abuse reporting and fatalities: The results of the 1995 annual fifty state survey. Chicago, IL: NCPCA.

Lutzker, J. R., \& Rice, J. M. (1987). Using recidivism data to evaluate Project 12Ways: An ecobehavioral approach to the treatment and prevention of child abuse and neglect. Journal of Family Violence, 2(4), 283-290.

Magura, S., \& Laudet, A. B. Parental substance abuse and child maltreatment: Review and implications for intervention. Children and Youth Services Review, 18(3), 193-220.

Marcus, B. H., Rossi, J. S., Selby, V. C., Niaura, R. S., \& Abrams, D. B. (1992). The stages and processes of exercise adoption and maintenance in a worksite sample. Health Psychology, 11, 257-261.

McConnaughy, E. A., DiClemente, C. C., Prochaska, J. O. \& Velicer, W. F. (1989). Stages of change in psychotherapy: A follow-up report.

Psychotherapy, 4 , 494-503.

McConnaughy, E. A., Prochaska, J. O., and Velicer, W. F. (1983). Stages of change in psychotherapy: Measurement and sample profiles. Psychotherapy, $\underline{3}, 368-375$.

Milligan, G. W. (1981). A review of Monte Carlo tests of cluster analysis. Multivariate Behavioral Research, 16, 379-407.

Milner, J. S. (1998). Individual and family characteristics associated with intrafamilial child physical and sexual abuse. In P. K. Trickett and C. J. Schellenbach (Eds.), Violence against children in the family and the community (pp. 141-170). Washington D. C.: American Psychological Association. 
Murphy, C. M., \& Baxter, V. A. (1997). Motivating batterers to change in the treatment context. Journal of Interpersonal Violence, 12(4), 607-619.

National Research Council. (1993). Understanding child abuse and neglect. Washington, D. C.: National Academy Press.

National Research Council. (1998). Violence in families: Assessing prevention and treatment programs. Washington, D. C.: National Academy Press.

Oates, R. K. \& Bross, D. C. (1995). What have we learned about treating child physical abuse? A literature review of the last decade. Child Abuse \& Neglect, 19(4), 463-473.

O'Connell, D., \& Velicer, W. F. (1988). A decisional balance measure and the stages of change model for weight loss. The International Journal of the Addictions, $\underline{23}, 729-750$.

Prochaska, J. O., \& DiClemente, C. C. (1982). Toward a more integrative model of change. Psychotherapy: Theory, Research, and Practice, 19, 276-288.

Prochaska, J. O., \& DiClemente, C. C. (1983a). Stages and processes of selfchange of smoking: Toward an integrative model of change. Joumal of Consulting and Clinical Psychology, 51(3), 390-395.

Prochaska, J. O., \& DiClemente, C. C. (1983b). Transtheoretical therapy: Toward a more integrative model of change. Psychotherapy: Theory, Research. and Practice, 20, 161-173.

Prochaska, J. O., \& DiClemente, C. C. (1984). The Transtheoretical approach: Crossing traditional boundaries of therapy. Howewood, IL: Dow JonesIrwin.

Prochaska, J. O., \& DiClemente, C. C. (1986). The Transtheoretical approach. In J. Norcross (Ed.), Handbook of eclectic psychotherapy. New York: Brunner/Mazel. 
Prochaska, J. O., \& DiClemente, C. C. (1992). Stages of change in the modification of problem behaviors. In M. Hersen, R.M. Eisler \& P.M. Miller (Eds.), Progress on Behavior Modification. Sycamore, IL: Sycamore Press.

Prochaska, J. O., DiClemente, C. C., \& Norcross, J. C. (1992). In search of how people change: Applications to addictive behaviors. American Psychologist, 47(9), 1102-1114.

Prochaska, J. O., DiClemente, C. C, Velicer, W. F., Ginpil, S. E., \& Norcross, J. C. (1985). Predicting change in smoking status for self-changers. Addictive Behaviors, 10 , 395-406.

Prochaska, J. O., \& Velicer, W. F. (1997). The Transtheoretical Model of health behavior. American Journal of Health Promotion, 12, 38-48.

Prochaska, J. O., Velicer, W. F., Guadagnoli, E., Rossi, J. S., \& DiClemente, C. C. (1991). Patterns of change: Dynamic typology applied to smoking cessation. Multivariate Behavioral Research, 26, 83-107.

Prochaska, J.O., Velicer, W.F., Rossi, J.S., Goldstein, M., Marcus, B.H., Rakowski, W., Fiore, C., Harlow, L., Redding, C., Rosenbloom, D., \& Rossi, S.R. (1994). Stages of change and decisional balance for twelve problem behaviors. Health Psychology, $\underline{13}, 39-46$.

Rossi, J. S., Blais, L. M., Redding, C. A., \& Weinstock, M. A. (1995). Preventing skin cancer through behavior change: Implications for interventions. Dermatoepidemiology, 13(3), 613-622.

Schellenbach, C. J. (1998). Child maltreatment: A critical review of research on treatment for physically abusive parents. In P. K. Trickett and C. J. Schellenbach (Eds.), Violence Against Children in the Family and the Community (pp. 251-268). Washington D.C: American Psychological Association. 
Smokowski, P. R., \& Wodarski, J. S. (1996). The effectiveness of child welfare services for poor, neglected children: A review of the empirical evidence. Child Welfare Services, 6(4), 504-523.

Swenson, C. C., \& Hanson, R. F. (1998). Sexual abuse of children: Assessment, research, and treatment. In J. R. Lutzker, (Ed.), Handbook of child abuse research and treatment (pp. 475-499). New York: Plenum Press.

Tsoh, J. Y. (1995). Stages of change, dropouts, and outcome in substance abuse treatment. Unpublished doctoral dissertation, University of Rhode Island.

U.S. Department of Health and Human Services, Children's Bureau. (1990). Child abuse and neglect: Critical first steps in response to a national emergency. Washington DC: Government Printing Office.

U.S. Department of Health and Human Services, Children's Bureau. (1994). National study of protective, preventive, and reunification services delivered to children and their families. Washington DC: U.S. Government Printing Office.

U.S. Department of Health and Human Services, Children's Bureau. (1998). Child maltreatment 1996: Reports from the states to the national child abuse and neglect data system. Washington DC: Government Printing Office.

Velicer, W. F., DiClemente, C. C., Prochaska, J. O., \& Brandenburg, N. (1985). A decisional balance measure for predicting smoking cessation. Journal of Personality and Social Psychology, 48, 1279-1289.

Wang, C. T., \& Daro, D. (1998). Current trends in child abuse reporting and fatalities: The result of the 1997 annual fifty state survey. Chicago, IL: National Committee to Prevent Child Abuse.

Ward, J. H. (1963). Hierarchical grouping to optimize an objective function. Journal of the American Statistical Association, 58, 236-244. 
Willet, J. B., Ayoub, C. C., \& Robinson, D. (1991). Using growth modeling to examine systematic differences in growth: An example of change in the functioning of families at risk of maladaptive parenting, child abuse, or neglect. Journal of Consulting and Clinical Psychology, 59, 38-47.

Wolfe, D. A. (1987). Child abuse: Implications for Child Development and Psychopathology. Newbury Park, CA: Sage.

Wolfe, D. A., \& Wekerle, C. (1993). Treatment strategies for child physical abuse and neglect: A critical progress report. Clinical Psychology Review, 13 , 473-500. 

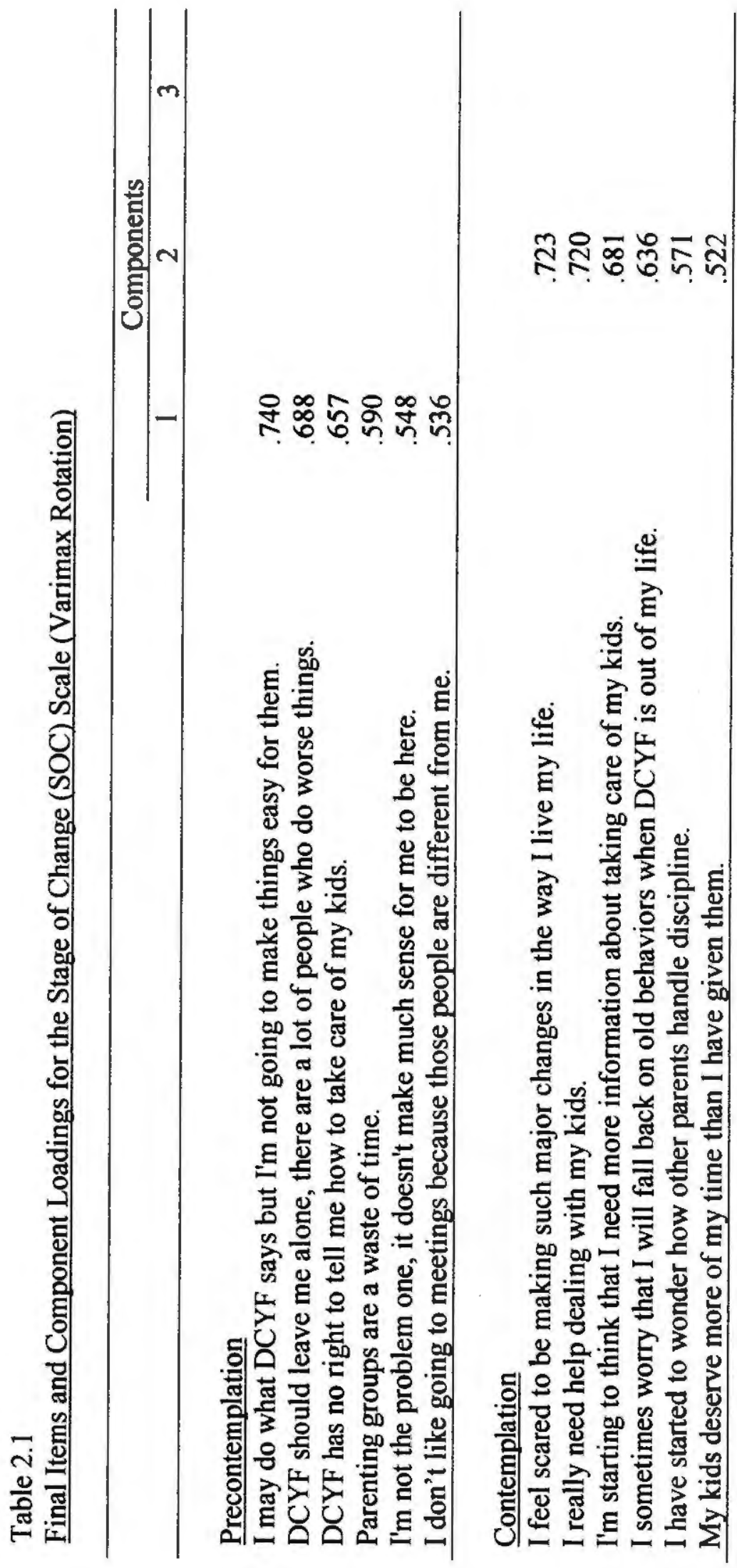

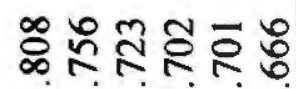

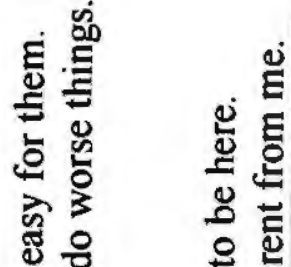

홍

$\stackrel{\Xi}{\Xi} \stackrel{\mathscr{2}}{\Xi}$

¿

$\geqq \quad \stackrel{0}{\Xi}$



웜

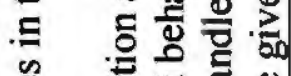

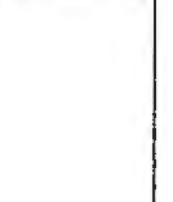




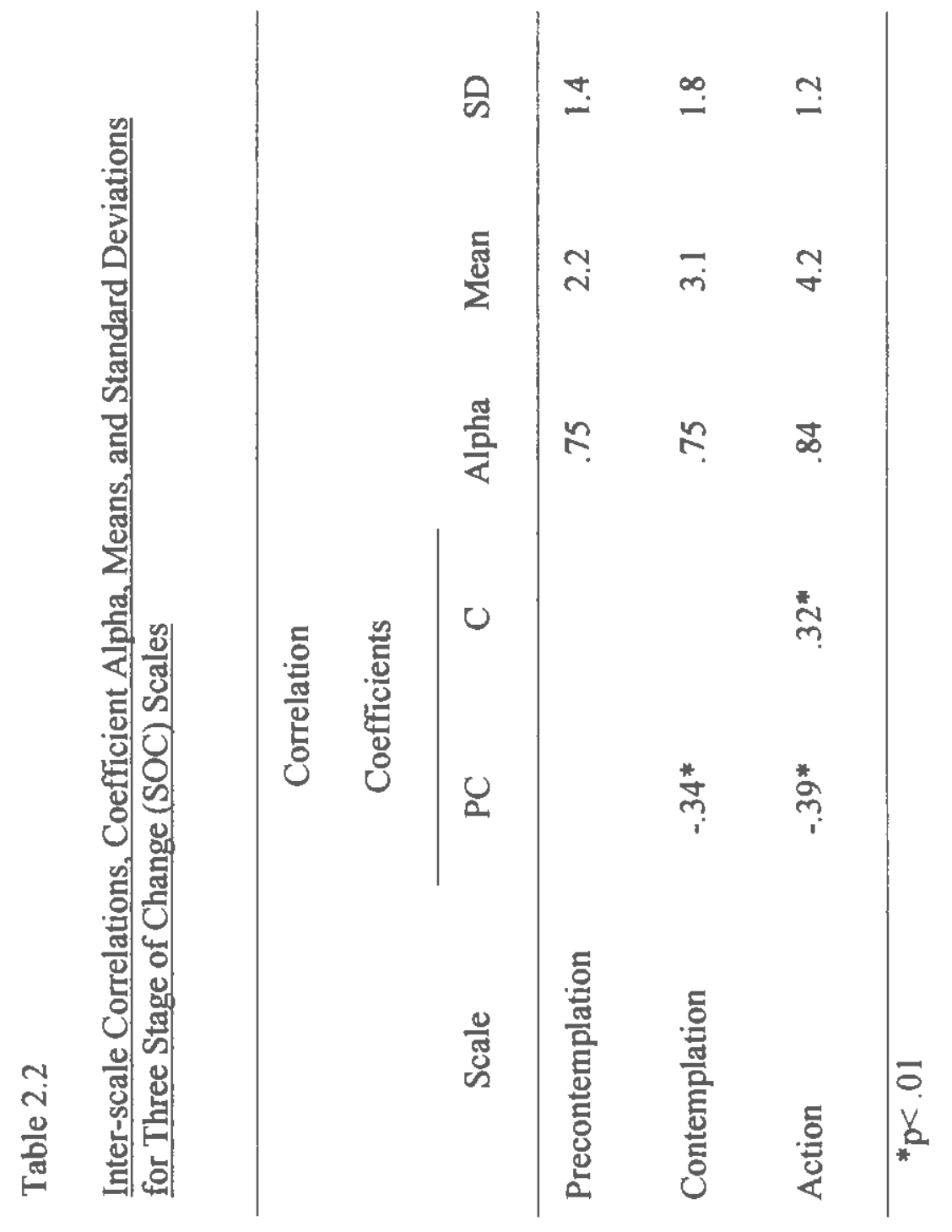




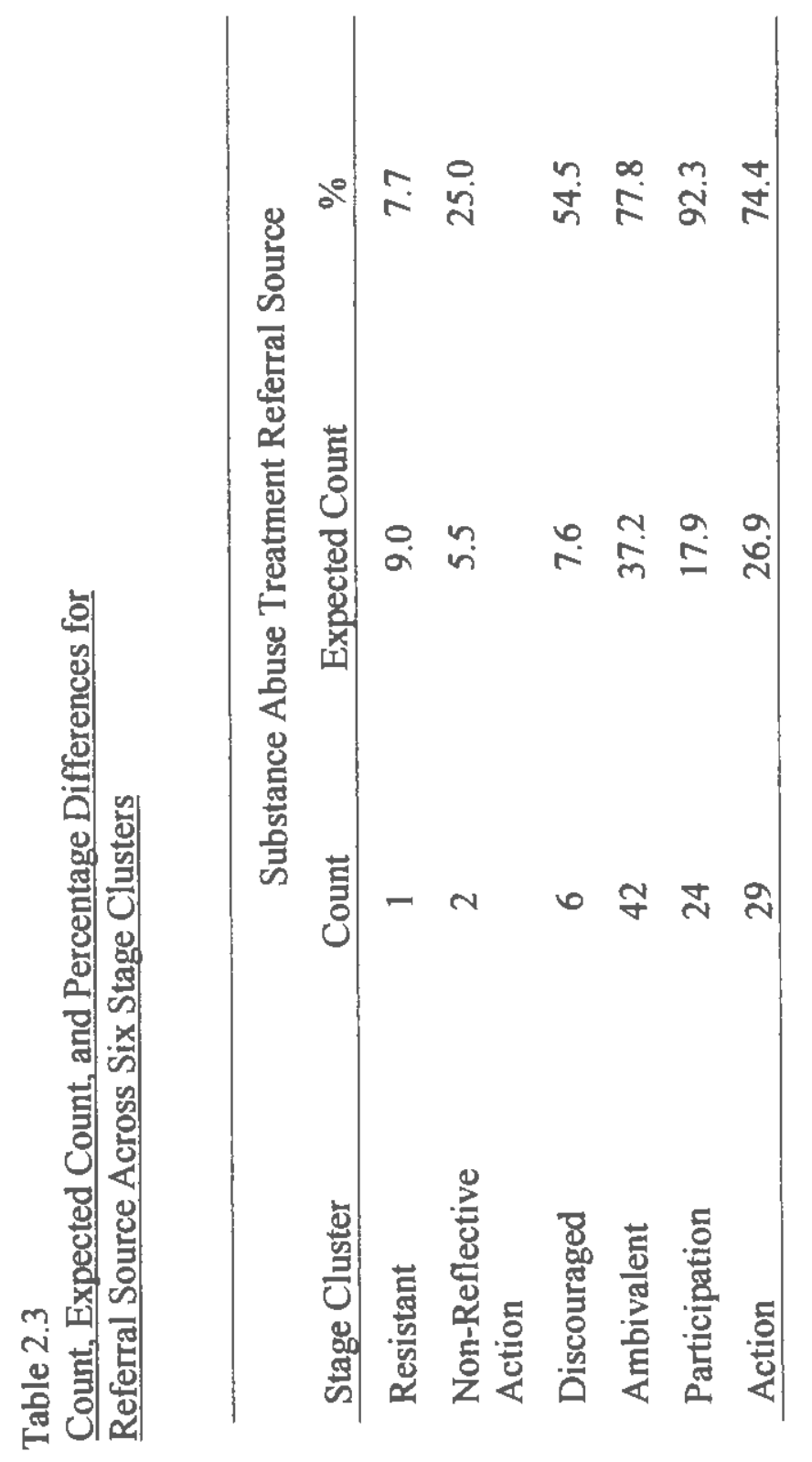




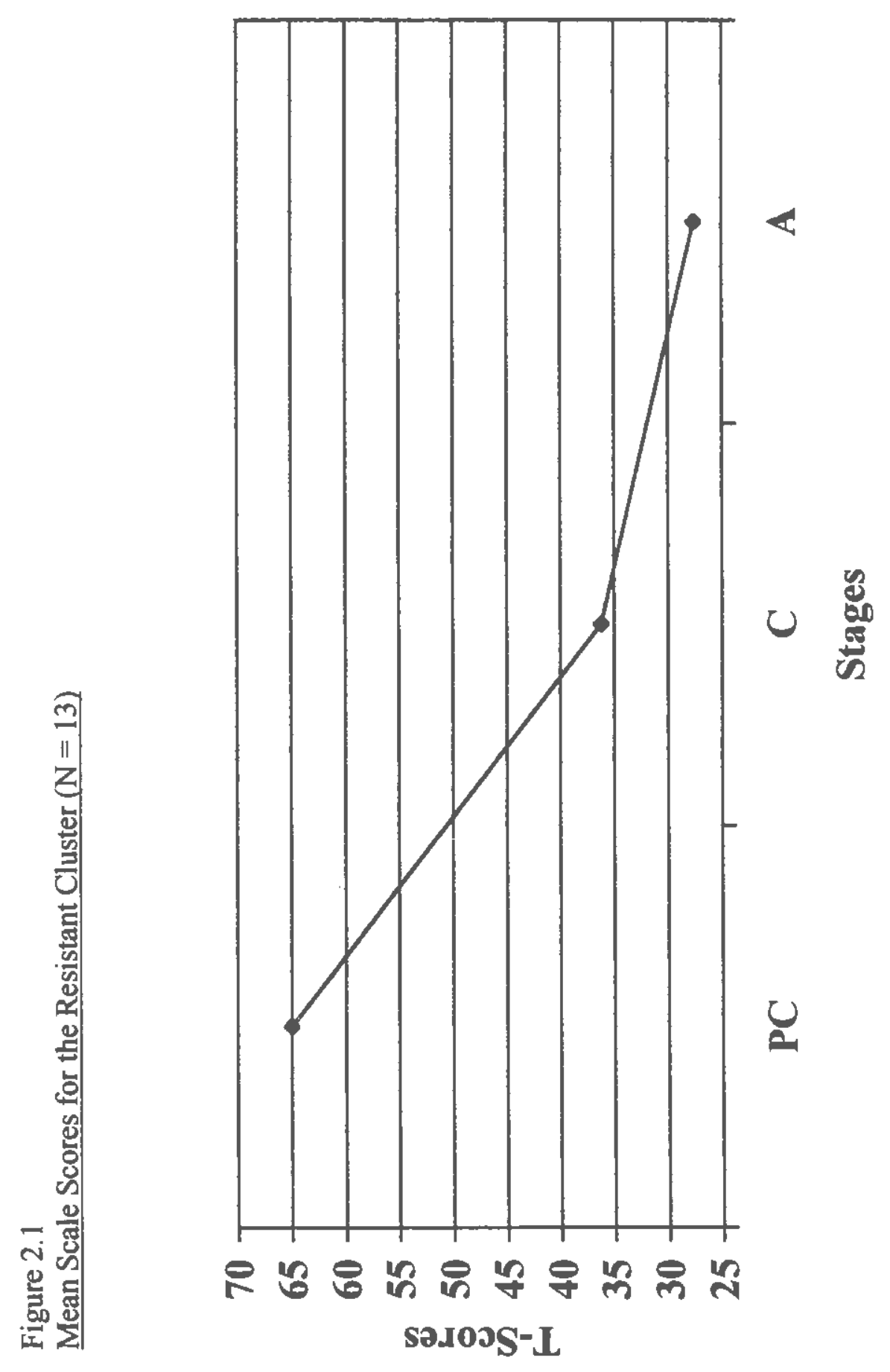




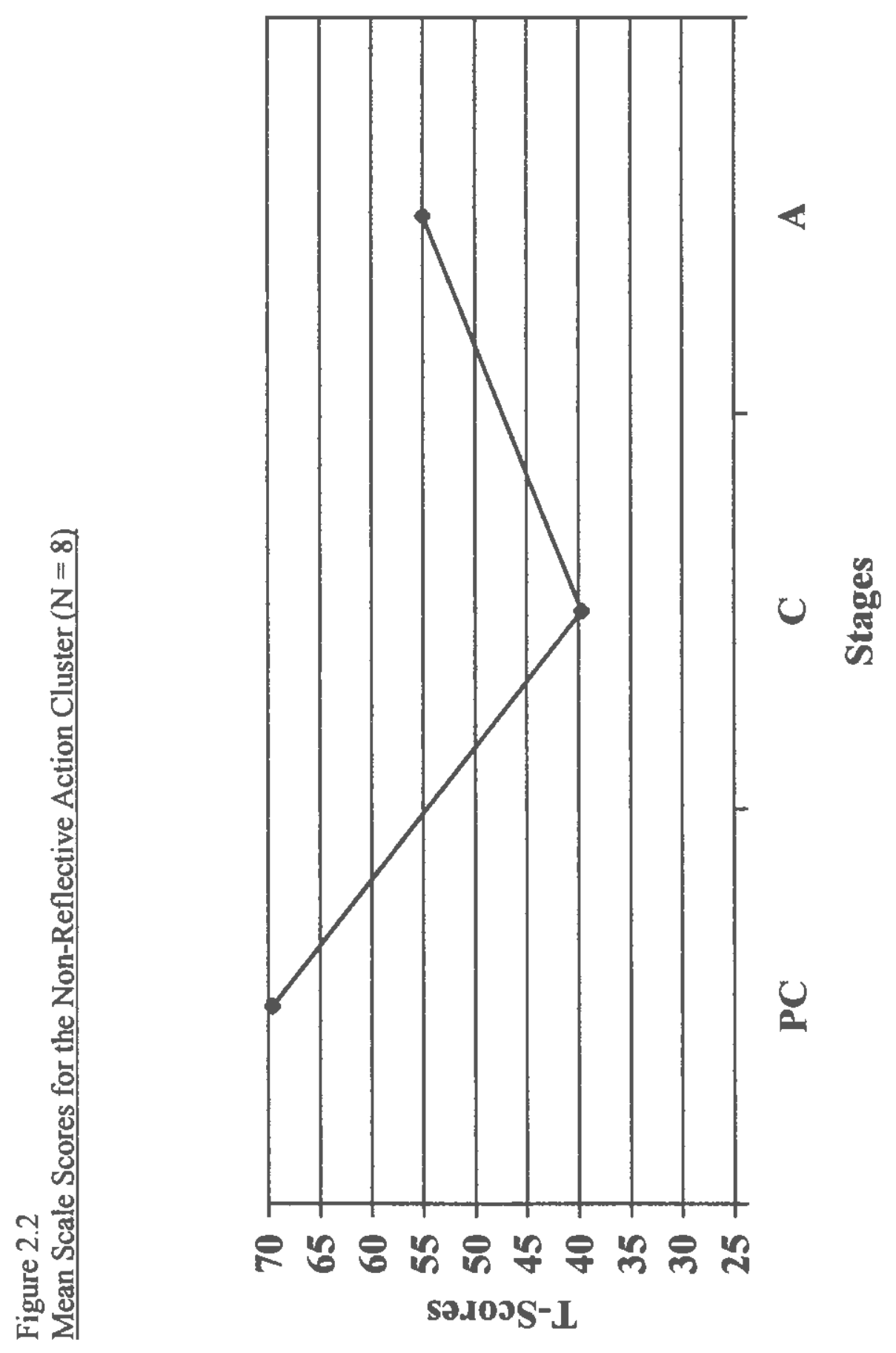




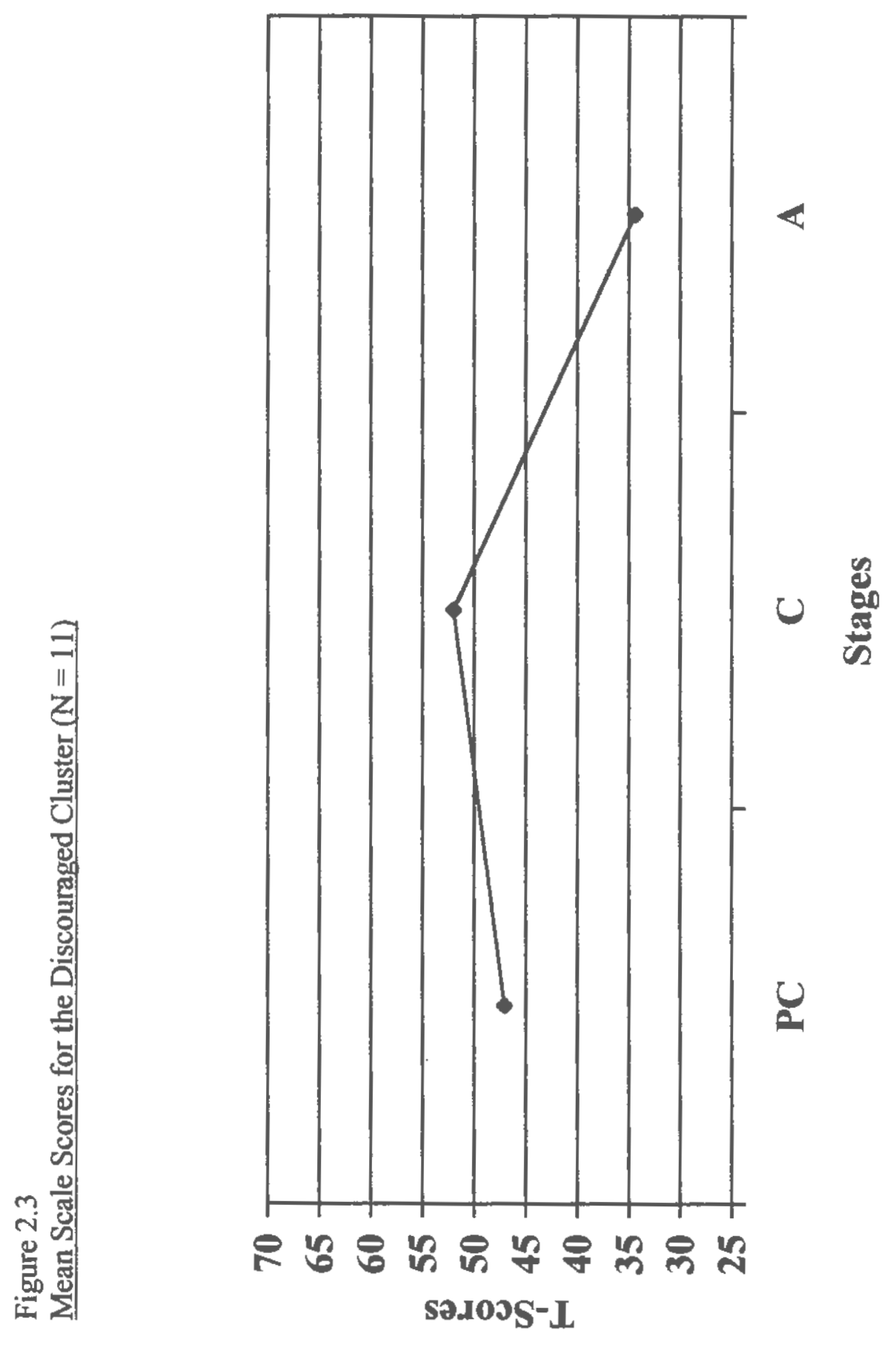




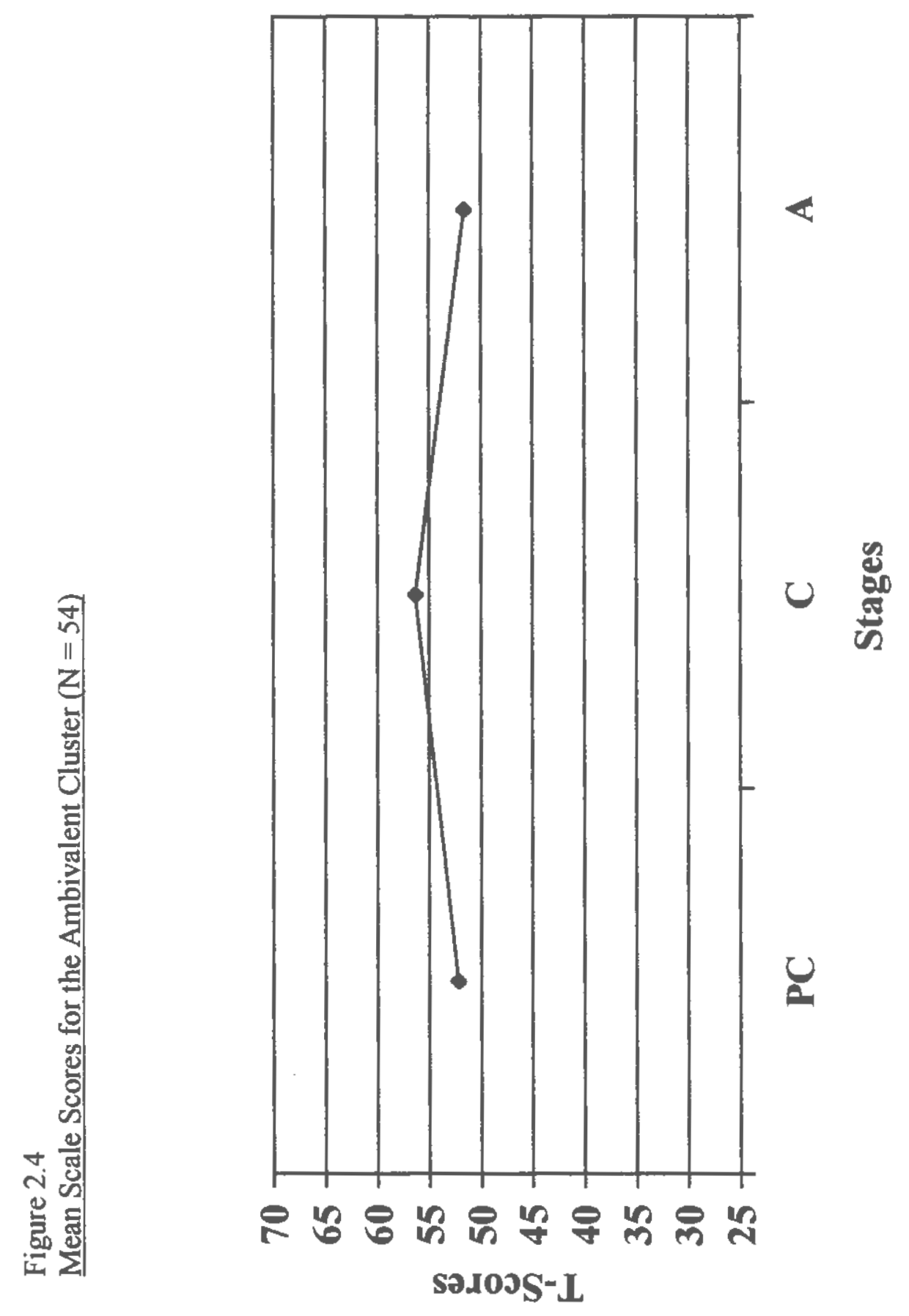




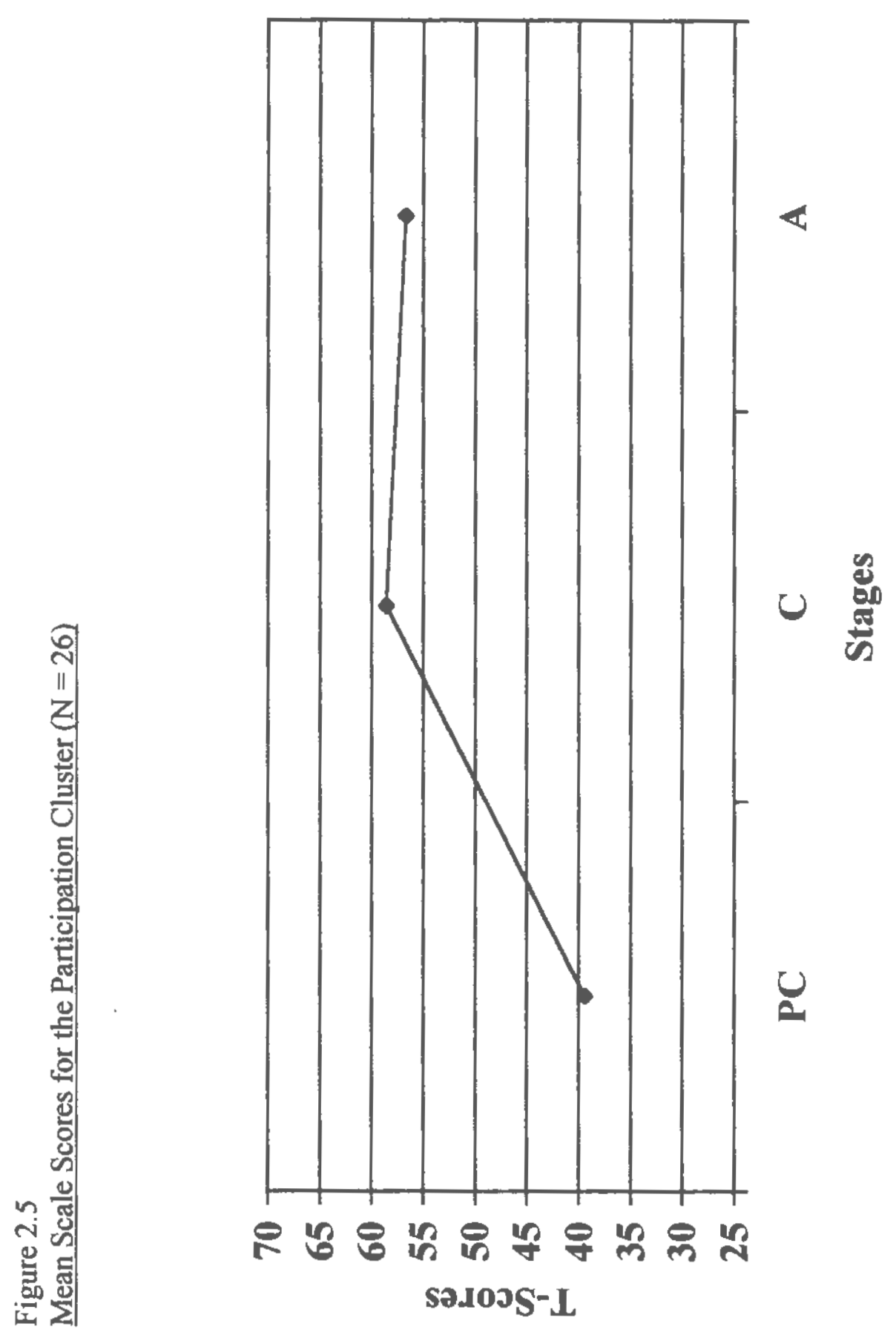









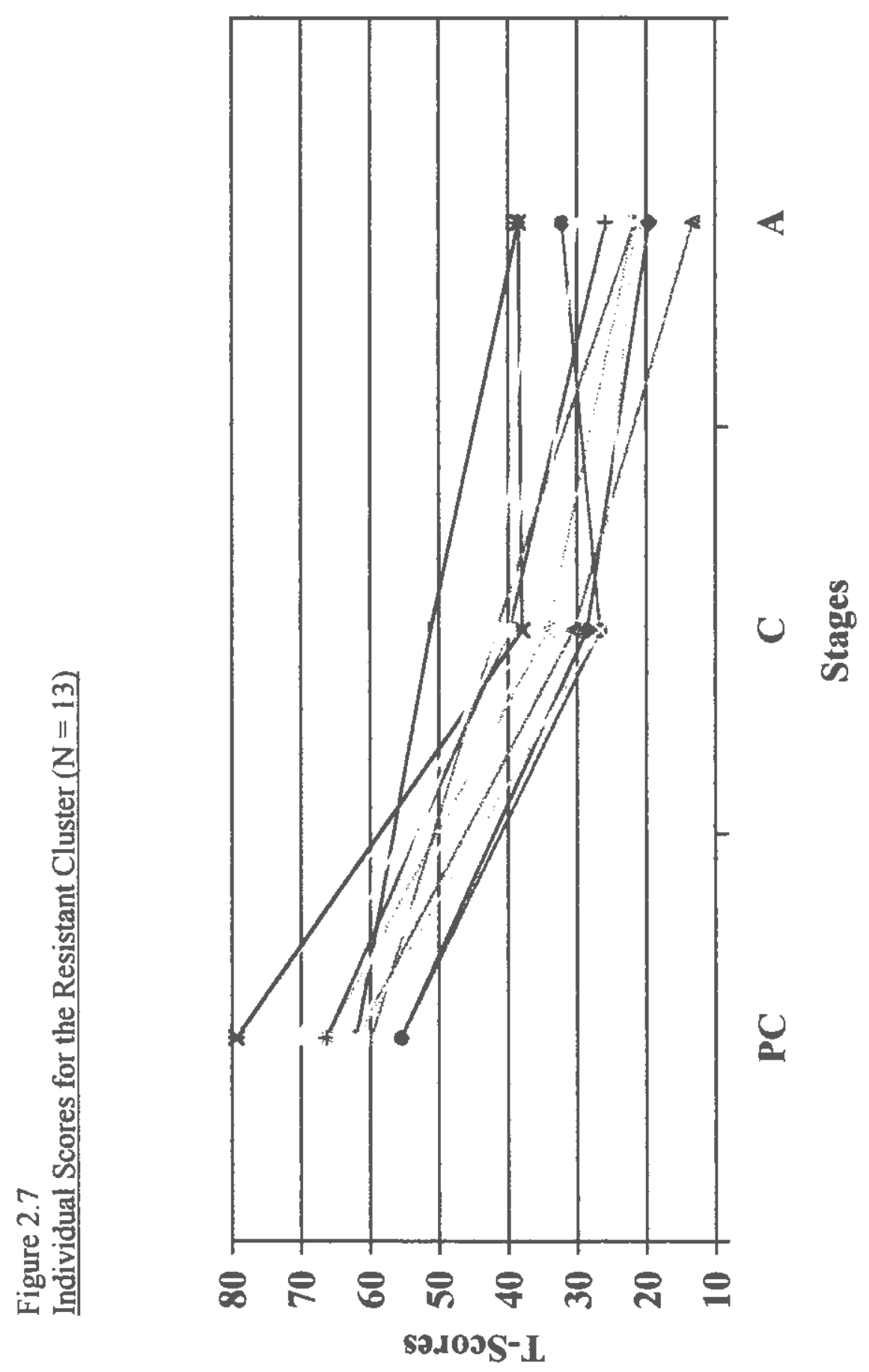




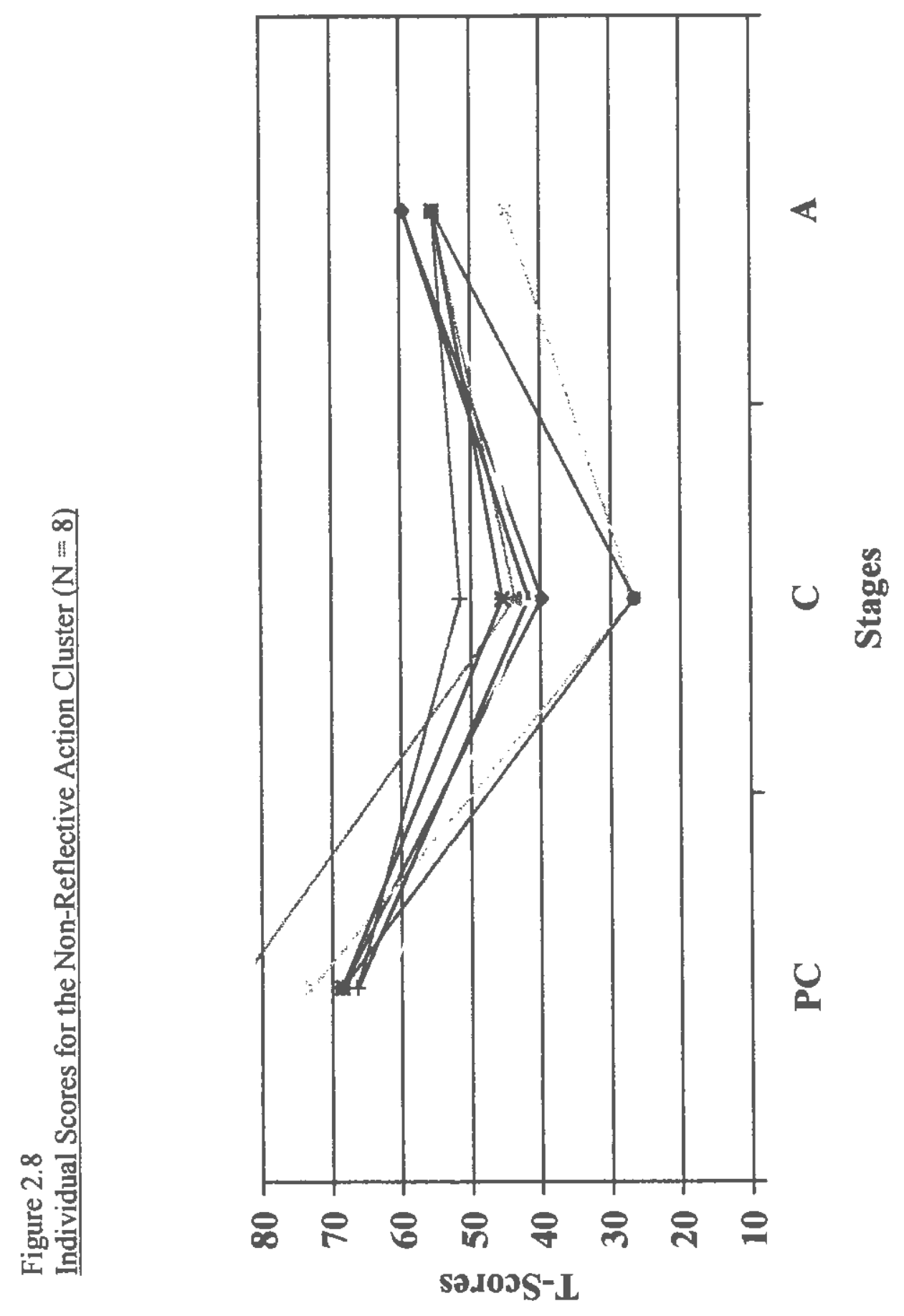




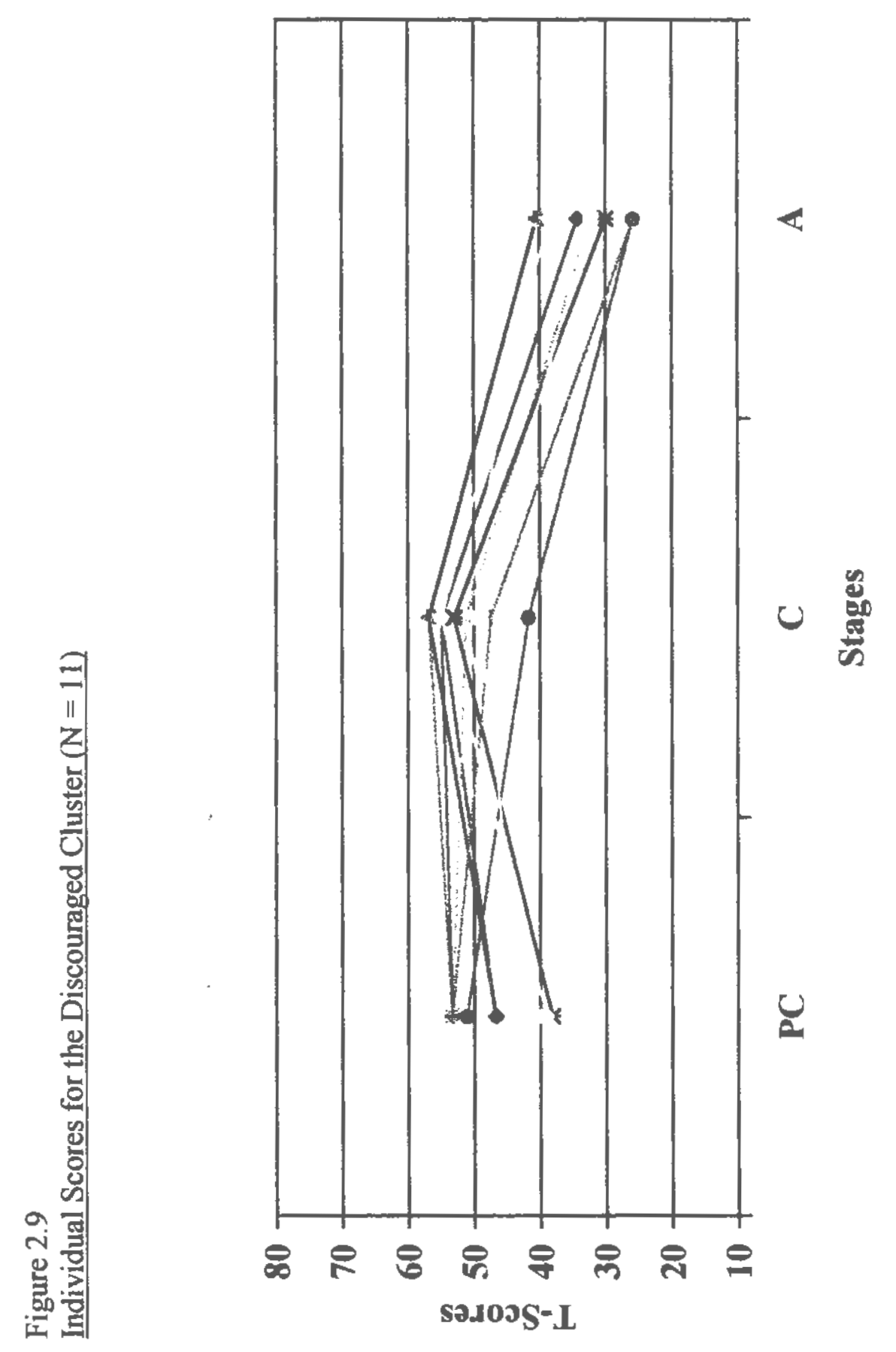








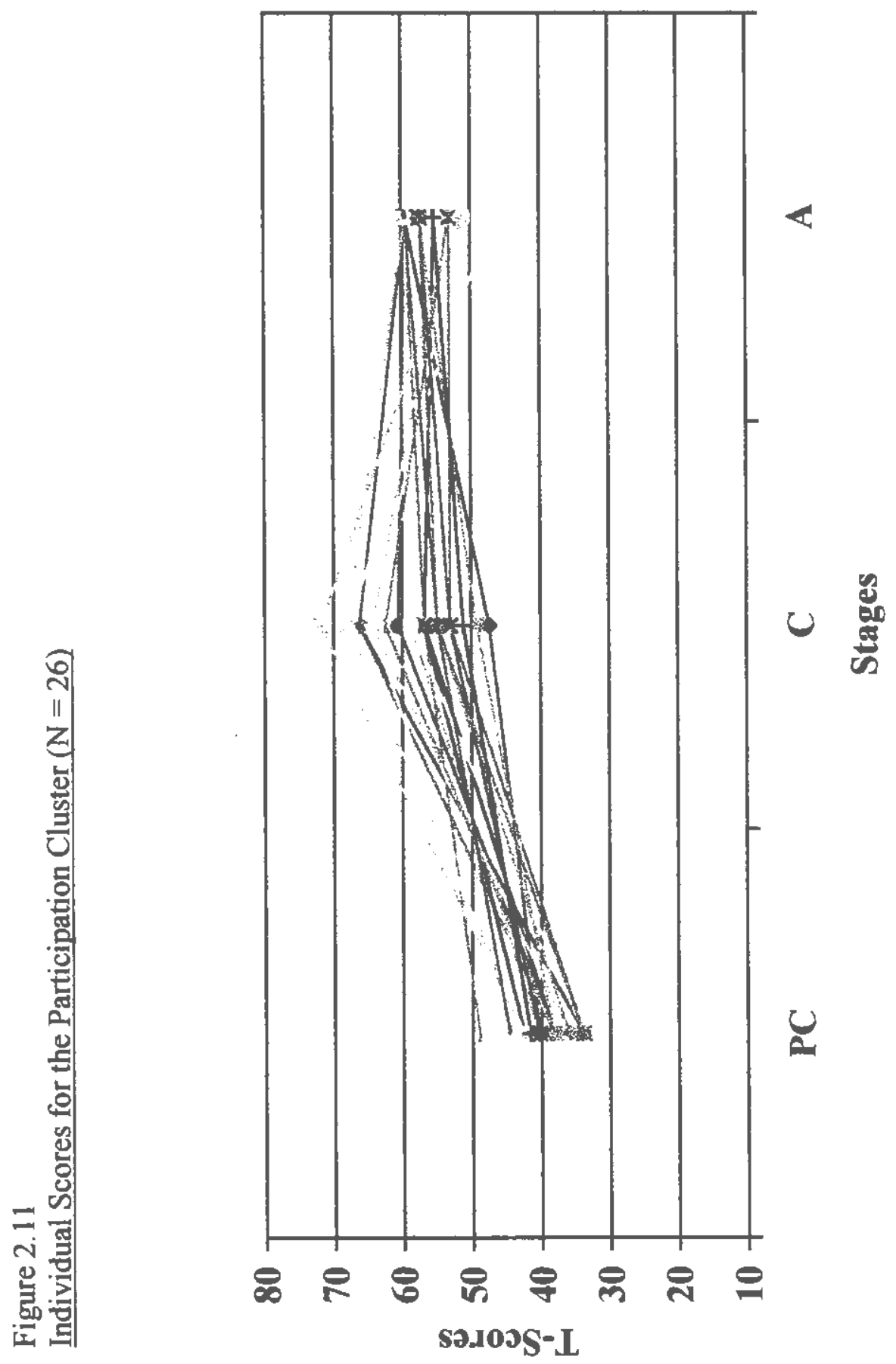







\section{CHAPTER 3}

Measuring Change in Maltreating Caregivers: Additional Tests of the Applicability of the Transtheoretical Model 


\section{Introduction}

Recently the National Resource Center on Child Maltreatment (NRCCM) published a monograph with articles summarizing the most recent research on decision-making in children's protective services (Morton \& Holder, 1997). In it, Wilson and Morton (1997) outline six decision sets that occur as a part of the functioning of the child protective service (CPS) system (p. 13):

1) Do we accept the reports and how do we respond?

2) Which cases are selected for a service intervention?

3) Is the child safe and what actions are necessary to assure safety?

4) What must change and what actions are necessary to promote change?

5) What response is associated with progress or lack of progress and stepup or step-down interventions?

6) When should CPS involvement end?

The last three of these decision sets involve considerations and measurement of change. Yet, despite the centrality of assessing change in the functioning and decision-making process of child protective service agencies, very little is actually known about what changes are being asked of maltreating caregivers, what services are offered to help them change, how these services are distributed, and how decisions are made about who has successfully made changes and who has not. 
From the limited research on change in maltreating caregivers, one conclusion can be drawn: the current system is not effectively treating the majority of caregivers. Many families are not provided with services (USDHHS, 1994; Wang \& Daro, 1998), the services that are provided are limited in their effectiveness (Barth, 1998; Cohn \& Daro, 1987; Jones, 1987; NRC, 1993, 1998; Schellenbach, 1998; Willet, Ayoub, \& Robinson, 1991; Wolfe \& Wekerle, 1993), and re-abuse rates are high even given extensive intervention by the child protective system (DePanfilis \& Zuravin, 1998; Lung \& Daro, 1996; USDHHS, 1994).

Disagreements exist among researchers and advocates about the reasons that services for maltreating caregivers are not effective. Some feel that the problem lies in the limited available resources and the limitation on funds supporting treatment and intervention services (Kaufman \& Zigler, 1996; Pelton, 1997). Often those endorsing this view argue that the child protective service system as a whole needs to be restructured so that its sole purpose is voluntary service delivery. Other researchers (Barth, 1998; Gelles, 1996; Kolko, 1996; Oates \& Bross, 1995) feel that part of the reason for the lack of effectiveness of child protective service delivery is simply that many caregivers are not able to change, either because they don't want to or because their problems are so complex that they are unable to do so in the amount of time necessary to protect their children from physical and emotional harm. Given this perspective, providing extra 
funds for services or offering services on a voluntary basis will not ameliorate the problem of ineffective service delivery.

Wilson (1997) argues that what the system needs is the ability to distinguish subgroups of maltreating caregivers based on their likely response to intervention:

The debate about whether reunification of children with birth parents should be a fundamental goal of CPS is less important to decision makers at the line level than an identification of subgroups of abused and neglected children for whom reunification efforts should not be required. Arguments concerning which community agency should investigate child abuse and neglect referrals are less helpful to practitioners than criteria for deciding which families referred to CPS can be 'assessed' and offered voluntary services rather than be investigated within a substantiation framework (p. 195).

In order to accomplish these objectives, an assessment of dangerousness is needed with a method for determining who would most benefit from which services and who might not benefit from services at all.

The Transtheoretical Model (Prochaska \& DiClemente, 1982, 1983b, 1984, 1986, 1992; Prochaska, Norcross, \& DiClemente, 1994) offers the possibility of conceptualizing and measuring change with maltreating caregivers and empirically identifying some of the subgroups described by Wilson (1997). The potential utility of the model in distinguishing caregivers in which reunification efforts are unlikely to be in the child's best interest has already been outlined (Gelles, 1996). The model could also theoretically: 1) help to distinguish those caregivers who are more likely to make use of voluntary services from those who are not; and, 2) help to 
identify the types of intervention likely to be effective for different subgroups of caregivers based on their readiness to change.

The Transtheoretical Model conceptualizes change as occurring in a series of stages. Individuals move from having no interest in making changes, to thinking about making changes, and eventually to making and then maintaining those changes. The ability of the model to identify where an individual is along this continuum of change has been well established in the area of smoking cessation (DiClemente et al., 1991; Prochaska, DiClemente, Velicer, Ginpil, \& Norcross, 1985; Prochaska, Velicer, Guadagnoli, Rossi, \& DiClemente, 1991; Velicer, DiClemente, Prochaska, \& Brandenburg, 1985) and other areas of health behavior (Prochaska \& Velicer, 1997; Prochaska, Velicer, et al., 1994). Preliminary work using the model has also been initiated with problem behaviors that are more comparable to child abuse and neglect including juvenile delinquency (FioreLerner, 1990), substance abuse (DiClemente \& Hughes, 1990; Tsoh, 1995), criminal activity (Brown, Varna Garis, \& Mitchell, 1999) and domestic violence (Daniels \& Murphy, 1997; Levesque, 1998; Murphy \& Baxter, 1997). In all of these areas, as with child maltreatment, measuring readiness to change offers the possibility of offering better targeted treatments to individuals struggling with complex and difficult behavior change.

Research with the Transtheoretical Model has shown that individuals at different stages of change are more or less able to learn from different types of interventions (DiClemente \& Prochaska, 1982; Prochaska \& DiClemente, 1992; 
Prochaska \& Velicer, 1997). These interventions, or "processes" of change, were drawn from some of the more common theories of psychotherapy and were also found to be used by individuals who changed their own behavior without professional assistance. "Consciousness raising," "Self-reevaluation," "Reinforcement management," and "Helping Relationships" are examples of some of the categories of processes the authors describe (Prochaska, Diclemente, \& Norcross, 1992). Research has indicated that "experiential processes" (thinking about, evaluating, and emotionally reacting to one's problem) tend to be used earlier in the process of change while "behavioral processes" (committing to change, removing temptations, planning rewards for success) are employed later in the process.

Prior to the use of the Transtheoretical Model in decision-making and treatment-matching for maltreating caregivers, its applicability with this population must be examined. The first step in this process is the development and refinement of scales designed to measure the constructs of the model for changing abusive and neglectful behaviors. The applicability of the model can then be tested by 1) assessing predicted relationships within and among the constructs and 2) comparing the results of this application of the model to previous applications.

The remainder of the chapter will summarize previously reported results (see Chapter 2) from an instrument designed to measure one of the model's core constructs, Stages of Change (SOC). Then the creation of four additional scales will be described, two based on the model's constructs of Decisional Balance and 
Self-Efficacy and two scales that were added to measure attitudes toward substance use and toward child protective services. Finally, the relationship between these four scales and the SOC scale will be examined and compared to the expected relationships given previous work using the Transtheoretical Model.

The Transtheoretical Model of Change

The Transtheoretical Model of Change was originally developed by Prochaska and DiClemente for assessing self-change in smoking behavior (DiClemente \& Prochaska, 1982; Prochaska \& DiClemente, 1983b) and the process of change for individuals seeking psychotherapy (McConnaughy, DiClemente, Prochaska, \& Velicer, 1989; McConnaughy, Prochaska, \& Velicer, 1983; Prochaska \& DiClemente, 1982, 1983a, 1984, 1986). These authors argued that change is a process in which individuals move thorough a series of stages in thinking about and implementing changes in their behavior. The Transtheoretical Model also integrates other theoretical constructs believed to be central to change such as Janis and Mann's theory of decisional balance (1977) and Bandura's theory of self-efficacy (1977).

\section{Stages of Change}

The organizing construct for the Transtheoretical Model is the Stages of Change measure, which assesses an individual's stage of readiness to make changes in their behavior. Prior research with the model has supported five stages:

precontemplation, contemplation, preparation, action, and maintenance. 
In precontemplation, individuals deny they have a problem and have no intention of changing their behavior in the foreseeable future. They are unaware of the negative consequences of their behavior, believe the consequences are insignificant, or have given up the thought of changing because they are demoralized. Those in contemplation are beginning to consider the benefits of changing. They are more likely to recognize or acknowledge some of the negative consequences of their problem behaviors. They may be seeking information on their problem but are not ready to take immediate action. In preparation, individuals have made a firm commitment to changing and are making plans to follow through with their goals in the near future, usually defined as within the next month. In action, individuals are actively modifying their behaviors and acquiring new, health-promoting behaviors. And, finally, in maintenance, individuals strive to maintain the changes they have made and to prevent relapse. At this stage, the changes have been sustained for an extensive period of time, often defined as at least six months.

One of the ways stage of change has been assessed in past applications of the Transtheoretical Model is with a continuous measure. Respondents rate, on a 5point Likert-type scale, the extent to which they agree with items that have been operationally defined to measure cognitive and behavioral markers of the Stages of Change. This was the design used in the original University of Rhode Island Change Assessment (URICA) instrument created by McConnaughy and her colleagues $(1989,1993)$ and has been used in subsequent research with the model 
(e.g., Brown, 1998; Brown et al., 1999; DiClemente \& Hughes, 1990; Johnson, 1995; Levesque, 1998; Prochaska \& DiClemente, 1992; Tsoh, 1995). The URICAstyle measure creates a score profile across the stages in which individuals can endorse relative identification with each of the stages of change. The profiles can then be compared with each other and hypotheses can be made about what groups with similar profiles have in common.

A URICA-style Stage of Change (SOC) measure has been created for use with caregivers involved with child protective service agencies (see Chapter 2). The SOC scale resulted in three subscales measuring the constructs of Precontemplation, Contemplation, and Action. The Precontemplation items indicate a reluctance to work with child protective services and a denial of serious parenting problems, the Contemplation items suggest an interest in making changes in parenting behaviors and fears about making these changes and the Action items reveal an engagement in active efforts to make changes.

In examining the differences among participant scores on the SOC scales, six cluster groups emerged that appear to represent subgroups of maltreating caregivers with different attitudes toward change. These were labeled 1) Resistant, 2) Non-Reflective Action, 3) Discouraged, 4) Ambivalent, 5) Participation, and 6) Action. Although the clusters are based on cross-sectional data, it is hypothesized that they represent a roughly progressive order from least to most advanced on a continuum of readiness to change. Figure 3.1 presents the mean profile scores of 
these cluster groups on each of the three staging components, Precontemplation, Contemplation, and Action.

Subjects in the Resistant cluster do not feel they have a problem, are not interested in working with child protective services, and show no indication that they are involved in making or planning to make changes. Those in the Non$\underline{\text { Reflective Action cluster seem to be strongly denying that they have a problem that }}$ needs changing and at the same time are claiming to be making active changes in their behavior. Subjects in the Discouraged cluster acknowledge ambivalence about whether they need help or have a problem but feel strongly that they are doing nothing to actively make changes. The Resistant, Non-Reflective Action, and Discouraged clusters could be considered subgroups of Precontemplators due to their high scores on this scale or notably low scores on the Action scale.

Individuals in the Ambivalent cluster appear to be struggling with at least a moderate endorsement of both the difficulty of working with DCYF and also of the belief that they need to make some changes. Those in the Participation cluster are reporting active efforts to change while also a large amount of worry and concern about trying to make the changes. And finally, those in the Action cluster seem to be actively engaged in efforts to change, feel comfortable about making those changes, and do not indicate a difficulty working with child protective services. The Ambivalent group was seen as comparable to a Contemplation stage and the Participation and Action groups could be considered earlier and later forms of 
Action given their relatively moderate to low scores on Precontemplation and high scores on Action.

These cluster groups were interpretable and, for the most part, mirrored groups that have been found in previous applications of the model. The data are encouraging evidence of the model's applicability and utility in the area of child abuse and neglect. However, additional research is needed to establish the reliability and the validity of these cluster groups and to examine the hypothesis that the cluster groups represent a linear progression of readiness to change. The reliability of the clusters will need to be checked by replication with an additional sample and the validity of the cluster groups will eventually need to be analyzed through longitudinal research. However, preliminary validity work can be done by comparing the groups on external, theoretically related variables. There are two constructs of the Transtheoretical Model that have been shown to have a consistent relationship with stage of change across behavior problems, Decisional Balance and Self-Efficacy. Comparison of the cluster groups of maltreating caregivers that resulted from the preliminary SOC scale with these constructs can be used to initiate preliminary tests of their validity.

\section{Decisional Balance}

Janis and Mann (1977) proposed that cognitive and motivational aspects of decision-making involve a comparison of the potential gains (pros) and the potential losses (cons) associated with a decision's consequences. Their comparative model suggested that a comparison of the pros and cons of making a 
decision involve assessments of: 1) utilitarian gains and losses for the self, 2) utilitarian gains and losses for others, 3) self-approval or disapproval, and 4) approval or disapproval from others. The concept of Decisional Balance was incorporated as a construct into the Transtheoretical Model and a predictable relationship emerged between this construct and readiness to change smoking behavior (Velicer, Diclemente, Prochaska, \& Brandenburg, 1985). Smokers in Precontemplation felt that the cons of changing outweighed the pros. The pros and cons were approximately equal during the Contemplation stage and then switched places of importance in Action with the pros outweighing the cons. The importance of both the pros and cons dropped during Action and Maintenance, suggesting to the authors that Decisional Balance is a greater concern during earlier stages (Precontemplation, Contemplation, and Preparation) when an individual is trying to acquire healthy behaviors (Prochaska \& DiClemente, 1992). A comparison of the pros and cons of changing smoking behavior was predictive of a decision to make the changes but not of the ability to maintain the changes.

The predicted relationship between Decisional Balance and Stage of Change has generalized across applications of the Transtheoretical Model in many different problem areas. In a recent integrative report of 12 studies, Prochaska, Velicer, et al. (1994) found that the balance of pros and cons was systematically related to stage of change in all 12 behaviors examined: the cons of changing outweighed the pros in the precontemplation stage and the pros outweighed the cons during the action and maintenance stages. The pros and cons tended to switch 
places of importance during a period immediately prior to the action stage. From this collection of data, Prochaska (1994) discovered that a progression from precontemplation to action involved approximately a one standard deviation increase in the pros of making the healthy behavior change, and a .5 standard deviation decrease in the cons of making the change.

Based on their research Prochaska, Velicer, et al. (1994) note that Decisional-Balance could potentially be used to assist in targeting interventions. Movement from Precontemplation to Contemplation generally involved an increase in pros and movement from Contemplation to Action involved a decrease in cons. This suggests that to move Precontemplators to Contemplation, interventions might be more effective if they focus on increasing the pros of changes. Then, for Contemplators, the intervention target could be decreasing the cons in order to move Contemplators into Action.

\section{Self-Efficacy}

Self-efficacy, or the degree to which an individual believes he or she has the capacity to attain a desired goal, can influence motivation and persistence and therefore also influence change (Bandura, 1977). In previous research applying the Transtheoretical Model to smoking cessation and alcohol use (DiClemente, Prochaska, \& Gibertini, 1985; Prochaska \& DiClemente, 1992), measures of selfefficacy were obtained by asking subjects to indicate on a 5-point Likert-style scale how confident they are that they could abstain from the problem behavior in a number of tempting situations. The salience of the situations for each individual 
was also assessed in a similar manner by asking the subjects how tempted they were in each situation to drink or smoke. Temptation and Confidence scores are usually negatively correlated and inversely related to each other (Prochaska \& DiClemente, 1992).

For smokers, levels of self-efficacy differed systematically across the stages of change, with subjects further along in the stages of change experiencing greater self-efficacy and less temptation regarding the behavior in question. Those in Precontemplation had the highest levels of temptation and the lowest levels of selfefficacy (Prochaska \& DiClemente, 1992). However, with alcohol abusers, those in precontemplation actually had higher levels of confidence than temptation. Prochaska \& DiClemente acknowledge that it is difficult to interpret self-efficacy for those in Precontemplation who are denying a problem at all. Issues of selfefficacy tend to be more crucial during later stages (Action and Maintenance) when an individual is trying to maintain a healthy pattern of behaviors and prevent relapse.

The difference in the self-efficacy findings between smokers and alcohol abusers may be the result of the deniability of the problem. Smokers would have less of a reason to deny that they are smoking. They, in fact, might not see a problem with smoking at all and therefore would admit to a lack of self-efficacy regarding cessation. Alcohol abusers who were in Precontemplation, on the other hand, may be denying a drinking problem at all and might not admit to a problem 
with confidence and resisting temptation. The latter situation would hypothetically be more comparable to child abuse and neglect.

Because both Decisional Balance and Self-Efficacy measures have been shown to have consistent relationships with the Stages of Change across behavior problems, they offer the ability to help establish the Transtheoretical Model's applicability in a new area. In the current instance, Decisional Balance and SelfEfficacy scales will be used to check the validity of the cluster groups found using a Stage of Change measure with abusive and neglectful caregivers. The creation of Decisional Balance (DB) and Self-Efficacy (SE) scales for use with this population will be outlined below along with the results from the scales across staging clusters. If, as hypothesized, the clusters represent a roughly linear progression from least to most ready to make changes, two hypotheses can be outlined regarding the DB and SE scales: 1) The cons of changing will outweigh the pros for the earlier cluster groups and will switch places of importance so that by the last group the pros will outweigh the cons; and 2) Temptation scores should decrease across the staging groups while Confidence scores increase.

It is also useful to have additional information about the staging clusters by examining differences on variables assumed to be related to making changes in abusive and neglectful behaviors. These would hypothetically vary with stage of change for this population. Two preliminary scales were developed from items included in the original SOC measure, a scale measuring the level of cooperative attitudes toward child protective services (CACPS) and a scale examining concerns 
about substance abuse (CASA). Based on previous qualitative research, both of these variables should vary systematically with staging cluster membership if the cluster groups represent a relatively linear increase in readiness to change. Qualitative research suggested that cooperative attitudes toward child protective services increase as caregivers increase their willingness to make changes in their abusive and neglectful behavior. Furthermore, given the extensive substance use in the larger population of maltreating caregivers (Kelleher, Chaffin, Hollenberg, \& Fischer, 1994; Magura \& Laudet, 1996) and the large proportion of substance abusers in the sample who participated in this study, it was hypothesized that an acknowledgement of substance abuse problems and the danger of such problems for children would be found to increase across stage of change. The development and psychometric properties of the CACPS and CASA scales will be outlined along with tests of the hypotheses that scores from these scales increase across staging clusters.

\section{Method}

\section{Item Generation}

A preliminary instrument was designed (Gelles et al., 1997) using the Transtheoretical Model to measure Stage of Change, Decisional-Balance, and SelfEfficacy in parents and caregivers who abuse and neglect their children (see Appendix A for instructions and items included in the questionnaire). Item development for the instrument was based on qualitative research with abusive and neglectful caregivers and RIDCYF supervisors, direct care workers, and service 
providers. These individuals were asked in semi-structured interviews about caregivers' efforts to make changes in abusive and neglectful behaviors. Item generation for the Self-Efficacy and Decisional Balance Scales was specifically based on responses to questions about the pros and cons of making changes and situations in which temptation to relapse was high.

Initially, 37 Decisional Balance items and 22 Self-Efficacy items were created based on the qualitative data and in an effort to cover many of the different areas of each construct that might be relevant for maltreating caregivers. The Decisional Balance items were created to cover a range of the original areas outlined by Janis and Mann as central to this construct. The Self-Efficacy items were designed to tap into the positive and negative, external and internal experiences that caregivers described as often leading to relapse in abusive and neglectful behaviors. The items for both scales were reduced in the interest of parsimony and based on feedback from "experts" of both child maltreatment (RIDCYF staff, supervisors, and service providers) and the Transtheoretical Model. The preliminary Decisional Balance scale (see Appendix A) included 20 items, 10 of which were designed to measure pros of changing, and 10 to measure the cons of changing. The Self-Efficacy scale included two subscales with 13 identical items. The "Temptation" subscale asked participants how tempted they would be in each situation to return to behaviors that led to child protective service involvement. The "Confidence" subscale asked how sure participants were that they could resist returning to the problematic behaviors in the same situations. 
The Cooperative Attitudes toward Child Protective Services (CACPS) and the Concerns about Substance Abuse (CASA) scales were created from items that were originally included with the Stages of Change (SOC) items. After examining the initial data from the SOC instrument, a decision was made that these items were not related to stage but were representative of their own constructs. Ten items dealing with substance abuse issues were included as part of the CASA scale and 16 items denoting a cooperative attitude toward child protective services were included in the CACPS scale.

\section{Participants}

The entire instrument, including demographic questions, the SOC scale, and the Decisional-Balance and Self-Efficacy scales, was administered to a group of 163 participants who either currently had a case open to the RIDCYF or who had a case open within the last year. Caregivers involved with the RIDCYF were informed of the study and invited to participate through their direct care worker, through a treatment group leader, by mail, or through pamphlets that were distributed around child protective offices and other community treatment centers. Prior to contacting the researchers, the subjects were informed in the flyer or through group leaders that the study was confidential and that they would receive $\$ 25$ for their participation. This information was re-emphasized prior to administration of the instrument along with more detailed information about the study and the subjects' rights to confidentiality. Over the course of a year, onehundred and sixty-three individuals contacted or were contacted by the researchers 
and agreed to participate. The survey administration was conducted either in the participant's home (46 participants) or in a private office at a community agency (RIDCYF office or substance abuse treatment facility) (117 participants). The majority of participants (114 participants or $70 \%$ of the sample) were identified and contacted through their participation in a substance abuse treatment program. Administration of the instrument took approximately 30 minutes. Seven questionnaires were discarded; four were discarded due to the participants' difficulty reading English, two were discarded because their cases were not open due to child abuse and neglect, and one was discarded due to extensive missing data.

The remaining 156 participants were primarily women (146 women and 10 men, mean age $=31.6$ years). Fifty-two percent of the sample identified themselves as "White", 25\% as "Black or African-American", 15.4\% as "Mixed Race", $8 \%$ as "Hispanic", and $4 \%$ as either "American Indian or Alaskan Native" or "Asian or Pacific Islander". The participants had an average of 2.3 children and 87 (56\%) had at least one of those children in foster care placement. While $66 \%$ of the sample described incomes of less than $\$ 10,000$ per year, the majority, or $59 \%$, had graduated from high school or had received their GED. At the time of the administration of the questionnaire, 127 participants' cases were open to the RIDCYF (8I\%) and 28 were closed (18\%). 


\section{Procedure}

\section{Instrument Development}

For the Decisional Balance (DB) instrument, a 20 X 20 matrix of inter-item correlations was calculated; no case was missing more than $10 \%$ of the data, so pairwise deletion was used to deal with missing values. Exploratory principal component analysis (PCA) using SPSS 8.0 for Windows was performed on the correlation matrix in order to examine the component structure of the DB instrument. Examination of the scree plot and theoretical considerations were used in extracting components. Varimax rotation was performed on the data to aid interpretation of the results. Decisions about the best items to retain for the DB scales were made based on component loadings, item variability, Coefficient Alphas for each scale with and without particular items included, and theoretical considerations.

A similar process was conducted in order to reduce items for the SE scales ( based on a $13 \times 13$ correlation matrix), for the Cooperative Attitudes toward Child Protective Services scale (CACPS) (a $10 \times 10$ correlation matrix) and for the Concerns about Substance Abuse (CASA) scale (a $13 \times 13$ correlation matrix).

\section{$\underline{\text { Scale Comparisons }}$}

Comparisons were then made between the four reduced scales and the Stage of Change (SOC) cluster groups described above in order to begin evaluating the external validity of those groups. Analysis of Variance (ANOVA) tests were conducted in order to evaluate differences among the scores on these scales for 
each cluster. Cluster membership was used as the grouping variable and the dependent variables were 1) pros and cons of changing abusive and neglectful behavior (DB scale), 2) temptation to re-engage in abusive and neglectful behavior (SE scale), 3) cooperative attitude toward child protective services (CACPS scale), and 4) concerns regarding substance use (CASA scale). Follow-up tests were conducted when significant differences were found. Examination of the relationship between the dependent variables and the cluster groups was further illustrated by plotting the standardized results of the scales and examining the pattern of variation across staging clusters.

Results

\section{Instrument Development}

Principal Components extraction with Varimax rotation was conducted in order to examine the component structure of the preliminary 20 -item Decisional Balance instrument. A clear two component solution was extracted, with Pros and Cons of change as the identified components. Four items in each of the two components were eliminated either because they were complex (loadings $>.40$ on both scales), did not load well on either scale (loadings $<.40$ on both scales), were not theoretically consistent, had low variability, or did not contribute to the over-all reliability of the scale. Table 3.1 presents the 12 items that were retained for the two scales ( 6 items per scale) with corresponding component loadings. All items had a component loading of 50 or greater after rotation. Loadings for each item on 
the other components were under .30 . The twelve items that were retained for the Pros and Cons scales had been theoretically designed to load on those components.

Principal Components analyses were also run on the 13-item Temptation and Confidence scales of the Self-Efficacy measure, the 13-item CACPS scale and the 10-item CASA scale. For all of these scales, analyses resulted in a 1component solution. Items in the Temptation and Confidence scales were reduced to 5 items. Because the 2 scales together form a measure of Self-Efficacy, the items in each of these scales needed to be identical. Eight items from each scale were deleted due to low factor loadings $(<.50)$ and in the interest of balancing scale brevity and comprehensiveness. All items on each scale had component loadings of over .80 (mean loading, Temptation scale $=.85$, mean loading, Confidence scale $=.87$ ). The five items retained for each scale are presented in Table 3.2 with the corresponding component loadings.

The CACPS scale and the CASA scale were also reduced to five items each. Items were deleted based on factor loadings, scale Coefficient Alphas, item variability and item content. Items and component loadings are presented in Tables 3.3 and 3.4 for the CACPS scale and CASA scale respectively. Item loadings for both scales were all greater than .70 (mean loading, CACPS scale $=.79$; mean loading, CASA scale $=.85$ ). The CACPS items specify a trust in the RIDCYF and a view of the agency as supportive. The CASA items, when endorsed, suggest that the participant believes that he or she has a substance abuse problem and that the problem is affecting their parenting. 
Scale scores for the six scales described above (Pros, Cons, Temptations, Confidence, CACPS, and the CASA scales) were calculated by summing the unweighted scores of the items representing each scale and converting the summed scores to $\mathrm{T}$-scores (mean $=50, \mathrm{SD}=10$ ). Inter-scale correlations, Cronbach's Coefficient Alphas, means, and standard deviations are presented for each scale in Table 3.5. As expected the Temptations and Confidence scales had a minimal, negative correlation with each other $(r=-.32)$. It is also not surprising that the CASA, CACPS, and Pros scales are intercorrelated $\left(r^{\prime} s=.33, .44, .36\right)$ given the hypothesis that scores for all of these scales should increase across staging clusters. The positive correlations of the Temptation scale with the Pros, Cons, and CASA scales, (respective r's $=.26, .24, .35$ ) however, was unexpected. A correlation between the Temptation and the Cons scales could be an indication that temptation to relapse increases with a greater identification with the cons of changing. However, the simultaneous correlations with the Pros and CASA scales cloud the interpretation of these findings.

An additional concern is the low variability of scores on the Pros items. The mean score on these items was 4.4 (range $=1-5$ ), with a standard deviation of 1.1. This suggests that a ceiling effect was occurring where participants generally all agreed that these items were important in their decision-making process. The low variability of these items could affect the ability to detect significant relationships between this and other scales, and will have to be taken into account when interpreting data based on its use. 


\section{Scale Comparisons}

In order to begin examining the external validity of the six staging clusters, participant scores on the Pros, Cons, Temptations, Confidence, CACPS, and CASA scales were compared across groups. Analysis of Variance (ANOVA) tests were performed on the data in order to determine if differences existed among cluster groups on these scales. Cluster membership was used as the grouping variable and the six scales listed above served as dependent variables. When significant differences were found, post-hoc comparisons with Tukey's honestly significant difference tests were used to identify the source of the differences. Mean t-scores and corresponding standard deviations for each cluster, the results of the ANOVA tests, and the post-hoc comparison results are presented in Table 3.6. Raw mean and standard deviations for each scale are presented by cluster in Table 3.7.

Univariate ANOVAs found significant differences among cluster groups on both the Pros and Cons scales of the Decisional Balance measure $(\underline{F}(5,145)=$ $18.6, \omega^{2}=.391, \mathrm{p}<.05$ and $\mathrm{F}(5,145)=3.78, \omega^{2}=.115, \mathrm{p}<.05$ respectively). The follow-up tests showed significantly lower Pros scores for the Resistant group compared with all other cluster groups. There was also a significant discrepancy between the Discouraged and Participation groups, with the Participation group showing higher scores on the Pros scale. Interestingly, the differences in scores on the Cons scale were primarily between the Resistant and the Non-Reflective Action groups, which had the lowest and highest mean scores, respectively, on this scale. 
A clearer picture of the relationship between the Decisional Balance scales and the cluster groups can be seen in Figure 3.2, where the mean standardized scores of these scales have been plotted for each cluster. The Pros start out 2 standard deviations below the mean for the Resistant cluster and then show a gradually rising trend with a peak at the Participation group. The Cons scores are $1 / 2$ standard deviations below the mean for the Resistant group, rise sharply to $1 / 2$ standard deviations above the mean for the Non-Reflective Action group and then drop towards the mean showing a slightly decreasing trend across the remaining clusters. The Pros and the Cons switch places of importance between the Ambivalent and Participation clusters supporting the hypothesis that these two groups are comparable to the Contemplation and Action stages of the Transtheoretical Model.

The ANOVA tests also found significant differences for the Temptations scale $\left(\underline{F}(5,144)=5.43, \omega^{2}=.159, \mathrm{p}<.05\right)$. Post-hoc comparisons revealed that the Temptation scores were lowest for the Resistant cluster and were significantly higher for the Ambivalent and Participation groups. Contrary to expectations, no significant differences across clusters were found for the Confidence scale. Figure 3.3 graphically demonstrates the relationship of the Self-Efficacy scales to the cluster groups by plotting the mean standard scores on the two scales across the groups. The Temptation scores are over $1 / 2$ standard deviation below the mean for the Resistant cluster and then rise across the groups to peak at $1 / 2$ standard deviations above the mean for the Participation Cluster. The scores then sharply 
drop to almost $1 / 2$ standard deviation below the mean for the Action cluster. The Confidence scores hover around the mean for all of the clusters; they are, however, slightly higher for the Resistant, Non-Reflective Action, and Action groups and are slightly lower for the Discouraged and Ambivalent groups.

Significant differences across clusters were also found for the CACPS $\left(\underline{\mathrm{F}}(5,145)=16.58, \omega^{2}=.364, \mathrm{p}<.05\right)$ and $\operatorname{CASA}\left(\underline{\mathrm{F}}(5,144)=21.08, \omega^{2}=.423\right.$, p<.05) scales. The Resistant and Non-Reflective Action groups scored significantly lower on the CACPS scale than the other cluster groups. The Participation cluster, on the other hand scored significantly higher on this scale than the Discouraged and Action clusters. Figure 3.4 displays the CACPS standardized mean scores across cluster groups. The scores are over a standard deviation below the mean for the Resistant and Non-Reflective Action groups and then rise steadily to the Participation cluster where scores are almost a standard deviation above the mean. On the CASA scale, the first three cluster groups (Resistant, Non-Reflective Action, and Discouraged clusters) are all significantly lower on this scale than the last three cluster groups (Ambivalent, Participation, and Action clusters). Figure 3.5 illustrates the differences in scores across the clusters for the CASA scale. Scores for the first three clusters are 1 to $11 / 2$ standard deviations below the mean. The scores then rise sharply and the last three clusters' scores on this scale are almost $1 / 2$ standard deviations above the mean. Although low scores for the first three clusters on this scale could indicate that these individuals do not have a problem with substance abuse, they could also be due to denial of substance abuse 
problems. Given that 9 out of the 31 individuals in these groups were contacted to participate in the study through a substance abuse agency, the latter is likely to be at least a partially contributing factor.

\section{Discussion}

The research presented in this chapter had two primary goals:

1) The development of instruments to measure two constructs central to the Transtheoretical Model of Change, Decisional Balance and Self-Efficacy, for use with maltreating caregivers.

2) An examination of the relationship between these two constructs and the staging clusters developed in Chapter 2.

The results from both sets of analyses, although preliminary, offer encouraging support for the use of the model in child abuse and neglect.

The development of the Decisional Balance and Self-Efficacy scales resulted in sets of items with sound psychometric properties. Additionally, the predicted relationships within and among the scales were achieved. The Decisional Balance items supported two uncorrelated scales that described the pros (Pros scale, six items) and the cons (Cons scale, six items) of changing behaviors that led to child protective service involvement. These findings parallel work with the Decisional Balance construct in other areas of behavior change in which a twocomponent model was also found (Brown et al., 1999; Fiore-Lerner, 1990; O'Connell \& Velicer, 1998; Rossi, 1993; Rossi \& Blais, 1991; Velicer et al., 1985). 
The items on the Pros scale covered all of the categories outlined originally by Janis and Mann (1977) in their theory of decision-making: self-approval, approval from others, and utilitarian gains for self and others. The Cons were composed of items that generally focused on utilitarian losses for self and others. Efforts had been made to include items in the Decisional Balance scales that reflected decision-making issues related to changing substance abusing behaviors. Such changes are often required by child protective services as a part of a reunification plan. However, these items did not load well with the others. This suggests that decision-making related to changing abusive and neglectful behaviors is qualitatively different from decision-making regarding substance abuse behaviors. Given the overlap, however, of child maltreatment and substance abuse that has been documented in the literature (Kelleher, Chaffin, Hollenberg, \& Fischer, 1994; Magura and Laudet, 1996), the relationship between changes in maltreating behaviors and changes in substance use will have to be explored more carefully in future research.

The two revised Self-Efficacy scales supported single constructs measuring the temptation to re-abuse or re-neglect in a variety of situations (Temptations scale, five items) and the confidence that temptation to relapse can be resisted in each of these situations (Confidence scale, five items). The items included in the Temptations and Confidence scales generally described negative emotional or negative social conditions. The Self-Efficacy scales had a slight negative correlation with each other. This correlation is expected given that confidence to 
resist temptation and degree of temptation should have a negative relationship. The strength of the relationship found in the current study, in fact, is slightly lower than the average correlation found in previous work with this construct (Prochaska \& DiClemente, 1992).

Two additional scales, the Cooperative Attitudes Toward Child Protective Services (CACPS) and the Concerns About Substance Abuse (CASA) scales, were also developed in a decision to gain further information from participants in areas hypothesized by the original developers of the measure to be related to changing abusive and neglectful behavior (Gelles, Brown, Jones, \& Youngblood, 1997). These scales were composed of five items each and had been included as part of the preliminary Stages of Change instrument. The CACPS measures a spirit of trust and cooperation with child protective services and the CASA identifies those participants with concerns about their substance use.

Comparisons of scores on the Decisional Balance, Self-Efficacy, CACPS, and CASA scales across staging clusters further supported the use of the Transtheoretical Model in this area and also provided support for the hypothesis that the clusters represent an increase from least to most likely to make changes. In general, the patterns of scores across staging clusters on these theoretically related variables were similar to the relationships that have been found in previous research.

The scores on the Decisional Balance scales across cluster groups were comparable to applications of this construct with other problem behaviors. When 
the staging clusters were lined up to represent a hypothetical increase in readiness to change and the Pros and Cons were plotted separately across those clusters, the patterns were similar to those found in twelve other studies in which the Pros and Cons were compared across stages (Prochaska, Velicer, et al., 1994). Similar relationships between the Decisional Balance scales and staging clusters has also been found in applications of the model with batterers (Levesque, 1998) and with incarcerated women (Brown et al., 1999).

Scores on the Pros increased almost 2 1/2 standard deviations from the first group, the Resistant cluster to the last two groups, the Participation and the Action clusters. The Cons began low with the Resistant cluster, rose to the highest point with the Non-Reflective Action cluster and then generally decreased almost a standard deviation. As predicted there was a cross-over between the Ambivalent and the Participation groups where the Pros and Cons switched places of importance. It is interesting that for the Resistant cluster, scores on both the Pros and the Cons were low, although scores on the Cons were comparatively higher. With the Non-Reflective Action cluster, the Cons were at their highest point.

The results of these analyses must be explained cautiously due to the small sample sizes of the first several groups. It will be important to replicate these patterns in future research before confidence can be placed in interpretations. However, if these patterns are found to be reliable, they may have interesting implications for interventions. It might be, for example, that individuals in the Resistant cluster are notably uninterested in the pros of changing their behavior, 
while, on the other hand, the Non-Reflective Action group may be strongly identifying with the cons of changing. If individuals in these two groups can be identified, interventions could target the two different areas for each group in an effort to move them forward to a more advanced stage of readiness to change.

The results of the Temptations and Confidence scales are more complex. The pattern for the Temptations scale across cluster groups is somewhat contrary to predictions. The Transtheoretical Model generally predicts that temptation to relapse should be high with Precontemplators and drop across the stages. The opposite pattern should occur with confidence to resist temptation. The current data show scores on the Temptations at their lowest level with the Resistant cluster. These generally increase until they are at their highest point with the Participation cluster and then drop almost a standard deviation with the Action cluster. The Confidence scores, on the other hand, show little variation across cluster, but are highest for the Resistant, Non-Reflective Action, and Action clusters. The Discouraged cluster shows the lowest Confidence scores. Interestingly, there are two areas in which the scores cross-over. For the Resistant, Non-Reflective Action and Action clusters, Confidence scores are greater than Temptation scores. For the Discouraged, Ambivalent, and Participation clusters, Temptation scores are higher than Confidence scores.

A few interpretations of these findings are possible. First of all, as mentioned previously, given the small numbers of individuals in the first several groups, the stability of the findings is questionable and results will need to be 
replicated. It may be with a greater number of participants, for example, significant differences will be found among groups on Confidence scores. But previous research with the Transtheoretical Model supports the relationship between staging group and Self-Efficacy that was found in the current study. As mentioned earlier, Prochaska and DiClemente (1992) found similar results for Self-Efficacy measures with alcohol abusers. Application of the Temptation and Confidence scales with alcohol abusers resulted in a pattern in which Precontemplators scored higher on the Confidence scale than on the Temptations scale. This pattern was also found on a Self-Efficacy measure with incarcerated women (Brown et al., 1999). Prochaska and DiClemente's (1992) assertion that Self-Efficacy measures are only predictive for individuals in the later stages appears to be even more relevant for behaviors that have strong negative social stigmas and for behaviors that can be denied by the individual.

The CACPS and CASA scales offer some additional information on the staging clusters. The earlier three clusters do not acknowledge any problems with substance abuse and endorse no feelings of cooperation with child protective services. The last three clusters in this sample on the other hand, generally admit to having a drug or alcohol problem and feel that this problem is impairing their ability to parent their children. The Participation cluster scored over a $1 / 2$ standard deviation above the mean on this scale. These last three clusters also endorse strong views that the RIDCYF can be trusted and is there to help them become better parents. If admitting to substance use and cooperating with child protective 
services aids in efforts to change maltreating behaviors, these findings support the view that the first three clusters are an earlier stage of change while the latter three cluster represent more advanced stages.

It is important to note that the CASA scale is not a measure of actual substance use but is only capturing an individual's belief that they have a substance use problem. An objective measure of substance abuse is very different from an acknowledgement by the individual that they have a problem with drugs and alcohol. It is likely that both assessments are important to understanding the relationship between substance abuse and the process of change for maltreating caregivers. Future research should include a validated alcohol and drug use scale in order to clarify this relationship. Future research should also use expanded measures of the relationship between child protective services to more carefully examine the impact of this variable on change in maltreating behaviors.

Although the implications of the results for measuring readiness to change in maltreating caregivers are exciting, the data bring forward further questions. For example, can the Pros and the Cons predict movement of an individual from one group to another? Do the different weights given to the Pros and Cons in the earlier cluster groups offer important information regarding subgroups of Precontemplators? Do changes in Self-Efficacy scores for the groups predict movement or vice versa? Do the earlier cluster groups differ in actual substance use or just in their belief that they have a problem? And what are the sources for the feelings of mistrust towards child protective services that are exhibited by the 
earlier cluster groups? Answering those questions will require additional research on change with maltreating caregivers, research that attempts to replicate the current findings, examines variables related to change in more detail, and expands on the current methodology by using longitudinal analyses. 


\section{References}

Bandura, A. (1977). Self-efficacy: Toward a unifying theory of behavior change. Psychological Review, 84, 191-215.

Barth, R. P. (1998). Abusive and neglecting parents and the care of their children. In M. A. S Mason, A. Skolnick, \& S. D. Sugarman (Eds.), All our families: New policies for a new century (pp. 217-235). New York: Oxford University Press.

Brown, J. (1998, July). The process of change in abused women scale (PROCAWS): Stage of change, pros and cons, and self-efficacy as measurable outcomes. Paper presented at the Program Evaluation and Family Violence Research: An International conference, Durham, NH.

Brown, J., Varna Garis, A., \& Mitchell, K. (1999, March). Beyond recidivism: Assessing change in incarcerated women--challenges and rewards. Paper presented at the meeting of the Academy of Criminal Justice Sciences, Orlando, FL.

Cohn, A. H., \& Daro, D. (1987). Is treatment too late? What ten years of evaluative research tell us. Child Abuse \& Neglect, 11, 433-442.

Daniels, J. W., \& Murphy, C. M. (1997). Stages and processes of change in batterers' treatment. Cognitive and Behavioral Practice, 4, 123-145.

DePanfilis, D., \& Zuravin, S. J. (1998). Rates, patterns, and frequency of child maltreatment recurrences among families known to CPS. Child Maltreatment, $3(1), 27-42$.

DiClemente, C. C., \& Hughes, S. O. (1990). Stages of change profiles in outpatient alcoholism treatment. Journal of Substance Abuse, 2 , 217-235.

DiClemente, C. C., \& Prochaska, J. O. (1982). Self-change and therapy change of smoking behavior: A comparison of processes of change in cessation and maintenance. Addictive Behaviors, $\underline{7}, 133-142$. 
DiClemente, C. C., Prochaska, J. O., \& Gibertini, M. (1985). Self-efficacy and the stages of self-change of smoking. Cognitive Therapy Research, $\underline{9}, 181-200$.

DiClemente, C. C., Prochaska, J. O., Fairhurst, S., Velicer, W. F., Velasquez, M. M., \& Rossi, J. S. (1991). The process of smoking cessation: An analysis of precontemplation, contemplation and preparation stages of change. Journal of Consulting and Clinical Psychology, 59, 295-304.

Fiore-Lerner, C. (1990). The Transtheoretical Model of change: Self-change in adolescent delinquent behaviors. Unpublished doctoral dissertation, University of Rhode Island, Kingston.

Gelles, R. J. (1996). The book of David: How preserving families can cost children's lives. New York: BasicBooks.

Gelles, R. J., Brown, J., Jones, L. M., \& Youngblood, J. (1997, June).

Compliance or change: Issues in risk assessment for abusive and neglectful parents using the Transtheoretical Model of Change. Paper presented at the meeting of the $5^{\text {th }}$ International Family Violence Research Conference, Durham, NH.

Janis, I. L., \& Mann, L. (1977). Decision making: A psychological analysis of conflict, choice and commitment. New York: Free Press.

Johnson, S. S. (1995). Profiles and predictors of compliance in oral contraceptive users. Unpublished master's thesis, University of Rhode Island.

Jones, D. P. H. (1987). The untreatable family. Child Abuse and Neglect, 11 , 409-420.

Kaufman, J., \& Zigler, E. F. (1996). Child abuse and social policy. In Zigler, E. F., Kagan, S. L., \& Hall, N. W. (Eds.), Children, families, and government: Preparing for the 21st century (pp. 233-255). New York: Cambridge University Press. 
Kelleher, K., Chaffin, M., Hollenberg, J, \& Fischer, E. (1994). Alcohol and drug disorders among physically abusive and neglectful parents in a communitybased sample. American Journal of Public Health, 84(10), 1586-1590.

Kolko, D. J. (1996). Child physical abuse. In J. Briere, L. Berliner, J. A. Bulkley, C. Jenny, \& T. Reid (Eds.), The APSAC handbook on child maltreatment (pp. 21-50). Thousand Oaks, CA: Sage.

Levesque, D. (1998). Violence desistance among battering men: Existing interventions and the application of the Transtheoretical Model of Change. Unpublished doctoral dissertation, University of Rhode Island, Kingston, Rhode Island.

Lung, C. T. \& Daro, D. (1996). Current trends in child abuse reporting and fatalities: The results of the 1995 annual fifty state survey. Chicago, IL: NCPCA.

Magura, S., \& Laudet, A. B. Parental substance abuse and child maltreatment: Review and implications for intervention. Children and Youth Services Review, 18(3), 193-220.

McConnaughy, E. A., DiClemente, C. C., Prochaska, J. O. \& Velicer, W. F. (1989). Stages of change in psychotherapy: A follow-up report. Psychotherapy, 4 , 494-503.

McConnaughy, E. A., Prochaska, J. O., and Velicer, W. F. (1983). Stages of change in psychotherapy: Measurement and sample profiles. Psychotherapy, $\underline{3}, 368-375$.

Morton, T. D., \& Holder, W. (Eds.). (1997). Decision making in children's protective services: Advancing the state of the art. Atlanta, GA: Child Welfare Institute.

Murphy, C. M., \& Baxter, V. A. (1997). Motivating batterers to change in the treatment context. Journal of Interpersonal Violence, 12(4), 607-619. 
National Research Council. (1993). Understanding child abuse and neglect. Washington, D. C.: National Academy Press.

National Research Council. (1998). Violence in families: Assessing prevention and treatment programs. Washington, D. C.: National Academy Press.

Oates, R. K. \& Bross, D. C. (1995). What have we learned about treating child physical abuse? A literature review of the last decade. Child Abuse \& Neglect, 19(4), 463-473.

O'Connell, D., \& Velicer, W. F. (1988). A decisional balance measure and the stages of change model for weight loss. The International Journal of the Addictions, $\underline{23}$, 729-750.

Pelton, L. H. (1997). Child welfare policy and practice: The myth of family preservation. American Journal of Orthopsychiatry, 67(4), 545-553.

Prochaska, J. O. (1994). Strong and weak principles for progressing from Precontemplation to Action on the basis of twelve problem behaviors. Health Psychology, 13 (1), 47-51.

Prochaska, J. O., \& DiClemente, C. C. (1982). Toward a more integrative model of change. Psychotherapy: Theory, Research, and Practice, 19, 276-288.

Prochaska, J. O., \& DiClemente, C. C. (1983a). Stages and processes of selfchange of smoking: Toward an integrative model of change. Journal of Consulting and Clinical Psychology, 51(3), 390-395.

Prochaska, J. O., \& DiClemente, C. C. (1983b). Transtheoretical therapy: Toward a more integrative model of change. Psychotherapy: Theory, Research, and Practice, 20, 161-173.

Prochaska, J. O., \& DiClemente, C. C. (1984). The Transtheoretical approach: Crossing traditional boundaries of therapy. Howewood, $\mathrm{IL}$ : Dow JonesIrwin. 
Prochaska, J. O., \& DiClemente, C. C. (1986). The Transtheoretical approach. In J. Norcross (Ed.), Handbook of eclectic psychotherapy. New York: Brunner/Mazel.

Prochaska, J. O., \& DiClemente, C. C. (1992). Stages of change in the modification of problem behaviors. In M. Hersen, R.M. Eisler \& P.M. Miller (Eds.), Progress on Behavior Modification. Sycamore, IL: Sycamore Press.

Prochaska, J. O., DiClemente, C. C., \& Norcross, J. C. (1992). In search of how people change: Applications to addictive behaviors. American Psychologist, 47(9), 1102-1114.

Prochaska, J. O., DiClemente, C. C, Velicer, W. F., Ginpil, S. E., \& Norcross, J. C. (1985). Predicting change in smoking status for self-changers. Addictive Behaviors, 10 , 395-406.

Prochaska, J. O., Norcross, J. C., \& DiClemente, C. C. (1994). Changing for good. New York: Morrow.

Prochaska, J. O., \& Velicer, W. F. (1997). The Transtheoretical Model of health behavior. American Journal of Health Promotion, 12, 38-48.

Prochaska, J. O., Velicer, W. F., Guadagnoli, E., Rossi, J. S., \& DiClemente, C. C. (1991). Patterns of change: Dynamic typology applied to smoking cessation. Multivariate Behavioral Research, 26, 83-107.

Prochaska, J.O., Velicer, W.F., Rossi, J.S., Goldstein, M., Marcus, B.H., Rakowski, W., Fiore, C., Harlow, L., Redding, C., Rosenbloom, D., \& Rossi, S.R. (1994). Stages of change and decisional balance for twelve problem behaviors. Health Psychology, 13, 39-46.

Rossi, J. S., \& Blais, L. M. (1991, March). The pros and cons of using sunscreens. Paper presented at the $12^{\text {th }}$ annual meeting of the Society of Behavioral Medicine, Washington, DC. 
Rossi, S. R. (1993). Application of the Transtheoretical Model of behavior change to dietary fat reduction in a naturalistic environment. Unpublished doctoral dissertation. University of Rhode Island, Kingston, RI.

Schellenbach, C. J. (1998). Child maltreatment: A critical review of research on treatment for physically abusive parents. In P. K. Trickett and C. J. Schellenbach (Eds.), Violence Against Children in the Family and the Community (pp. 251-268). Washington D.C: American Psychological Association.

Tsoh, J. Y. (1995). Stages of change, dropouts, and outcome in substance abuse treatment. Unpublished doctoral dissertation, University of Rhode Island.

U.S. Department of Health and Human Services, Children's Bureau. (1994). National study of protective, preventive, and reunification services delivered to children and their families. Washington DC: U.S. Government Printing Office.

Velicer, W. F., DiClemente, C. C., Prochaska, J. O., \& Brandenburg, N. (1985). A decisional balance measure for predicting smoking cessation. Journal of Personality and Social Psychology, 48, 1279-1289.

Wang, C. T., \& Daro, D. (1998). Current trends in child abuse reporting and fatalities: The result of the 1997 annual fifty state survey. Chicago, $\mathbb{L}$ : National Committee to Prevent Child Abuse.

Willet, J. B., Ayoub, C. C., \& Robinson, D. (1991). Using growth modeling to examine systematic differences in growth: An example of change in the functioning of families at risk of maladaptive parenting, child abuse, or neglect. Journal of Consulting and Clinical Psychology, 59, 38-47.

Wilson, D. (1997). Emerging issues. In T. D. Morton and W. Holder (Eds.), Decision making in children's protective services: Advancing the state of the art (pp.192-206). Atlanta, GA: Child Welfare Institute. 
Wilson, D., \& Morton, T. D. (1997). Issues in CPS decision making. In T. D. Morton and W. Holder (Eds.), Decision making in children's protective services: Advancing the state of the art (pp.1-16). Atlanta, GA: Child Welfare Institute.

Wolfe, D. A., \& Wekerle, C. (1993). Treatment strategies for child physical abuse and neglect: A critical progress report. Clinical Psychology Review, 13, 473-50 


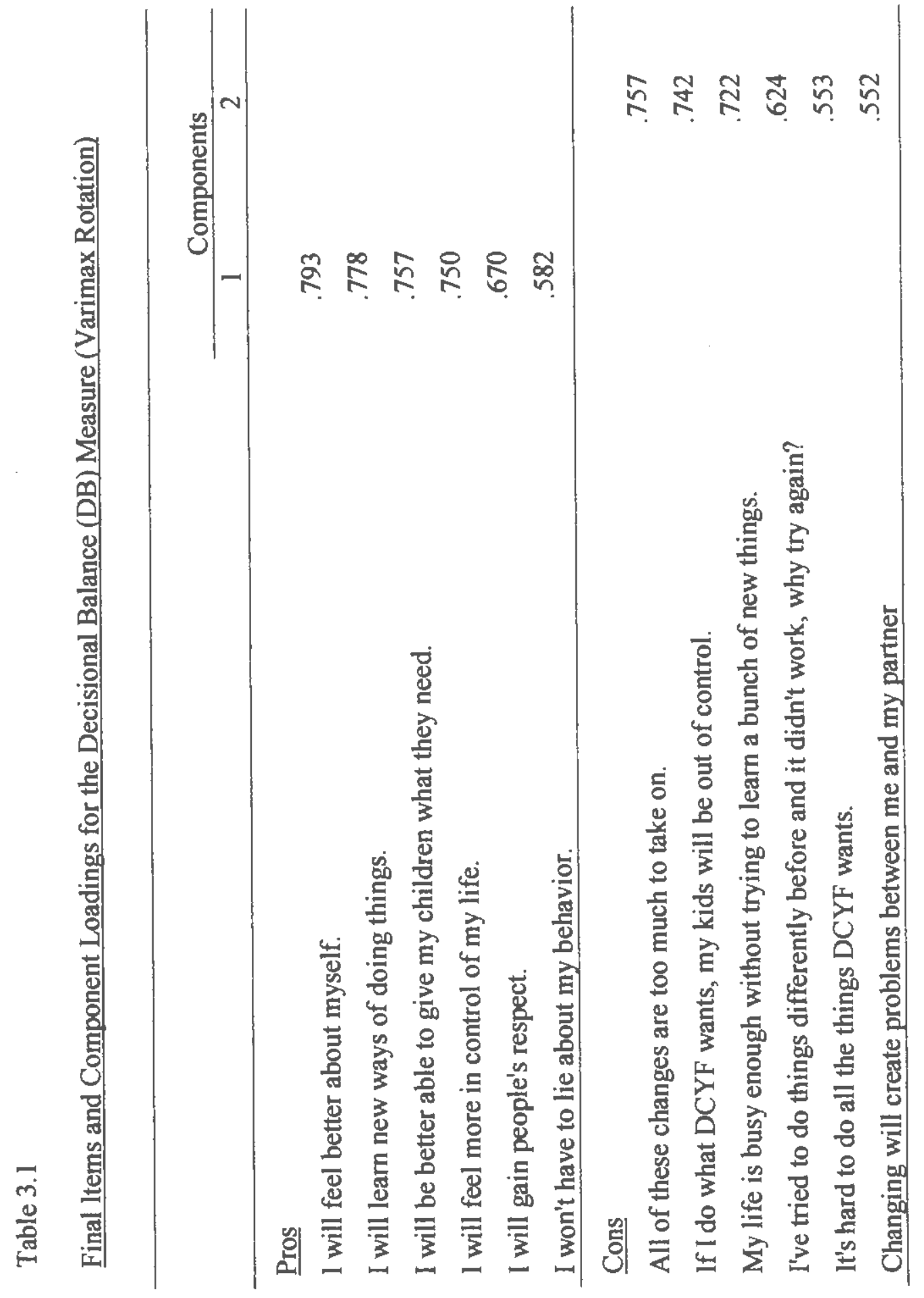




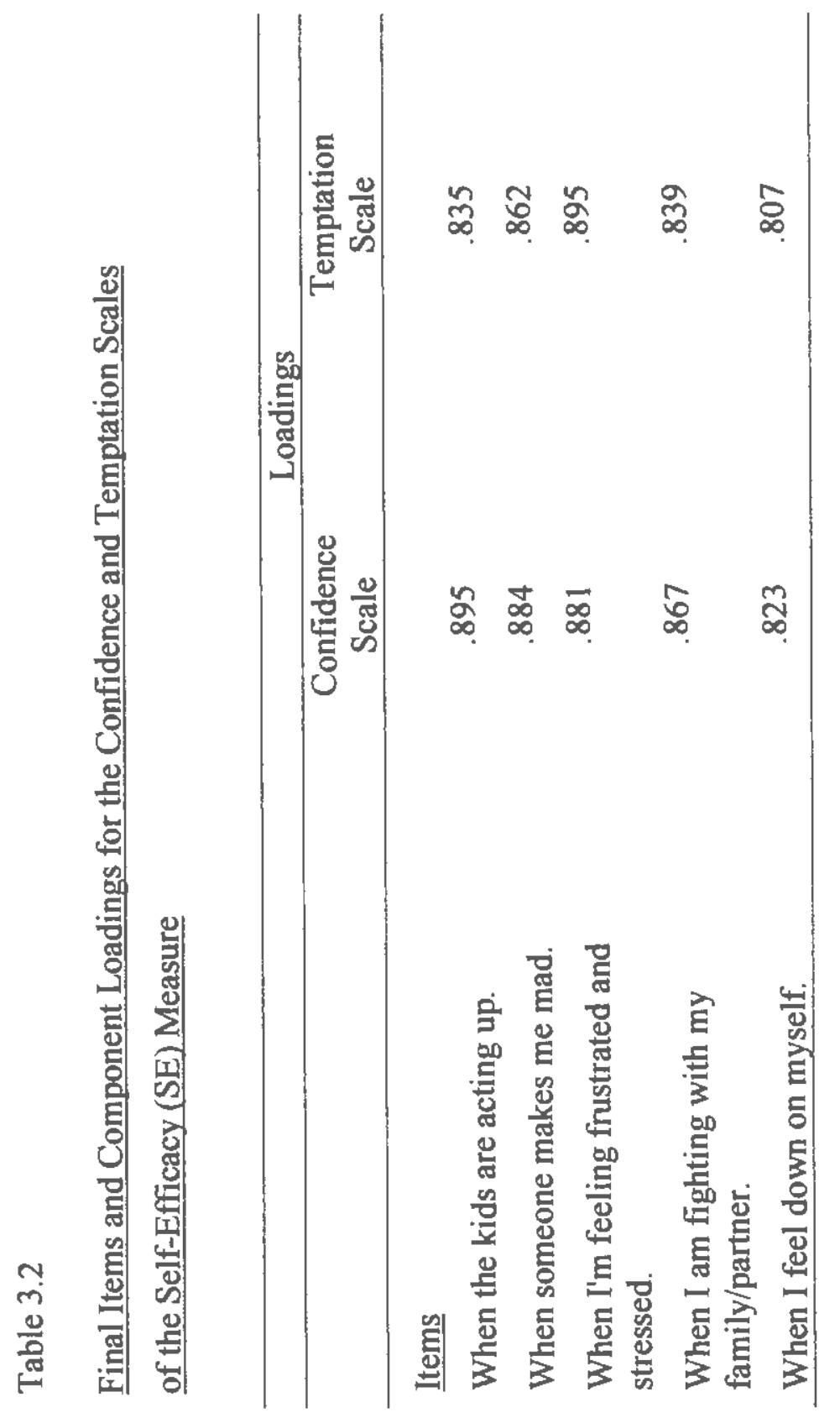




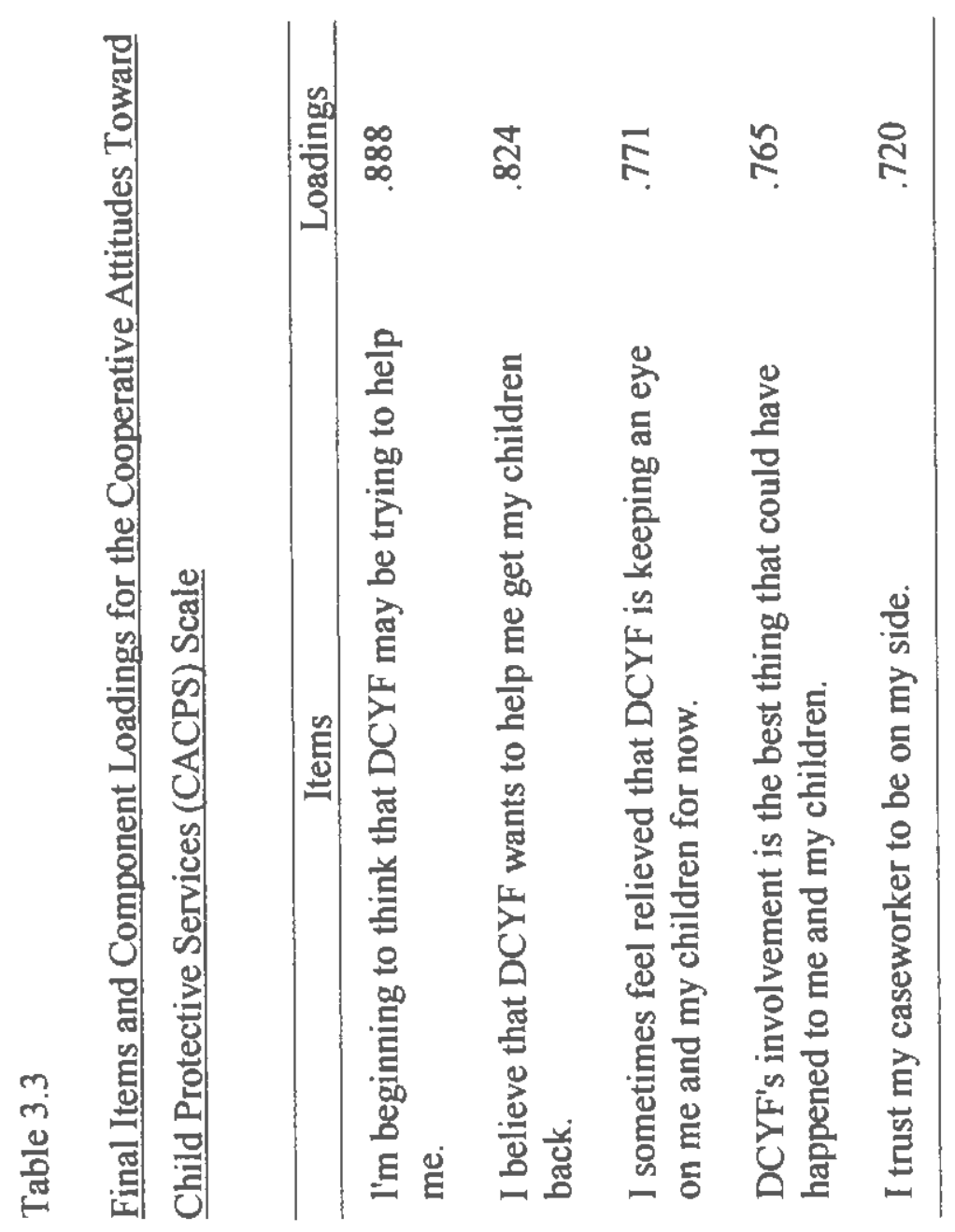




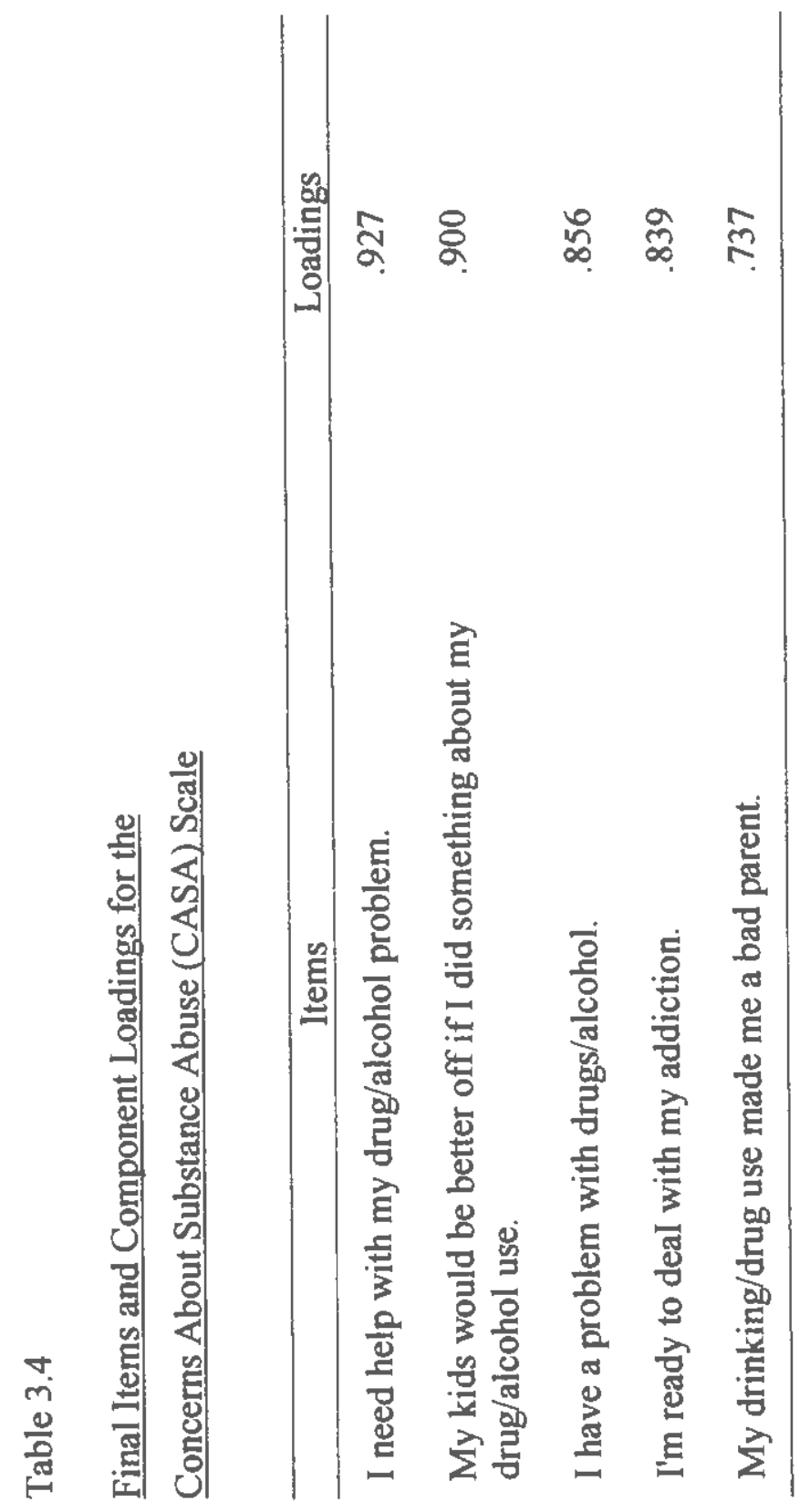




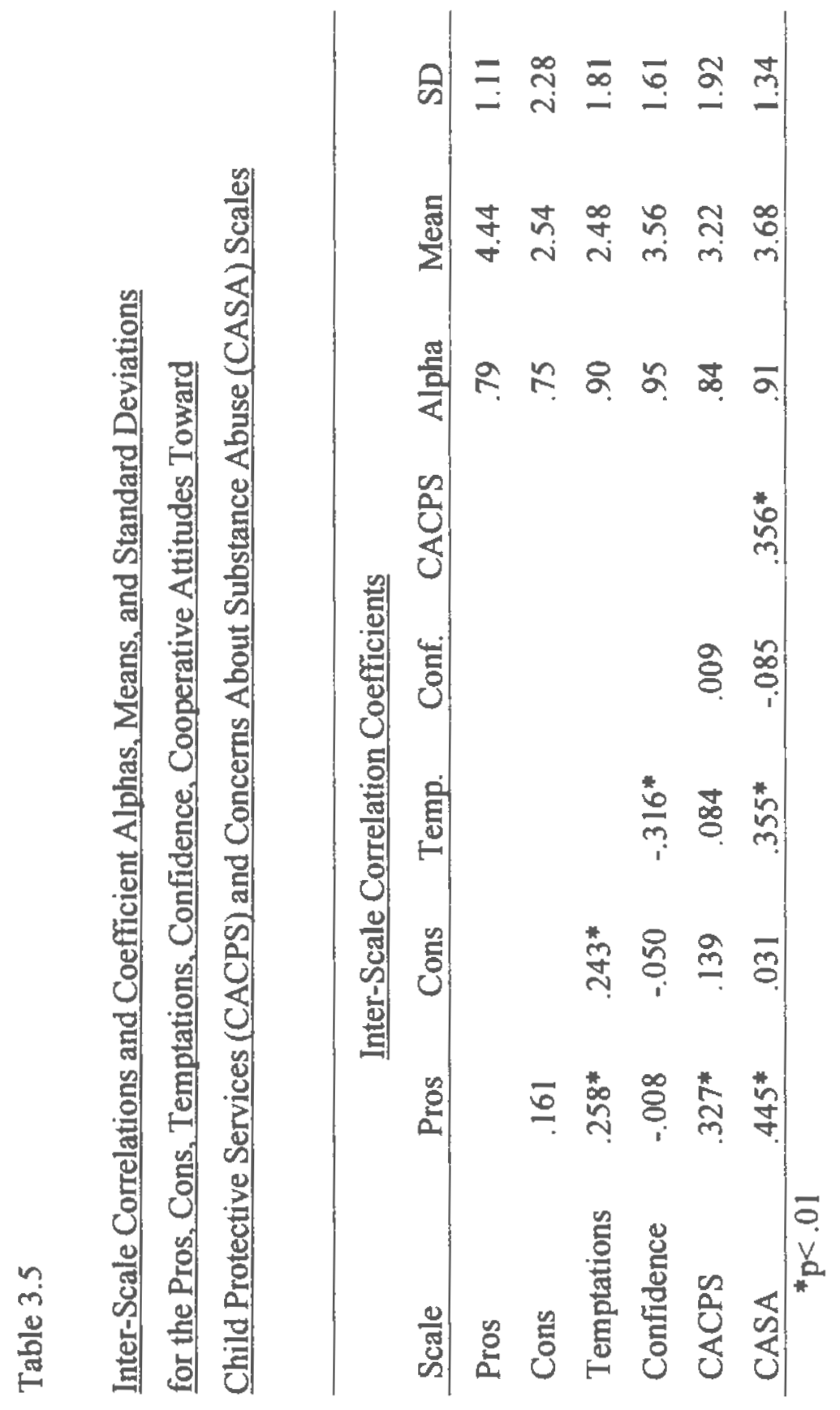




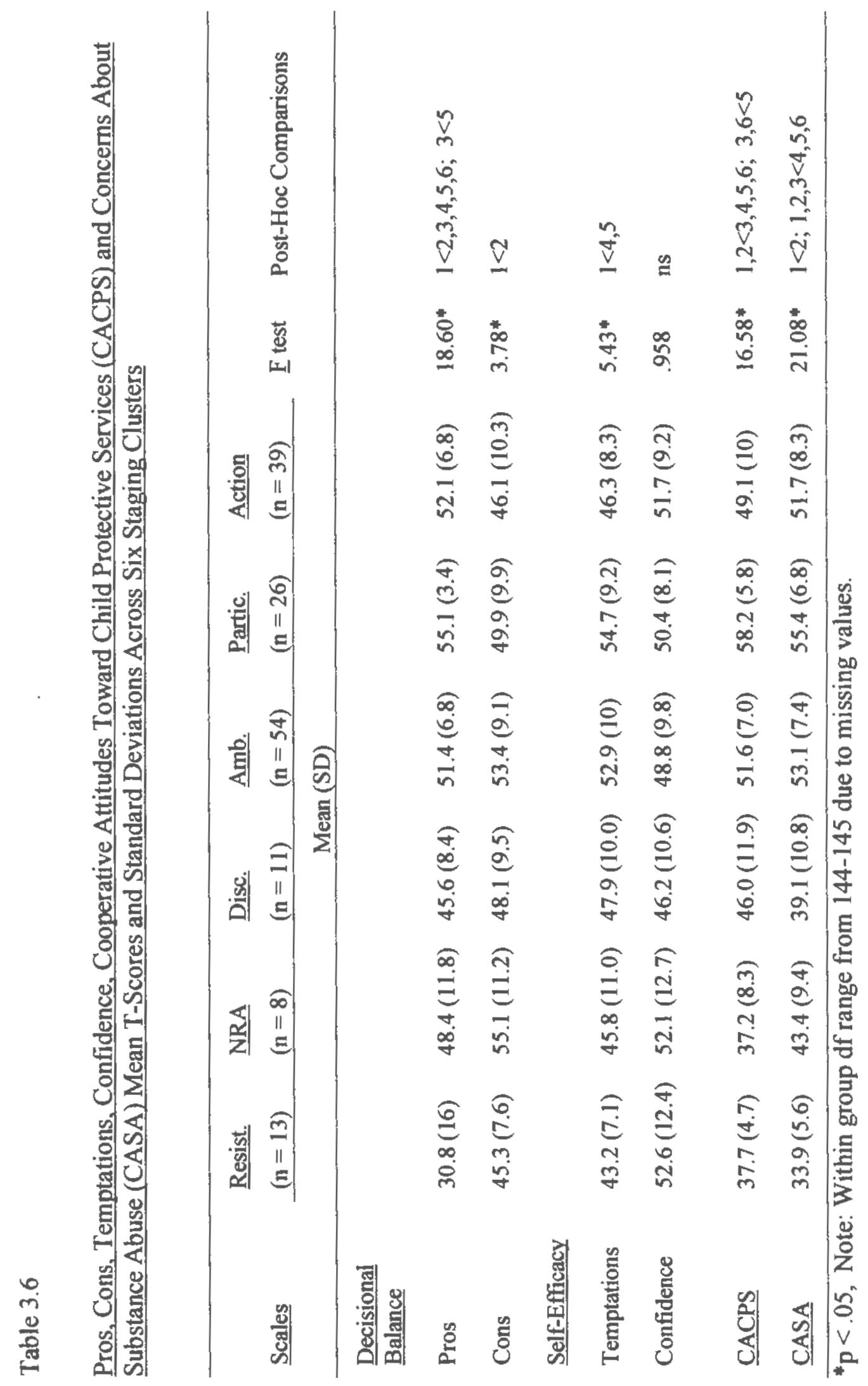




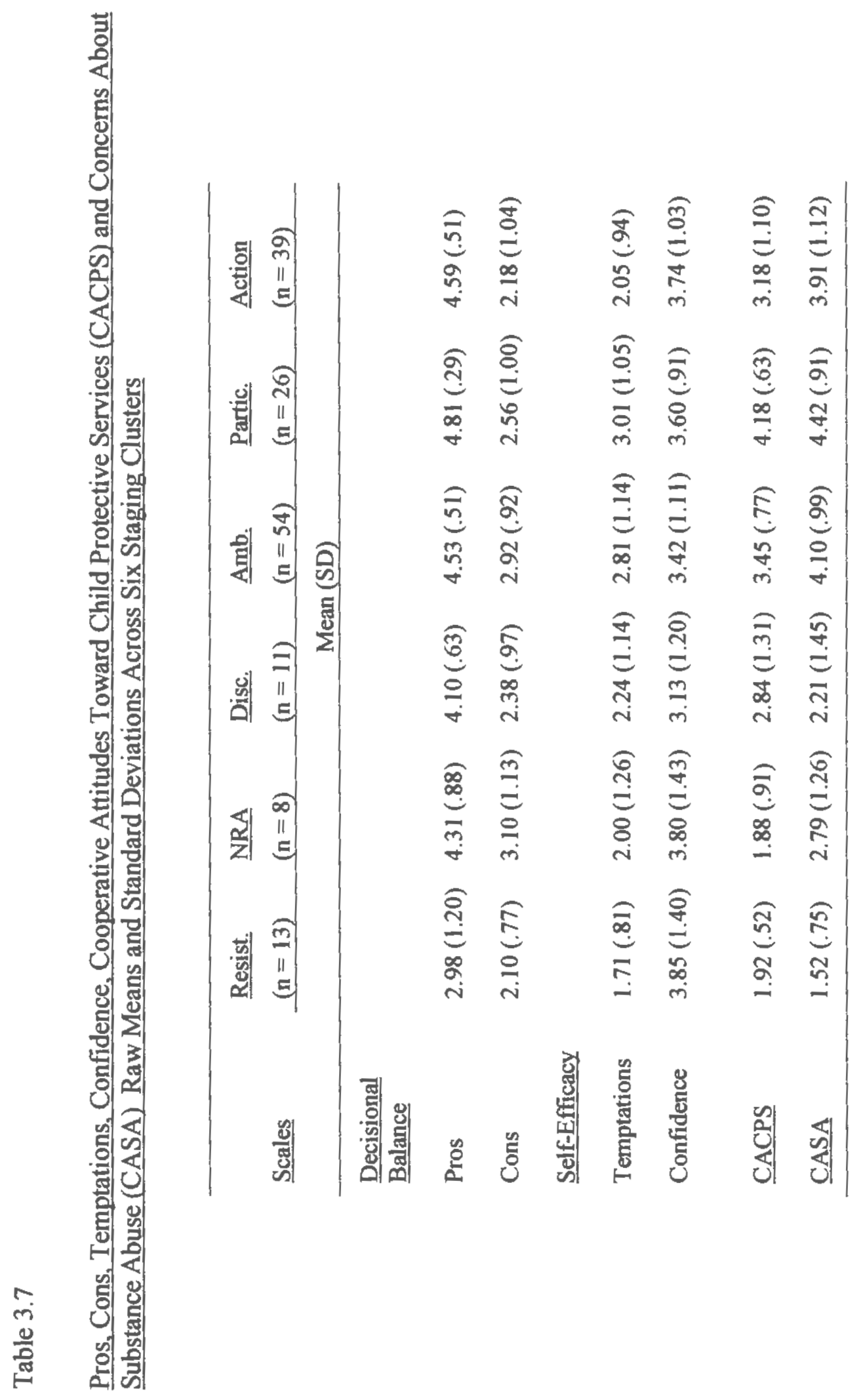


Figure 3.1

Mean profiles of six staging cluster groups

Resistant Cluster $(\mathbf{N}=13)$

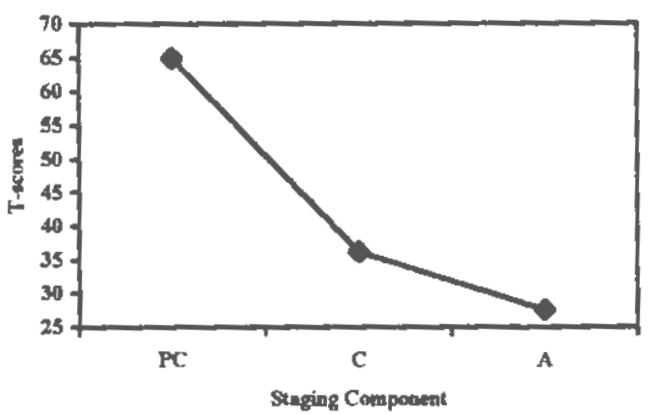

Discouraged Cluster $(\mathrm{N}=11)$

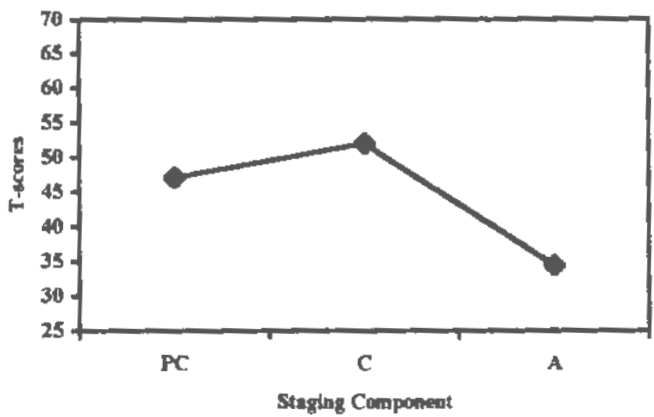

Participation Cluster $(N=26)$

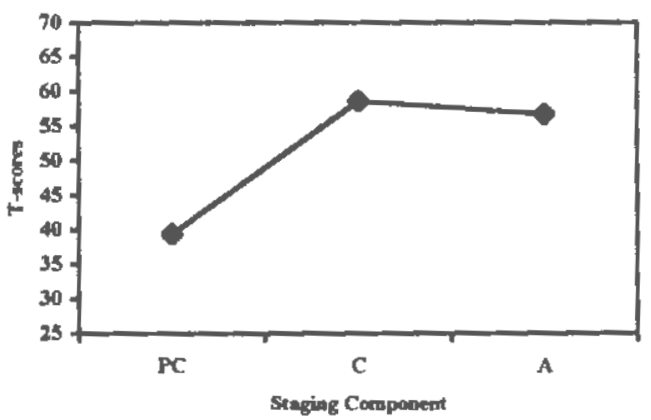

Non-Reflective Action $(\mathrm{N}=8)$

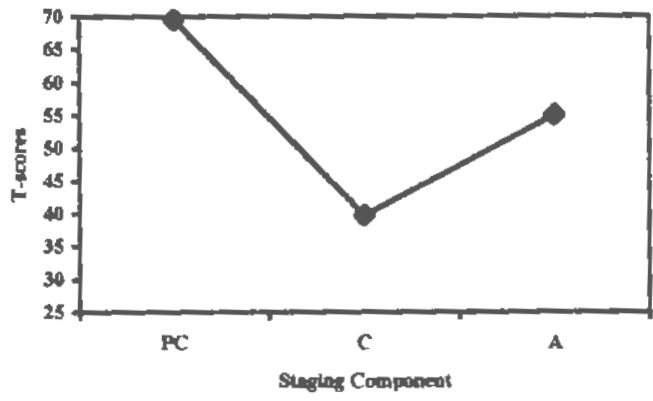

Ambkalent Cluster $(\mathrm{N}=54)$

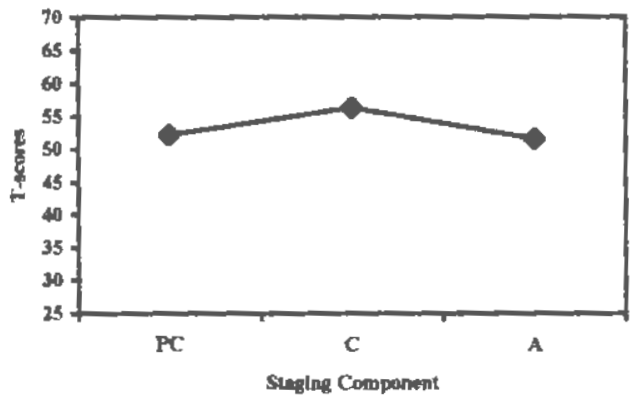

Action Cluster $(\mathrm{N} \neq 39$ )

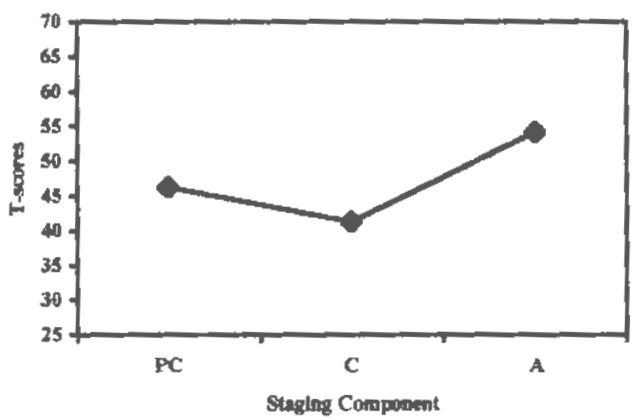




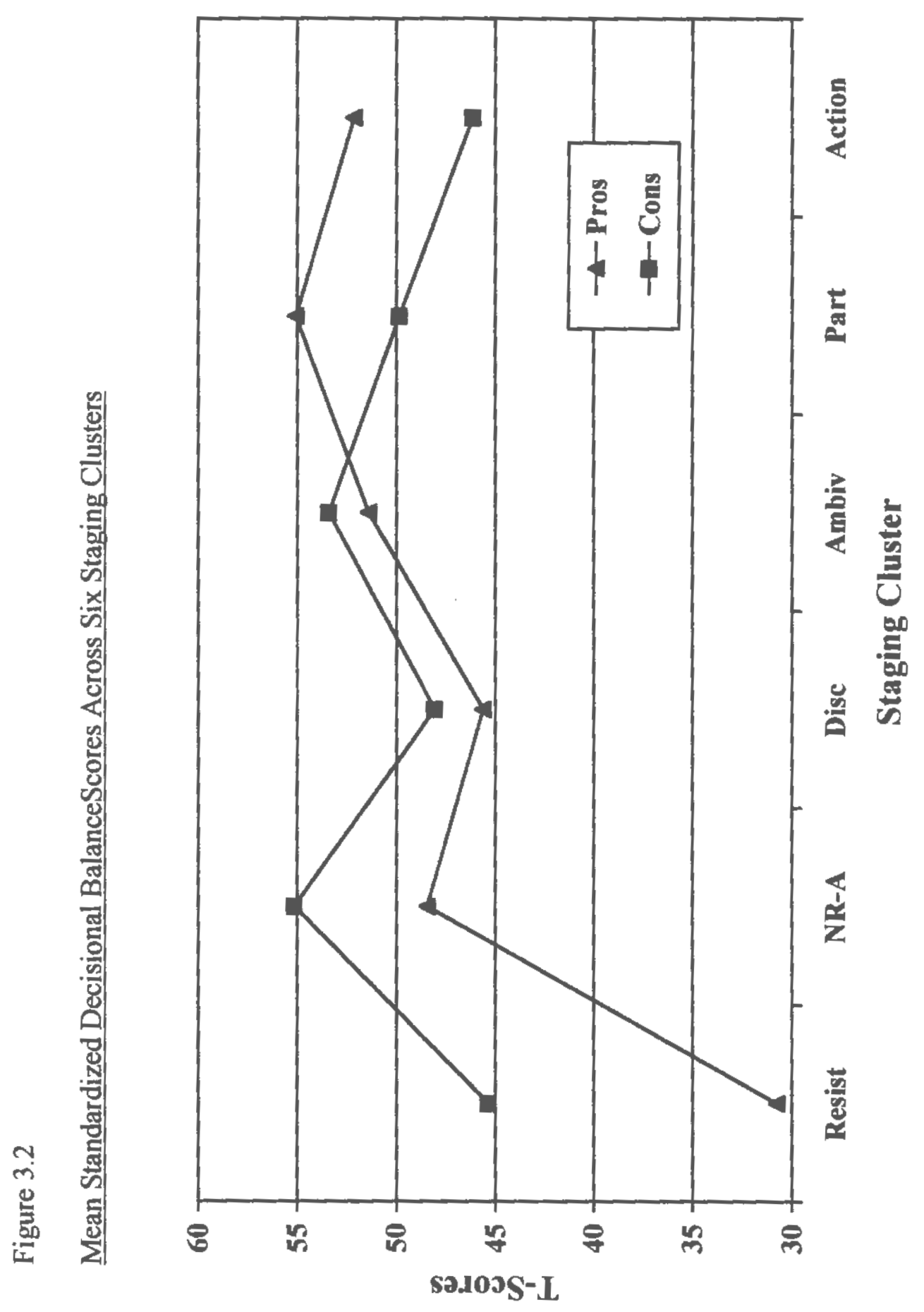




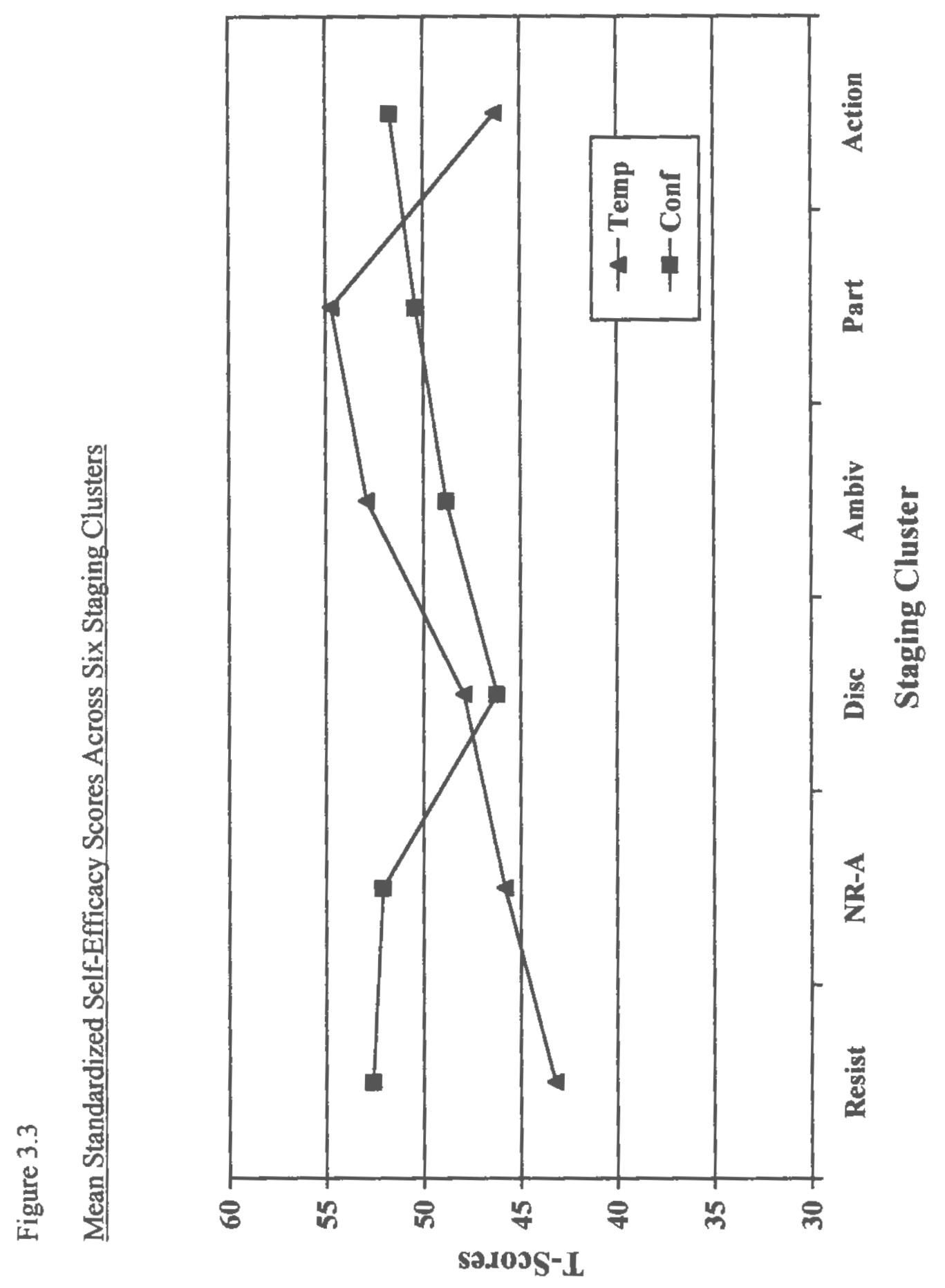




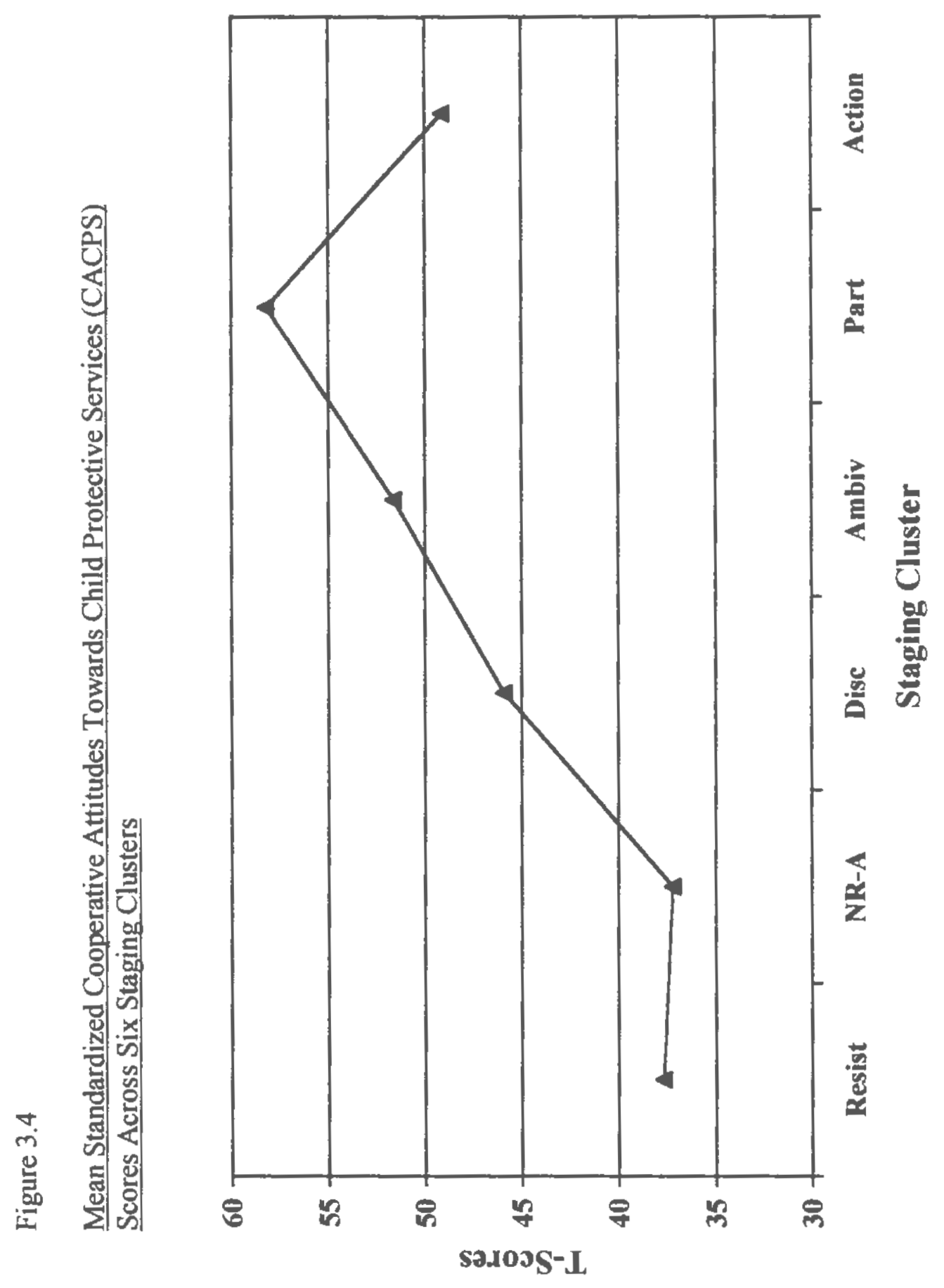




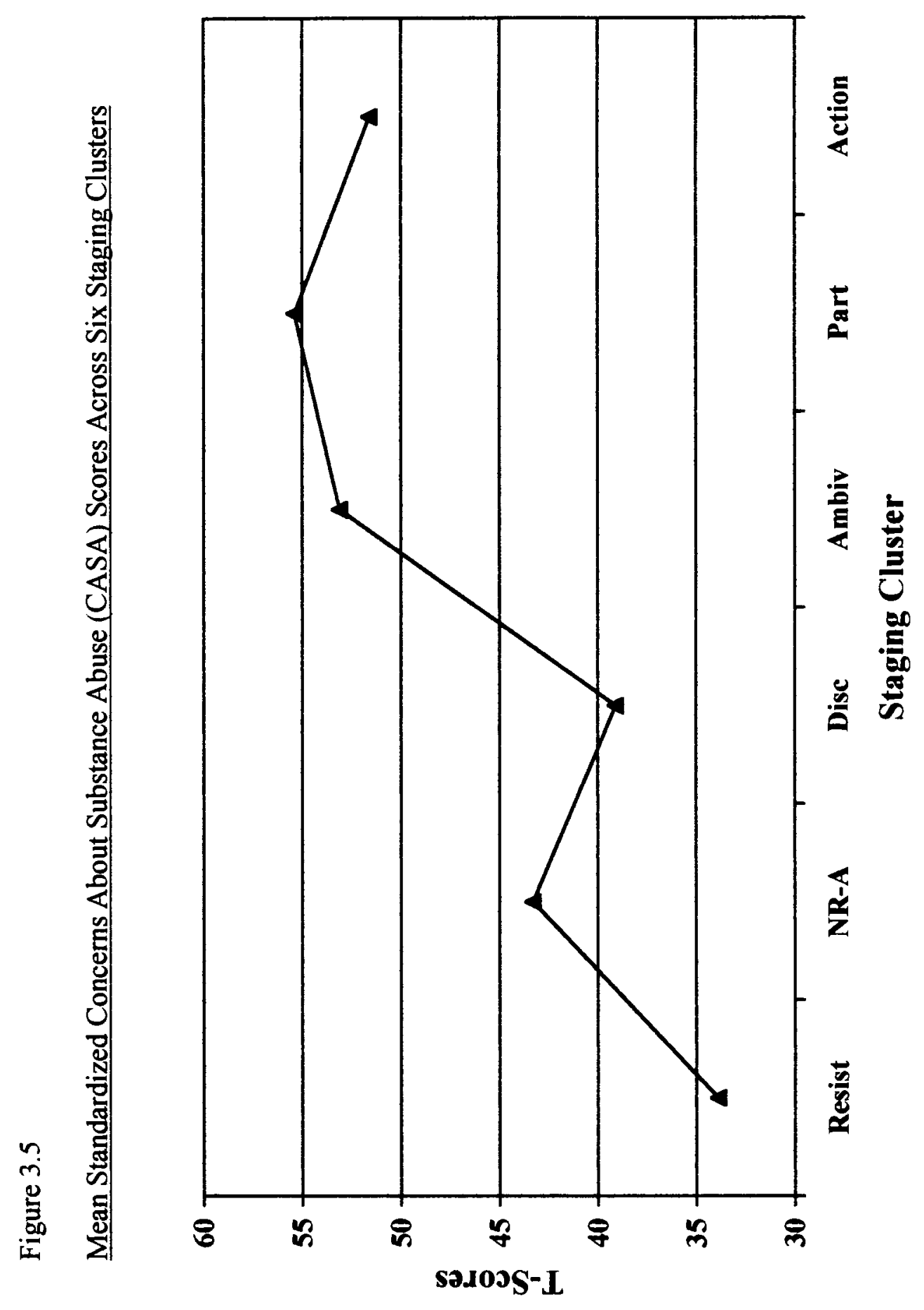




\section{CHAPTER 4}

Measuring Change in Maltreating Caregivers:

Conclusions and Recommendations 
The research that has been outlined in the previous three chapters has sought to make the case that too little is known about how abusive and neglectful caregivers make changes in their parenting behavior and in their lives. This lack of knowledge leaves an enormous hole in the decision-making and service delivery functions of the child protective system. Decisions are made daily about what kind of interventions to offer families, when services should be increased or decreased, when the caregiver has successfully made the necessary changes, and when the caregiver is unlikely to make these changes and the child needs to be permanently removed from the home. Given the lack of knowledge about how to assess change, these decisions are necessarily made in a subjective and haphazard manner.

The Transtheoretical Model of Change offers a theory-based model that can guide efforts to learn about and measure change in maltreating caregivers. The model has been effective in measuring the cognitive and behavioral aspects of change in many different problem areas, including behaviors, such as juvenile delinquency and domestic violence, that are comparable to child maltreatment in their dangerousness and complexity. The research presented in the preceding chapters has established initial support for the applicability of the Transtheoretical Model in the area of child maltreatment. 


\section{Summary of Findings}

One accomplishment of the research was the development and refinement of psychometrically sound instruments that are able to measure three of the model's constructs with maltreating caregivers, Stage of Change, Decisional Balance, and Self-Efficacy. The results from those instruments offer several interesting hypotheses about the process of change for this population:

1) The Stages of Change scale distinguished six subgroups of maltreating caregivers with different attitudes toward making changes in their behaviors. Three of the subgroups appeared to represent individuals who do not want to cooperate with child protective services and are not interested in making or able to make changes in their behavior. Another group seemed to be considering making changes but were also not sure that they could trust child protective services to help them. Two groups seemed to be actively making changes, one acknowledging greater fears about relapse and the other expressing fewer of these concerns.

2) These groups differed significantly in their consideration of the pros and the cons of making changes. They also experienced different levels of temptation to return to the behaviors that involved them with child protective services. These findings offer initial validation of the subgroups and yield further information about how different caregivers may be thinking about the changes that child protective services is asking them to make. 
3) Finally, in light of previous research with the model, the patterns of the group differences on the Decisional Balance and Self-Efficacy scales show support for the hypothesis that the caregiver subgroups can be ranked to represent an approximate range from least to most ready to make changes in their behavior.

\section{Recommendations for Future Research}

Interpretations based on the research must, at this point, be extremely tentative. The sample size was small and replication of the findings is a crucial next step. Follow-up studies are needed to confirm the psychometric properties of the instruments and replicate the staging groups and the relationships found among the constructs that were demonstrated with this initial sample. Additional questions will also need to be answered in order to fully understand the process of change in maltreating caregivers and the implications of the Transtheoretical Model for this population.

The "processes of change" is an important construct of the Transtheoretical Model that was not measured in the current study due to concerns about instrument length. This construct assesses differential use of a number of change strategies by individuals in different stages or staging groups. This information would be useful in examining the types of interventions being used by maltreating caregivers and the effectiveness of interventions for different subgroups of the population. Future research should also make efforts to classify maltreating caregivers into specific stages of change through algorithms. Algorithms have been used in many of 
applications of the model and offer a simpler scoring format. Results from an algorithmic method of staging could then be compared to staging groups found using the continuous Stage of Change measure.

More information is also needed on the relationship of other variables to stage of change. It would be useful to examine differences among staging groups on case-related variables such as the nature of the maltreatment charge, the number of past maltreatment incidents, and time since the case was opened. It would also be useful to understand differences in concurrent problems experienced by the caregivers such as substance abuse, domestic violence and mental health difficulties. Future research should also examine the relationship of social desirability to scores on the constructs of the Transtheoretical Model.

Finally, longitudinal research will also be needed to ensure that we can measure changes in maltreating caregivers over time. This would provide necessary validity information on the staging groups found in the current study. Longitudinal research would also be important in testing the hypothesis that caregivers in different stages show differential responses to treatment.

Implications for Policy and Intervention

Although results need to be replicated and further research needs to be completed, the findings of the current study have major implications for decisionmaking, service delivery, and treatment evaluation in the child protective service system. 
Decision-making. Identifying subgroups of maltreating caregivers with different levels of readiness to change offers the possibility of more carefully structuring post-substantiation decisions by child protective agencies. If the subgroups represent different stages of change, they should theoretically demonstrate differing levels of amenability to treatment. Earlier groups might be less likely to respond to treatment, or they may respond at a pace that would not meet the safety and permanency needs of their children. Assessment of staging group membership could be combined with measures of severity of risk to form a two-dimensional risk assessment procedure. Reunification efforts would be contraindicated for those who presented a greater danger to their children and were uninterested or unable to make changes. Limited treatment resources could then be focused on those who indicated a greater readiness to make changes. Although it is likely that many of these factors are already being assessed informally by child protection workers, instruments like those developed in the current study offer the ability to quantify and objectify those decisions.

Service Delivery. The research findings also support the possibility that interventions could be targeted to those caregivers who were more likely to take advantage of them. Each of the subgroups of maltreating caregivers found using the preliminary Stage of Change measure are struggling with different issues. The earlier groups are dealing with a mistrust of child protective services and with the conviction that they do not have problems caring for their children. The later groups are struggling with a fear of relapse and the difficulty of keeping up the 
changes they are making. Targeting treatments to meet the needs of these groups makes better use of available resources and is likely to increase treatment efficacy.

Treatment Evaluation. Finally, assessments of change using the Transtheoretical Model could also aid in treatment evaluation. While reduced recidivism rates will always be the gold standard of treatment efficacy in the area of child maltreatment, they are a stringent standard. Due to the low base rate of maltreating behaviors, information on recidivism rates can only be accumulated with large groups over time. A more immediate goal of an intervention program might be to move its participants to a more advanced stage of change. Treatment efficacy could be partially demonstrated by showing an improvement over control groups in the number of individuals who improve their readiness to make changes.

Although the application of the Transtheoretical Model of Change to this area is only preliminary, it offers an initial attempt to better understand the process of change in caregivers who maltreat their children. An increased understanding of change could translate into better decision-making and service provision by the agencies that have been set up to assist these caregivers and evaluate their progress. Prevention programs are needed to reduce the numbers of children that are endangered by the abusive and neglectful behaviors of the adults responsible for their care, but many children will continue to need the intervention of their community and state to protect them from harm. The challenge for each community is to identify these children and their caregivers, offer effective strategies for change to those who are likely to take advantage of them, and remove 
those children from caregivers who are not able to do so. It should be the goal of researchers in this field to help the system designed to tackle these tasks perform more accurately, more smoothly, and more consistently. The results of the current study represent a preliminary step toward such a goal. 


\section{APPENDIX A}

ID \#:

Source :

\section{INTRODUCTION}

The following questionnaire is part of a study that is trying to understand how parents feel about making the changes that DCYF is asking them to make. You will be asked questions about how you feel about making changes in your life and in how you care for your children. We want to learn more about how you feel and what's important to you. Please read through the following questions and choose how you feel right now, based on your experiences with DCYF.

This questionnaire may take about 30 minutes to complete. Some parents will complete it more quickly; for others, it may take longer. We strongly appreciate your participation.

Thank you for your time and your help.

\section{Background Questions:}

1. How old are you? years old

2. Are you....? Male Female

3. Is your case with DCYF currently...? Open Closed

4. Are you currently employed? (Choose from the responses below.)

No $\quad \underline{\text { Yes }}$

Employed full-time

$0 \quad 1$

Employed part-time

0

In the military

0

Unemployed and looking for work

0

Retired and not working

A student

A homemaker

Something else 
5. What is the highest level of education you have completed?

$\begin{array}{ll}\text { No schooling } & 1 \\ \text { 1st-8th grade } & 2 \\ \text { Some high school } & 3 \\ \text { High school graduate } & 4 \\ \text { Some college } & 5 \\ \text { 4 year college degree(BA/BS) } & 6 \\ \text { Post graduate } & 7\end{array}$

6. Which of the following categories best describes your racial background?

$\begin{array}{ll}\text { American Indian or Alaskan Native } & 1 \\ \text { Asian or Pacific Islander } & 2 \\ \text { Black or African American } & 3 \\ \text { Mixed Race } & 4 \\ \text { White } & 5\end{array}$

7. Are you of Hispanic origin?

$\begin{array}{ll}\text { Yes, Hispanic } & 1 \\ \text { Not Hispanic } & 2\end{array}$

8. Including yourself, how many persons 18 years of age and older live in your household?

$$
\text { number of adults in household }
$$

9. How many children under 18 years of age live in your household?

$$
\text { children }
$$

10. How many of your children under 18 years of age are currently in foster care or residential placement? children 
11. If any, how many of the children mentioned above are yours by birth or adoption?

children

12. If any, how old are these children, beginning with the oldest?

$$
\begin{aligned}
& \text { Age }-1 \text { st child } \\
& \text { Age }-2 \text { nd child } \\
& \text { Age }-3 \text { rd child } \\
& \text { Age - last child }
\end{aligned}
$$

13. Including income from all sources, such as work, child support, AFDC, how much income did you personally receive in 1996 before taxes?

$\begin{array}{ll}\text { Less than } \$ 10,000 & 1 \\ \$ 10,000-\$ 20,000 & 2 \\ \$ 20,000-\$ 35,000 & 3 \\ \$ 35,000-\$ 50,000 & 4 \\ \$ 50,000-\$ 80,000 & 5 \\ \text { over } \$ 80,000 & 6\end{array}$

14. During the last 12 months, how often did you usually drink alcoholic beverages, including beer, light beer, wine, wine coolers, or liquor?

$\begin{array}{ll}\text { Every day } & 1 \\ \text { Nearly every day } & 2 \\ \text { Three or four days a week } & 3 \\ \text { One or two days a week } & 4 \\ \text { Two or three days a month } & 5 \\ \text { Once a month or less } & 6 \\ \text { Never } & 7\end{array}$

15. How many drinks did you average on the days that you drank alcoholic beverages? [One drink is a can of beer, a 4-ounce glass of wine, a wine-cooler, or an ounce of whiskey.] alcoholic beverages 
16. From the following list of drugs, please mark if you have used any of these drugs in the past month. (Please remember that all information is anonymous and will be kept strictly confidential.)

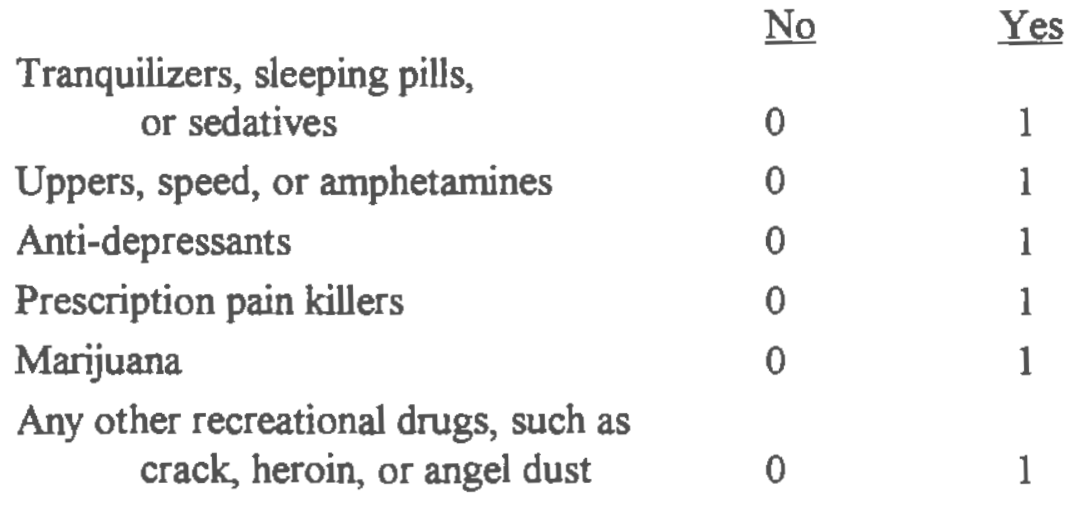

17. Which of the following best describes your current relationship? Are you currently....?

$\begin{array}{ll}\text { Married } & 1 \\ \text { Common-law relationship } & 2 \\ \text { Divorced } & 3 \\ \text { Separated } & 4 \\ \text { Widowed } & 5 \\ \text { Single, never married } & 6 \\ \text { Living together } & 7\end{array}$

If you have a current partner please answer 18-22, otherwise turn to page 6 .

18. How would you describe your current partner's current employment situation?

Employed full-time
Employed part-time
In the military
Unemployed and looking for work
Retired and not working
A student
A homemaker
Something else

$\begin{array}{ll}\frac{\text { No }}{0} & \frac{\text { Yes }}{1} \\ 0 & 1 \\ 0 & 1 \\ 0 & 1 \\ 0 & 1 \\ 0 & 1 \\ 0 & 1 \\ 0 & 1\end{array}$


19. Including income from all sources, such as work, child support, AFDC, how much income did you current partner personally receive in 1995 before taxes?

$\begin{array}{ll}\text { Less than } \$ 10,000 & 1 \\ \$ 10,000-\$ 20,000 & 2 \\ \$ 20,000-\$ 35,000 & 3 \\ \$ 35,000-\$ 50,000 & 4 \\ \$ 50,000-\$ 80,000 & 5 \\ \text { over } \$ 80,000 & 6\end{array}$

20. During the last 12 months, how often did your current partner usually drink any alcoholic beverages, including beer, light beer, wine, wine coolers, or liquor?

$\begin{array}{ll}\text { Every day } & 1 \\ \text { Nearly every day } & 2 \\ \text { Three or four days a week } & 3 \\ \text { One or two days a week } & 4 \\ \text { Two or three days a month } & 5 \\ \text { Once a month or less } & 6 \\ \text { Never } & 7\end{array}$

21. How many drinks did your partner average on the days that $s /$ he drank alcoholic beverages? alcoholic beverages

22. From the following list of drugs, please mark if your partner has used any of these drugs in the past month. (Please remember that all information is anonymous and will be kept strictly confidential.)

Tranquilizers, sleeping pills,

No $\quad \underline{\text { Yes }}$

or sedatives

$0 \quad 1$

Uppers, speed, or amphetamines $\quad 0 \quad 1$

Anti-depressants $\quad 0 \quad 1$

Prescription pain killers $\quad 0 \quad 1$

Marijuana

$0 \quad 1$

Any other recreational drugs, such as crack, heroin, or angel dust 


\section{MAKING CHANGES}

Please answer the following questions based on your experiences with DCYF. Circle the number that represents HOW MUCH YOU AGREE OR DISAGREE with each of the following statements.

Please circle the number that best describes how much you agree or disagree with each statement RIGHT NOW.

$\begin{array}{ll}\text { Strongly Agree } & 5 \\ \text { Agree } & 4 \\ \text { Undecided/Neutral } & 3 \\ \text { Disagree } & 2 \\ \text { Strongly Disagree } & 1\end{array}$

1. I have done nothing wrong: DCYF should get out of my life.

2. I am beginning to realize that I take my frustration out on my children.

3. I have a problem with drugs/alcohol.

4. Parenting groups are a waste of time.

5. I'm ready to deal with my addiction.

6. I'm starting to think that I need more information about taking care of my kids.

7. My kids deserve more of my time than I have given them.

8. I may be part of the problem but I don't really think I am.

9. I realize that all I ever thought about was me, not my children.

10. I need a boost right now to help me maintain the changes that I have already made.

11. I'm trying out the suggestions that I have gotten from groups/meetings.

12. I am not the problem, DCYF is the problem.

13. I feel scared to be making such major changes in the way I live my life.

14. I'm starting to think I have some problems I need to work on.

15. I sometimes worry that I will fall back on old behaviors when DCYF is out of my life.

16. There are a lot of things I need to change about myself.

17. It's my kids who need to change, not me.

18. I'm starting to think maybe I can trust my caseworker more than I thought. 


\section{MAKING CHANGES (cont.)}

Please answer the following questions based on your experiences with DCYF. Circle the number that represents HOW MUCH YOU AGREE OR DISAGREE with each of the following statements.

Please circle the number that best describes how much you agree or disagree with each statement RIGHT NOW.

$\begin{array}{ll}\text { Strongly Agree } & 5 \\ \text { Agree } & 4 \\ \text { Undecided/Neutral } & 3 \\ \text { Disagree } & 2 \\ \text { Strongly Disagree } & 1\end{array}$

19. I am working to repair the damage I have done to others.

20. I am doing something about the problems that had been bothering me.

21. I have started to wonder how other parents handle discipline.

22. DCYF should leave me alone, there are a lot of people who do worse things.

23. I trust my caseworker to be on my side.

24. I've made a lot of progress dealing with my addiction.

25. My drinking/drug use made me a bad parent.

26. It might be worthwhile to work on my problems.

27. It worries me that I might slip back on problems I have already changed, so I am ready to work on my problems.

28. As long as the kids have food and shelter, it's no one's business what I do.

29. I really want to change but I need help.

30. I'm beginning to think I may have a problem with drugs/alcohol.

31. Someone's out to get me, that's how come I got reported.

32. I thought that once I had resolved my problems, I would be free of them, but sometimes I find myself still struggling with them.

33. DCYF's involvement is the best thing that could have happened to me and my children.

34. I guess I have faults but there's nothing that I really need to change.

35. I've been thinking that I might want to change something about myself. 


\section{MAKING CHANGES (cont.)}

Please answer the following questions based on your experiences with DCYF. Circle the number that represents HOW MUCH YOU AGREE OR DISAGREE with each of the following stalements.

Please circle the number that best describes how much you agree or disagree with each statement RIGHT NOW.

$\begin{array}{ll}\text { Strongly Agree } & 5 \\ \text { Agree } & 4 \\ \text { Undecided/Neutral } & 3 \\ \text { Disagree } & 2 \\ \text { Strongly Disagree } & 1\end{array}$

36. Even now, I sometimes have to resist memories of the "good times" with drugs/alcohol.

37. I don't like going to meetings because those people are different from me.

38. I'm starting to think I could use some help with my drinking/drug use.

39. I am finally doing some work on my problems.

40. My case worker is the problem, not me.

41. Despite how I grew up, I need to do things differently.

42. I'm working to prevent myself from having a relapse.

43. I'm beginning to think that when I drink/use drugs I am not a good parent.

44. My past behaviors were dangerous to my children.

45. I tell the workers what they want to hear so I can get my kids back.

46. I believe that DCYF wants to heip me get my kids back.

47. I think I might be ready for some self-improvement.

48. I really need help dealing with my kids.

49. Change has been slow, but when I look back I see how much I've done.

50. My kids would be better off if I did something about my drugs/alcohol use.

51. Anyone can talk about changing; I'm actually doing something about it.

52. All this talk about psychology is boring, why can't people just forget about their problems?

53. I've started to think that I haven't been caring for my kids as well as I can. 


\section{MAKING CHANGES (cont.)}

\section{Please answer the following questions based on your experiences with DCYF. Circte the number that represents HOW MUCH YOU AGREE OR DISAGREE with each of thefollowing statements.}

Please circle the number that best describes how much you agree or disagree with each statement RIGHT NOW.

$\begin{array}{ll}\text { Strongly Agree } & 5 \\ \text { Agree } & 4 \\ \text { Undecided/Neutral } & 3 \\ \text { Disagree } & 2 \\ \text { Strongly Disagree } & 1\end{array}$

54. I realize how much damage my past behavior has done to me and my children.

55. I need help with my drug/alcohol problem.

56. Working on my problems is pretty much a waste of time for me because the problems don't have to do with me.

57. After all I have done to try and change my problems, every now and then they come back to haunt me.

58. I realize that I have been putting my own needs before my children's.

59. I have problems and I really think I should work on them.

60. I'm beginning to think that DCYF may be trying to help me.

61. DCYF has no idea what is needed to make my kids listen and obey.

62. DCYF is not the problem, I'm the problem.

63. I've been thinking that these DCYF services may be helpful.

64. I sometimes feel relieved that DCYF is keeping an eye on me and my children for now.

65. DCYF has no right to tell me how to take care of my kids.

66. I'm not the problem one, it doesn't make much sense for me to be here.

67. I am actively working on my problems.

68. DCYF may be right when they say that some of my behaviors put my children in danger.

69. I may do what DCYF says but I'm not going to make things easy for them.

70. I know what my triggers are and I actively avoid them. 
PROS AND CONS

The statements below represent different opinions
about making the changes that DCYF is asking you to
make. Please circle the number that represents
HOW IMPORTANT each statement is to your decision
whether or not to make these changes.

How important are the following statements in YOUR DECISION to make the changes that DCYF wants?

$\begin{array}{ll}\text { Extremely Important } & 5 \\ \text { Very Important } & 4 \\ \text { Moderately Important } & 3 \\ \text { Slightly Important } & 2 \\ \text { Not Important } & 1\end{array}$

1. I will miss getting high.

2. I will get to keep my kids.

3. It's hard to do all the things DCYF wants.

4. I will feel better about myself.

5. I won't have to worry about getting in trouble with DCYF.

6. I will miss the people I hang out with.

7. My kids will benefit from the changes l've made.

8. I will have to learn to do things differently.

9. I won't have to lie about my behavior.

10. Changing will create problems between me and my partner.

11. I will gain people's respect.

12. I've tried to do things differently before and it didn't work, why try again?

13. I will have to avoid some family and friends.

14. I will be a better parent.

15. I will learn new ways of doing things.

16. All these changes are too much to take on. 


\section{PROS AND CONS (cont.)}

The statements below represent different opinions about making the changes that DCYf is asking you to make. Please circle the number that repiesents HOW MPORTANT each statement is to your decision whether or not to make these changes

How important are the following statements in YOUR

DECISION to make the changes that DCYF wants?

Extremely Important

5

Very Important

4

Moderately Important

3

Slightly Important

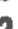

Not Important

1

17. If I do what DCYF wants, my kids will be out of control.

18. I will be better able to give my children what they need.

19. My life is busy enough without trying to learn a bunch of new things.

20. I will feel more in control of my life. 


\section{TEMPTING SITUATIONS}

Listed below are situations that tempt some people to continue with or retum to behaviors that led to DCYF involvement. Please circle the number that represents HOW TEMPTED you may be to retum to such behaviors in each situation.

\section{How tempted would YOU be in each situation to continue with or return to behaviors that led to DCYF involvement?}

$\begin{array}{ll}\text { Extremely Tempted } & 5 \\ \text { Very Tempted } & 4 \\ \text { Moderately Tempted } & 3 \\ \text { Not Very Tempted } & 2 \\ \text { Not at all Tempted } & 1\end{array}$

1. When I feel all alone in the world.

2. When the kids are acting up.

3. When l'm around my old friends.

4. When someone makes me mad.

5. When the kids don't listen to me.

6. When I'm visiting my old neighborhood.

7. When I feel like nothing I do will make a difference.

8. When I remember the high I felt from drinking/doing drugs.

9. When I'm feeling frustrated and stressed.

10. When I am fighting with my family/partner.

11. When I feel down on my self.

12. When I'm feeling overwhelmed.

13. When l'm celebrating or rewarding myself. 
CONFIDENCE IN TEMPTING SITUATIONS

Listed below are situations that tempt some people to continue with or return to behaviors that led to DCYF involvement. Please circle the number that represents HOW SURE you are that you could resist those behaviors in each of the following situations.

How sure are you that you could resist the behaviors that led to DCYF involvement in each situation?

\section{Extremely Sure}

Very Sure

Moderately Sure

Not Very Sure

Not at all Sure
5

4

3

2

1

1. When I feel all alone in the world.

2. When the kids are acting up.

3. When I'm around my old friends.

4. When someone makes me mad.

5. When the kids don't listen to me.

6. When I'm visiting my old neighborhood.

7. When I feel like nothing I do will make a difference.

8. When I remember the high I felt from drinking/doing drugs.

9. When I'm feeling frustrated and stressed.

10. When I am fighting with my family/partner.

11. When I feel down on my self.

12. When I'm feeling overwhelmed.

13. When I'm celebrating or rewarding myself. 


\section{BIBLIOGRAPHY}

Aldenderfer, M. S., \& Blashfield, R. K. (1984). Cluster analysis. Beverly Hills, CA: Sage.

Bandura, A. (1977). Self-efficacy: Toward a unifying theory of behavior change. Psychological Review, 84, 191-215.

Barth, R. P. (1998). Abusive and neglecting parents and the care of their children. In M. A. S Mason, A. Skolnick, \& S. D. Sugarman (Eds.), All our families: New policies for a new century (pp. 217-235). New York: Oxford University Press.

Berkowitz, S. (1991). Findings from the state survey component of the study of high risk child abuse and neglect groups. Rockville, MA: Westat.

Berry, M. (1998). Adoption in an era of family preservation. Children and Youth Services Review, 20(1), 1-12.

Belsky, J. (1980). Child maltreatment: An ecological integration. American Psychologist, $\underline{35}, 320-335$.

Blashfield, R. K. (1980). Propositions regarding the use of cluster analysis in clinical research. Journal of Consulting and Clinical Psychology, 48(4), 456-459.

Bowdry, C. (1990). Toward a treatment-relevant typology of child abuse families. Child Welfare, 69(4), 333-340.

Brown, J. (1997). Working toward freedom from violence: The process of change in battered women. Violence Against Women, 3(1), 5-26. 
Brown, J. (1998, July). The process of change in abused women scale (PROCAWS): Stage of change, pros and cons, and self-efficacy as measurable outcomes. Paper presented at the Program Evaluation and Family Violence Research: An International conference, Durham, NH.

Brown, J., Varna Garis, A., \& Mitchell, K. (1999, March). Beyond recidivism: Assessing change in incarcerated women--challenges and rewards. Paper presented at the meeting of the Academy of Criminal Justice Sciences, Orlando, FL.

Cicchetti, D. (1996). Child maitreatment: Implications for developmental theory and research. Human Development, 39 , 18-39.

Cicchetti, D., \& Howes, P. W. (1991). Developmental psychopathology in the context of the family: Illustrations from the study of child maltreatment. Canadian Journal of Behavioural Science, 23(3), 257-281.

Cicchetti, D., \& Rogosch, F. A. (1994). The toll of child maltreatment on the developing child: Insights from developmental psychopathology. Child and Adolescent Psychiatric Clinics of North America, 3(4), 759-776.

Cicchetti, D., \& Toth, S. L. (1995). A developmental psychopathology perspective on child abuse and neglect. American Academy of Child and Adolescent Psychiatry, 34(5), 541-565.

Cohn, A. H., \& Daro, D. (1987). Is treatment too late? What ten years of evaluative research tell us. Child Abuse \& Neglect, 11, 433-442.

Crittenden, P. M. (1996). Research on maltreating families: Implications for intervention. In J. Briere, L. Berliner, J. A. Bulkley, C. Jenny, \& T. Reid (Eds.), The APSAC handbook on child maltreatment (pp. 158-174). Thousand Oaks, CA: Sage. 
Crittenden, P. M. (1998). Dangerous behavior and dangerous contexts: A 35-year perspective on research on the developmental effects of child physical abuse. In P. K. Trickett \& C. J. Schellenbach (Eds.), Violence Against Children in the Family and the Community (pp. 11-38). Washington D.C: American Psychological Association.

Daniels, J. W., \& Murphy, C. M. (1997). Stages and processes of change in

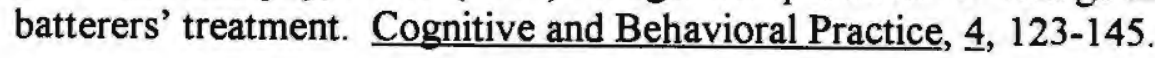

DePanfilis, D., \& Scannapieco, M. (1994). Assessing the safety of children at risk of maltreatment: Decision-making models. Child Welfare, 73(3), 229-245.

DePanfilis, D., \& Zuravin, S. J. (1998). Rates, patterns, and frequency of child maltreatment recurrences among families known to CPS. Child Maltreatment, 3(1), 27-42.

DiClemente, C. C., \& Hughes, S. O. (1990). Stages of change profiles in outpatient alcoholism treatinent. Journal of Substance Abuse, 2 , 217-235.

DiClemente, C. C., \& Prochaska, J. O. (1982). Self-change and therapy change of smoking behavior: A comparison of processes of change in cessation and maintenance. Addictive Behaviors, 7, 133-142.

DiClemente, C. C., Prochaska, J. O., Fairhurst, S., Velicer, W. F., Velasquez, M. M., \& Rossi, J. S. (1991). The process of smoking cessation: An analysis of precontemplation, contemplation and preparation stages of change. Journal of Consulting and Clinical Psychology, 59, 295-304.

DiClemente, C. C., Prochaska, J. O., \& Gibertini, M. (1985). Self-efficacy and the stages of self-change of smoking. Cognitive Therapy Research, 9 , 181-200.

Emery, R. E., \& Laumann-Billings, L. (1998). An overview of the nature, causes, and consequences of abusive family relationships: Toward differentiating maltreatment and violence. American Psychologist, 53(2), 121-135. 
English, D. J. (1997). Current knowledge about CPS decision making. In T. D. Morton \& W. Holder (Eds.), Decision making in children's protective services: Advancing the state of the art (pp. 56-74). Atlanta, GA: Child Welfare Institute.

English, D. J., \& Pecora, P. J. (1994). Risk assessment as a practice method in child protective services. Child Welfare, 73 (5), 451-473.

Everitt, B. S. (1980). Cluster analysis (2nd ed.). London: Heineman Educational Books Ltd.

Finkelhor, D. (1993). The main problem is still underreporting, not overreporting. In R. J. Gelles \& D. R. Loseke (Eds.), Current Controversies on Family Violence (pp. 273-287). Newbury Park, CA: Sage Publications.

Fiore-Lerner, C. (1990). The Transtheoretical Model of change: Self-change in adolescent delinquent behaviors. Unpublished doctoral dissertation, University of Rhode Island, Kingston.

Gelles, R. J. (1996). The book of David: How preserving families can cost children's lives. New York: BasicBooks.

George, C. (1996). A representational perspective of child abuse and prevention: Internal working models of attachment and caregiving. Child Abuse and Neglect, 20(5), 411-424.

Giovannoni, J. M. (1991). Unsubstantiated reports: Perspectives of child protection workers. Child and Youth Services Review, 15 (2), 51-62.

Grimley, D. M., Prochaska, J. O., Velicer, W. F., \& Prochaska, G. E. (1995). Contraceptive and condom use adoption and maintenance: A stage paradigm approach. Health Education Quarterly, 22(1), 20-35.

Hubner, J., \& Wolfson, J. (1996). Somebody else's children: The courts, the kids, and the struggle to save America's troubled families. NYC, New York: Crown Publishers. 
Janis, I. L., \& Mann, L. (1977). Decision making: A psychological analysis of conflict, choice and commitment. New York: Free Press.

Johnson, S. S. (1995). Profiles and predictors of compliance in oral contraceptive users. Unpublished master's thesis, University of Rhode Island.

Jones, D. P. H. (1987). The untreatable family. Child Abuse and Neglect, 11 , 409-420.

Kaufman, J., \& Zigler, E. F. (1987). Do abused children become abusive parents? American Journal of Orthopsychiatry, 57(2), 186-192.

Kaufman, J., \& Zigler, E. F. (1996). Child abuse and social policy. In Zigler, E. F., Kagan, S. L., \& Hall, N. W. (Eds.), Children, families, and government: Preparing for the 21st century (pp. 233-255). New York: Cambridge University Press.

Kelleher, K., Chaffin, M., Hollenberg, J, \& Fischer, E. (1994). Alcohol and drug disorders among physically abusive and neglectful parents in a communitybased sample. American Journal of Public Health, 84(10), 1586-1590.

Kempe, C. H., Silverman, F. N., Steele, B. F., Droegemueller, W., \& Silver, H. K. (1962). The battered-child syndrome. Journal of the American Medical Association, 181(1), 105-112.

Kinney, J., Madsen, B., Fleming, T., \& Haapala, D. (1977). Homebuilders: Keeping families together. Journal of Consulting and Clinical Psychology, 45(4), 671-672.

Kolko, D. J. (1996). Child physical abuse. In J. Briere, L. Berliner, J. A. Bulkley, C. Jenny, \& T. Reid (Eds.), The APSAC handbook on child maltreatment (pp. 21-50). Thousand Oaks, CA: Sage Publications. 
Levesque, D. (1998). Violence desistance among battering men: Existing interventions and the application of the Transtheoretical Model of Change. Unpublished doctoral dissertation, University of Rhode Island, Kingston, Rhode Island.

Lorr, M. (1983). Cluster analysis for social scientists. San Francisco, CA: Jossey-Bass Publishers.

Lung, C. T. \& Daro, D. (1996). Current trends in child abuse reporting and fatalities: The results of the 1995 annual fifty state survey. Chicago, IL: NCPCA.

Lutzker, J. R., \& Rice, J. M. (1987). Using recidivism data to evaluate Project $12-$ Ways: An ecobehavioral approach to the treatment and prevention of child abuse and neglect. Journal of Family Violence, 2(4), 283-290.

Magura, S., \& Laudet, A. B. Parental substance abuse and child maltreatment: Review and implications for intervention. Children and Youth Services Review, 18(3), 193-220.

Marcus, B. H., Rossi, J. S., Selby, V. C., Niaura, R. S., \& Abrams, D. B. (1992). The stages and processes of exercise adoption and maintenance in a worksite sample. Health Psychology, 11, 257-261.

McClain, P., Sacks, J., \& Frohlke, T. (1993). Estimates of fatal child abuse and neglect, United States, 1979 through 1988. Pediatrics, 91, 338-343.

McConnaughy, E. A., DiClemente, C. C., Prochaska, J. O. \& Velicer, W. F. (1989). Stages of change in psychotherapy: A follow-up report. Psychotherapy, 4 ,

494-503.

McConnaughy, E. A., Prochaska, J. O., and Velicer, W. F. (1983). Stages of change in psychotherapy: Measurement and sample profiles.

Psychotherapy, 3 , 368-375. 
McCurdy, K., \& Daro, D. (1994). Child maltreatment: A national survey of reports and fatalities. Journal of Interpersonal Violence, 9(1), 75-94.

Milligan, G. W. (1981). A review of Monte Carlo tests of cluster analysis. Multivariate Behavioral Research, 16, 379-407.

Milner, J. S. (1998). Individual and family characteristics associated with intrafamilial child physical and sexual abuse. In P. K. Trickett and C. J. Schellenbach (Eds.), Violence against children in the family and the community (pp. 141-170). Washington D. C.: American Psychological Association.

Morton, T. D., \& Holder, W. (1997). What must change? What actions are necessary for Change? In T. D. Morton and W. Holder (Eds.), Decision making in children's protective services: Advancing the state of the art (pp. 143-158). Atlanta, GA: Child Welfare Institute.

Morton, T. D., \& Holder, W. (Eds.). (1997). Decision making in children's protective services: Advancing the state of the art. Atlanta, GA: Child Welfare Institute.

Murphy, C. M., \& Baxter, V. A. (1997). Motivating batterers to change in the treatment context. Journal of Interpersonal Violence, 12(4), 607-619.

National Research Council. (1993). Understanding child abuse and neglect. Washington, D. C.: National Academy Press.

National Research Council. (1998). Violence in famlies: Assessing prevention and treatment programs. Washington, D. C.: National Academy Press.

Oates, R. K. \& Bross, D. C. (1995). What have we learned about treating child physical abuse? A literature review of the last decade. Child Abuse \& Neglect, 19(4), 463-473.

O'Connell, D., \& Velicer, W. F. (1988). A decisional balance measure and the stages of change model for weight loss. The International Journal of the Addictions, 23, 729-750. 
Pecora, P. J. (1991). Investigating allegations of child maltreatment: The strength and limitations of current risk assessment systems. In M. Robin (Ed.), Assessing reports of child maltreatment (pp. 73-92). Binghamton, NY: Haworth Press.

Pelton, L. H. (1997). Child welfare policy and practice: The myth of family preservation. American Joumal of Orthopsychiatry, 67(4), 545-553.

Prochaska, J. O. (1994). Strong and weak principles for progressing from Precontemplation to Action on the basis of twelve problem behaviors. Health Psychology, 13 (1), 47-51.

Prochaska, J. O., \& DiClemente, C. C. (1982). Toward a more integrative model of change. Psychotherapy: Theory, Research, and Practice, 19, 276-288.

Prochaska, J. O., \& DiClemente, C. C. (1983a). Stages and processes of selfchange of smoking: Toward an integrative model of change. Journal of Consulting and Clinical Psychology, 51(3), 390-395.

Prochaska, J. O., \& DiClemente, C. C. (1983b). Transtheoretical therapy: Toward a more integrative model of change. Psychotherapy: Theory, Research, and Practice, 20, 161-173.

Prochaska, J. O., \& DiClemente, C. C. (1984). The Transtheoretical approach: Crossing traditional boundaries of therapy. Howewood, IL: Dow JonesIrwin.

Prochaska, J. O., \& DiClemente, C. C. (1986a). Toward a comprehensive model of change. In W. Miller and N. Heather (Eds.), Addictive behaviors: Processes of change. New York: Plenum Press, pp.3-28.

Prochaska, J. O., \& DiClemente, C. C. (1986b). The Transtheoretical approach. In J. Norcross (Ed.), Handbook of eclectic psychotherapy. New York: Brunner/Mazel. 
Prochaska, J. O., \& DiClemente, C. C. (1992). Stages of change in the modification of problem behaviors. In M.Hersen, R.M. Eisler \& P.M. Miller (Eds.), Progress on Behavior Modification. Sycamore, IL: Sycamore Press.

Prochaska, J. O., DiClemente, C. C., \& Norcross, J. C. (1992). In search of how people change: Applications to addictive behaviors. American Psychologist, 47(9), 1102-1114.

Prochaska, J. O., DiClemente, C. C, Velicer, W. F., Ginpil, S. E., \& Norcross, J. C. (1985). Predicting change in smoking status for self-changers. Addictive Behaviors, 10, 395-406.

Prochaska, J. O., Norcross, J. C., \& DiClemente, C. C. (1994). Changing for good. New York: Morrow.

Prochaska, J. O., \& Velicer, W. F. (1997). The Transtheoretical Model of health behavior. American Journal of Health Promotion, 12, 38-48.

Prochaska, J. O., Velicer, W. F., Guadagnoli, E., Rossi, J. S., \& DiClemente, C. C. (1991). Patterns of change: Dynamic typology applied to smoking cessation. Multivariate Behavioral Research, 26, 83-107.

Prochaska, J.O., Velicer, W.F., Rossi, J.S., Goldstein, M., Marcus, B.H., Rakowski, W., Fiore, C., Harlow, L., Redding, C., Rosenbloom, D., \& Rossi, S.R. (1994). Stages of change and decisional balance for twelve problem behaviors. Health Psychology, 13, 39-46.

Rossi, S. R. (1993). Application of the transtheoretical model of behavior change to dietary fat reduction in a naturalistic environment. Unpublished doctoral dissertation. University of Rhode Island, Kingston, RI.

Rossi, J. S., \& Blais, L. M. (1991, March). The pros and cons of using sunscreens. Paper presented at the $12^{\text {th }}$ annual meeting of the Society of Behavioral Medicine, Washington, DC. 
Rossi, J. S., Blais, L. M., Redding, C. A., \& Weinstock, M. A. (1995). Preventing skin cancer through behavior change: Implications for interventions. Dermatoepidemiology, 13(3), 613-622.

Schellenbach, C. J. (1998). Child maltreatment: A critical review of research on treatment for physically abusive parents. In P. K. Trickett and C. J. Schellenbach (Eds.), Violence Against Children in the Family and the Community (pp. 251-268). Washington D.C: American Psychological Association.

Sedlak, A. J. \& Broadhurst, M. L. A. (1996). Third National Incidence study of Child Abuse and Neglect (NIS-3). National Center on Child Abuse and Neglect. U.S. Department of Health and Human Services. United States Governments Printing Office: Washington DC.

Smokowski, P. R., \& Wodarski, J. S. (1996). The effectiveness of child welfare services for poor, neglected children: A review of the empirical evidence. Child Welfare Services, 6(4), 504-523.

Straus, M. A., \& Gelles, R. J. (1986). Societal change and change in family violence from 1975 to 1985 as revealed by two national surveys. Journal of Marriage and the Family, 48, 465-479.

Straus, M. A., Hamby, S. L., Finkelhor, D., Moore, D. W., Runyan, D. (1998). Identification of child maltreatment with the parent-child Conflict Tactics Scales: Development and psychometric data for a national sample of American parents. Child Abuse and Neglect, 22(4), 249-270.

Swenson, C. C., \& Hanson, R. F. (1998). Sexual abuse of children: Assessment, research, and treatment. In J. R. Lutzker, (Ed.), Handbook of child abuse research and treatment (pp. 475-499). New York: Plenum Press.

Tsoh, J. Y. (1995). Stages of change, dropouts, and outcome in substance abuse treatment. Unpublished doctoral dissertation, University of Rhode Island. 
U.S. Department of Health and Human Services, Children's Bureau. (1990). Child abuse and neglect: Critical first steps in response to a national emergency. Washington DC: Government Printing Office.

U.S. Department of Health and Human Services, Children's Bureau. (1994). National study of protective, preventive, and reunification services delivered to children and their families. Washington DC: U.S. Government Printing Office.

U.S. Department of Health and Human Services, Children's Bureau. (1995). $\underline{A}$ nation's shame: Fatal child abuse and neglect in the United States. Washington DC: Government Printing Office.

U.S. Department of Health and Human Services, Children's Bureau. (1998). Child maltreatment 1996: Reports from the states to the national child abuse and neglect data system. Washington DC: Government Printing Office.

Velicer, W. F., DiClemente, C. C., Prochaska, J. O., \& Brandenburg, N. (1985). A decisional balance measure for predicting smoking cessation. Journal of Personality and Social Psychology, 48, 1279-1289.

Velicer, W. F., Fava, J. L., Prochaska, J. O., Abrams, D. B., Emmons, K. M., \& Pierce, J. P. (1995). Distribution of smokers by stage in three representative samples. Preventive Medicine, 24, 401-411.

Wald, M. S., \& Woolverton, M. (1990). Risk assessment: The emperor's new clothes? Child Welfare, 64 (6), 483-511.

Wang, C. T., \& Daro, D. (1998). Current trends in child abuse reporting and fatalities: The result of the 1997 annual fifty state survey. Chicago, IL: National Committee to Prevent Child Abuse.

Ward, J. H. (1963). Hierarchical grouping to optimize an objective function. Journal of the American Statistical Association, 58, 236-244. 
Wekerle, C., \& Wolfe, D. A. (1996). Child maltreatment. In E. J. Mask \& R. Barkley (Eds.), Child psychopathology. New York City, NY: The Guilford Press.

Wells, S. J. (1997). Screening in child protective services: Do we accept a report? How do we respond. In T. D. Morton \& W. Holder (Eds.), Decision making in children's protective services: Advancing the state of the art. (pp. 94-106). Atlanta, GA: Child Welfare Institute.

Wells, S. J., Downing, J., Fluke, J. (1991). Responding to reports of child abuse and neglect. Child and Youth Services Review, 15(2), 63-72.

Willet, J. B., Ayoub, C. C., \& Robinson, D. (1991). Using growth modeling to examine systematic differences in growth: An example of change in the functioning of families at risk of maladaptive parenting, child abuse, or neglect. Journal of Consulting and Clinical Psychology, 59, 38-47.

Wilson, D. (1997). Emerging issues. In T. D. Morton and W. Holder (Eds.), Decision making in children's protective services: Advancing the state of the art (pp.192-206). Atlanta, GA: Child Welfare Institute.

Wilson, D., \& Morton, T. D. (1997). Issues in CPS decision making. In T. D. Morton and W. Holder (Eds.), Decision making in children's protective services: Advancing the state of the art (pp.1-16). Atlanta, GA: Child Welfare Institute.

Wolfe, D. A. (1987). Child abuse: Implications for Child Development and Psychopathology. Newbury Park, CA: Sage.

Wolfe, D. A., \& Wekerle, C. (1993). Treatment strategies for child physical abuse and neglect: A critical progress report. $\underline{\text { Clinical Psychology Review, }} \underline{13}$, 473-500.

Zellman, G. L. (1990). Child abuse reporting and failure to report among mandated reporters. Journal of Interpersonal Violence, $\underline{5}, 3-22$. 